NBER WORKING PAPER SERIES

\title{
COMMODITY-PRICE COMOVEMENT AND GLOBAL ECONOMIC ACTIVITY
}

\author{
Ron Alquist \\ Saroj Bhattarai \\ Olivier Coibion \\ Working Paper 20003 \\ http://www.nber.org/papers/w20003 \\ NATIONAL BUREAU OF ECONOMIC RESEARCH \\ 1050 Massachusetts Avenue \\ Cambridge, MA 02138 \\ March 2014, Revised October 2018
}

For helpful comments, the authors are grateful to Yuriy Gorodnichenko, Lance Bachmeier, John Baffes, Olivier Blanchard, John Bluedorn, Zeno Enders, Julian di Giovanni, Lutz Kilian, Peter Nagle, Serena Ng, Hashem Pesaran, Benjamin Wong and Choongryul Yang; seminar participants at the Bank of France; the Bundesbank; the Board of Governors of the Federal Reserve System; the Centre for Applied Macro and Petroleum Economics conference "Oil and Macroeconomics"; the European Central Bank; the Norges Bank; the Toulouse School of Economics; UC Irvine; the Federal Reserve Banks of Dallas, Minneapolis and San Francisco; the Reserve Bank of Australia; the Reserve Bank of New Zealand; the FEEM conference "Oil and Commodity Price Dynamics"; and the Barcelona GSE Summer Forum. Data for the project were kindly provided by Andrea Bastianin, Christiane Baumeister, Lutz Kilian and the trade associations of the aluminum (EEA), copper (ICSG), tin (ITRI) and nickel (INSG) industries. The paper was previously distributed under the title "Commodity Price Comovement: Sources and Implications" while Alquist was at the Bank of Canada and Coibion was a visiting scholar at the International Monetary Fund. The support of both organizations is greatly appreciated. AQR Capital Management is a global investment management firm that may or may not apply similar investment techniques or methods of analysis described in this paper. The views expressed in the paper are those of the authors and should not be interpreted as reflecting the views of AQR Capital Management, the Bank of Canada, its Governing Council, the International Monetary Fund, the National Bureau of Economic Research, or any other institution with which the authors are or have been affiliated.

NBER working papers are circulated for discussion and comment purposes. They have not been peer-reviewed or been subject to the review by the NBER Board of Directors that accompanies official NBER publications.

(C) 2014 by Ron Alquist, Saroj Bhattarai, and Olivier Coibion. All rights reserved. Short sections of text, not to exceed two paragraphs, may be quoted without explicit permission provided that full credit, including $\left({ }^{\circ}\right.$ notice, is given to the source. 
Commodity-Price Comovement and Global Economic Activity

Ron Alquist, Saroj Bhattarai, and Olivier Coibion

NBER Working Paper No. 20003

March 2014, Revised October 2018

JEL No. E3,F4

\begin{abstract}
$\underline{\text { ABSTRACT }}$ apply a new factor-based identification strategy to decompose the historical sources of changes in commodity prices and global economic activity. The model yields a factor structure for commodity prices and identification conditions that provide the factors with an economic interpretation: one factor captures the combined contribution of shocks that affect commodity markets only through general-equilibrium forces. Applied to a cross-section of commodity prices since 1968, the theoretical restrictions are consistent with the data and yield structural interpretations of the common factors in commodity prices. Commodity-related shocks have contributed modestly to global economic fluctuations.

Ron Alquist

AQR Capital Management

Two Greenwich Plaza

Greenwich, CT 06830

ronalquist@gmail.com

Saroj Bhattarai

University of Texas at Austin

Department of Economics

2225 Speedway, Stop C3100

Austin, TX 78712-1690

saroj.bhattarai@austin.utexas.edu

Olivier Coibion

Department of Economics

University of Texas at Austin

2225 Speedway

Austin, TX 78712

and NBER

ocoibion@gmail.com
\end{abstract}

Guided by a macroeconomic model in which commodity prices are endogenously determined, we 


\section{$1 \quad$ Introduction}

Between January 2003 and July 2008, the prices of most major commodities grew rapidly: wheat by 120\%, copper by $363 \%$, aluminum by $100 \%$ and nickel by $138 \%$. Many observers concluded that the simultaneous rise in prices across such a broad cross-section of commodities reflected a common cause - an increase in the global demand for commodities due to growth in emerging Asia and especially China. Other episodes of widespread comovement in commodity prices have similarly suggested that global demand is a common source of movements in commodity prices, such in the early 1970s or in the late 1990s. But this explanation is not necessarily the only one: exogenous changes in the prices of oil and other energy products could simultaneously drive the prices of many non-energy commodities because of the important role played by transportation costs in their distribution. In addition, changing preferences on the part of consumers could shift the demand for commodity-intensive products, as could technological changes that affect the relative importance of raw materials in the production of consumption goods. Decomposing the sources of commodity price comovement is therefore inextricably linked to identifying the sources of global business cycle fluctuations.

In this paper, we develop and implement a new methodology for decomposing the sources of commodity price comovement and global business cycle fluctuations. Underlying this methodology is a general-equilibrium model of global business cycles with commodities that predicts a factor structure for real commodity prices. The predicted factor structure decomposes the sources of global business cycle fluctuations and commodity price movements, and the theory suggests several ways to recover a structural interpretation to the common factors extracted from commodity prices. In other words, this methodology provides a way to use the comovement in commodity prices to disentangle the simultaneous determination of commodity prices and business cycles.

The factor structure in commodity prices predicted by the model separates exogenous forces (or "shocks") into two types. The first set of shocks includes those that directly shift the supply and demand curves for commodities and thus would affect commodity prices, even in the absence of general-equilibrium changes in aggregate income, though such forces may also have general-equilibrium effects on aggregate income and therefore additional indirect effects on commodity prices. We refer to these factors as direct factors. They potentially reflect a variety of common shocks to the prices of inputs used to produce commodities, such as labor or energy, common productivity shocks, or demand factors such as changes in the relative need for commodities to produce final consumption goods. The second set of shocks includes those that affect commodity prices only indirectly through their effects on aggregate output. We refer to these as indirect factors. The indirect effects can come through two channels. One is the standard demand channel. When aggregate economic activity is high, the demand for commodities used to produce the final good is also high, thereby raising the prices of all commodities. The second is a supply-side channel. When aggregate income is high, agents may be less willing to supply the inputs used to produce commodities because of income effects, thereby pushing up the prices of commodities. Both channels induce positive comovement in the prices of commodities. 
The theory predicts a new result about indirect shocks. Because their effects on commodity prices are summarized entirely by their effects on aggregate output, each of the indirect shocks induces the same comovement among commodity prices. As a result, their combined effect on commodity prices can be aggregated into a single factor. Furthermore, this factor has a precise structural interpretation in the model. It corresponds to the counterfactual level of global economic activity that would have been obtained without direct commodity shocks. Identifying this factor therefore provides a new way to recover historical changes in global economic activity and commodity prices that reflect endogenous responses to non-commodity-related shocks.

However, because standard empirical factor decompositions identify factors only up to a rotation, one cannot immediately recover the indirect common factor from a simple factor decomposition of commodity prices. The second element of our approach is to impose identification conditions, again grounded in the predictions of the theoretical model, to recover the direct and indirect factors underlying commodity price movements. The theoretical model provides two ways to do this: sign restrictions on factor loadings of the indirect common factor and orthogonality conditions with respect to a set of instruments for either the direct or indirect factors. Using a crosssection of 40 non-energy commodity prices available since 1968, we apply both identification strategies to identify the indirect factor and find similar results across specifications, indicating that the results are robust to the choice of identification strategy and instruments.

Our main empirical finding is that the vast majority of historical commodity price movements are associated with the indirect factor, i.e., broad-based changes in commodity prices can largely be attributed to a generalequilibrium response to aggregate non-commodity shocks rather than direct shocks to commodity markets. While there are a number of historical episodes during which direct shocks to commodity markets played some role in accounting for commodity price movements and changes in global production (e.g., 1979-80, the run-up in commodity prices in the 2000 s and the decline in prices in 2008-09), the primary source of commodity price movements is their endogenous response to non-commodity-related shocks.

Our approach is related to the literature on the macroeconomic effects of shocks to oil and commodity prices (Bosworth and Lawrence 1982; Hamilton 1983; Barsky and Kilian 2002; Hamilton 2009; Blinder and Rudd 2012; Stuermer 2017) as well as a growing body of recent research on identifying the sources of oil price movements following Kilian (2009). We differ from this line of research in that we focus on a broad range of non-energy commodities (rather than just oil), which are essential to implement our identification strategy. Second, our identification strategy is new: we apply factor methods that decompose the comovement across different commodity prices then exploit the predictions about this decomposition from a microfounded model to identify the structural sources of fluctuations in commodity prices and aggregate output. ${ }^{1}$ Third, while identification in VARs of

\footnotetext{
${ }^{1} \mathrm{We}$ are not the first to apply factor methods to commodity prices. Some papers have examined whether there is excess comovement among unrelated commodities - that is, price comovement in excess of what one would expect, conditional on macroeconomic fundamentals (e.g. Pindyck and Rotemberg 1990). Other papers have investigated the forecasting performance of the common factor in metals prices for individual metals prices (West and Wong 2014) and commodity convenience yields for inflation (Gospodinov and Ng 2013). But there has been little attempt at interpreting the resulting factors in a structural sense.
} 
commodity markets decomposes shocks into supply and demand shocks, our general-equilibrium model allows for the fact that exogenous forces should tend to have both supply and demand effects.

Our model provides a structural interpretation of a factor representation for commodity prices along with the requisite identification conditions, so that we are able to disentangle the different economic channels underlying commodity price movements. In this respect, our approach is related to work that uses economic theory to assign factors an economic interpretation (e.g. Forni and Reichlin 1998). Other work identifies the factors driving macroeconomic aggregates common to all countries and specific subsets of countries (Stock and Watson 2005; and Kose et al. 2012). Factor methods have also been used to identify relative price changes for specific goods and the absolute price changes common to all goods (Reis and Watson 2010) and the relative importance of aggregate and sector-specific shocks for U.S. industrial production (Foerster et al. 2011). Our paper differs from this line of research in that we use commodity price dynamics to identify the sources of global business cycle fluctuations and in our identification strategy, which relies on the use of sign restrictions and orthogonality conditions rather than zero restrictions on the factor loadings.

Finally, we also show that our factor-based method can help with forecasting commodity prices. Using recursive out-of-sample forecasts, we find that a bivariate factor-augmented VAR with each commodity's price and the first common factor extracted from the cross-section of commodities generates improvements in forecast accuracy relative to the no-change forecast, particularly at short horizons. This result extends to broader commodity price indices as well as real oil prices. An additional advantage of our approach is that it relies only on commodity prices that can be readily updated at monthly or quarterly frequencies and does not require information about production and inventory data that are often unavailable at these frequencies. Our approach thus provides a unified framework to forecast commodity prices in real-time as well as a structural interpretation of these forecasts.

The remainder of the paper is organized as follows. Section 2 presents a general-equilibrium business cycle model with commodities and shows how the model can be used to assign a structural interpretation to the common factors in commodity prices. The section also shows how to recover the economic factors from typical factor decompositions through identification restrictions. Section 3 applies these results to a historical cross-section of commodity prices. Section 4 uses the indirect common factor in a recursive out-of-sample forecasting exercise. Section 5 concludes.

\section{The Sources of Commodity Price Comovement: Theory}

In this section, we present a model that characterizes the sources of commodity price comovement. In particular, we show that the model yields a tractable factor structure for a cross-section of commodity prices, which permits an economic interpretation of the factors.

\subsection{Model of commodity prices}


The baseline model consists of households, an energy-producing sector, a continuum of heterogeneous primary commodities, a sector that aggregates these commodities into a single intermediate commodity input, and a final goods sector that combines commodities, labor and technology into a final good.

\section{The Household}

A representative consumer maximizes expected discounted utility over consumption $(C)$, labor supplied to the final good sector $\left(N^{s}\right)$ and labor supplied to the energy sector $\left(N^{e}\right)$ :

$$
\max E_{t} \sum_{i=0}^{\infty} \beta^{i}\left[\frac{C_{t+i}^{1-\sigma}}{1-\sigma}-e^{-\varepsilon_{t+i}^{n}} \varphi_{n} \frac{N_{t+i}^{S}{ }^{1+\frac{1}{\eta}}}{1+\frac{1}{\eta}}-\varphi_{e} \frac{N_{t+i}{ }^{1+\frac{1}{\eta}}}{1+\frac{1}{v}}\right]
$$

where $\beta$ is the discount factor. We refer to the two types of labor as final-goods labor and energy-specific-labor. With $\varphi_{n}>0$ and $\varphi_{e}>0$, welfare is decreasing in hours worked in either sector. The $e^{\varepsilon_{t}^{n}}$ term is an exogenous shock to the disutility of hours worked in the final goods sector. ${ }^{2}$

The household pays a price $P_{t}$ for the consumption good, receives wage $W_{t}$ for each unit of labor supplied to the final goods sector and and wage $W_{t}^{e}$ for labor in the energy sector. The household also can purchase risk-free bonds $B_{t}$ that pay a gross nominal interest rate of $R_{t}$. The budget constraint is $P_{t} C_{t}+B_{t}=B_{t-1} R_{t-1}+W_{t} N_{t}^{S}+$ $W_{t}^{e} N_{t}^{e}+\int_{0}^{1} R_{t}^{L}(j) L_{t}^{S}(j) d j+T_{t}$ where $T_{t}$ represents payments from the ownership of firms.

\section{The Energy Production Sector}

A representative energy firm produces a total supply of the energy good $\left(\Sigma_{t}\right)$ subject to an exogenous energy-specific productivity shock $\left(\Xi_{t}\right)$ and a decreasing returns production function that uses energy-specific labor $\left(N_{t}^{d, e}\right): \Sigma_{t}=$ $\Xi_{t}\left(N_{t}^{d, e}\right)^{1-\gamma}$. This representative firm takes the price of the energy good $\left(S_{t}\right)$ as given and therefore chooses how much labor to hire to maximize its profits which are given by $S_{t} \Xi_{t}\left(N_{t}^{d, e}\right)^{1-\gamma}-W_{t}^{e} N_{t}^{d, e}$. Equilibrium in the labor market for energy requires that $N_{t}^{d, e}=N_{t}^{e}$.

\section{The Primary Commodity-Production Sector}

There is a continuum of primary commodities of mass 1 . Each primary commodity $j$ is produced by a representative price-taking firm which uses energy $\Sigma_{t}(j)$ to produce an amount of the commodity $Q_{t}(j)$ using a decreasing returns in energy production function $Q_{t}(j)=A_{t}(j) \Sigma_{t}(j)^{1-\alpha_{j}}$ where $A_{t}(j)$ is the exogenously determined level of productivity for commodity $j$. The value $1-\alpha_{j}\left(0<\alpha_{j}<1\right)$ determines the commodity-specific degree of diminishing returns to energy and is in equilibrium equal to the ratio of firm $j$ 's expenditures on energy to its total

\footnotetext{
${ }^{2}$ One could alternatively model the household as providing a single type of labor which can be used in both the final goods and energy sector. This would not change the qualitative results. One could also introduce a preference shock to the household's willingness to supply labor the energy sector but this would have the same qualitative effects as the productivity shock in the energy sector.
} 
revenues. Given the price of commodity $j P_{t}(j)$ and the price of energy $S_{t}$, the firm chooses the amount of energy input to maximize profits.

We assume the steady-state level of productivity $\overline{A(J)}$ is such that the steady-state level of production in each sector is equal. Equilibrium in the supply and demand for energy requires that $\Sigma_{t}=\int_{0}^{1} \Sigma_{t}(j) d j$.

\section{The Intermediate Commodity}

A perfectly competitive sector purchases $Y_{t}(j)$ of each primary commodity $j$ and aggregates it into an intermediate commodity $Q_{t}^{C}$ using the Dixit-Stiglitz aggregator

$$
Q_{t}^{c}=\left(\int_{0}^{1} Y_{t}^{j \frac{\theta_{c}-1}{\theta_{c}}} d j\right)^{\frac{\theta_{c}}{\theta_{c}-1}}
$$

where $\theta_{c}$ is the elasticity of substitution across commodities and the price of the intermediate commodity aggregate is given by $P_{t}^{C}=\left(\int_{0}^{1} P_{t}(j)^{1-\theta_{c}} d j\right)^{\frac{1}{1-\theta_{c}}}$. Market clearing for each commodity sector $j$ requires $Q_{t}(j)=Y_{t}(j)$. This setup implicitly assumes that no storage of commodities takes place, since all commodities produced must be used in the same period. We discuss the rationale for this assumption and its implications in more detail in Appendix I.

\section{The Final Goods Sector}

A perfectly competitive sector combines purchases of the intermediate commodity good $Y_{t}^{C}$ and labor $N_{t}^{d}$ (at prices $P_{t}^{C}$ and $W_{t}$ respectively) according to the Cobb-Douglas production function $Y_{t}=A_{t} Y_{t}^{C^{\alpha_{t}}} N_{t}^{d^{1-\alpha_{t}}}$ to maximize profits, taking all prices as given and $A_{t}$ is an exogenously determined aggregate productivity process. ${ }^{3}$ Since all of the final good is purchased by the household, equilibrium in the final goods market requires $C_{t}=Y_{t}$. The fact that $\alpha_{t}$ may be time-varying allows for exogenous variation in the relative demand for commodities and labor in the production of the final good.

\section{The Linearized Model}

A detailed solution of the model is provided in Appendix A. We assume that exogenous processes are stationary around their steady-state levels, so that all real variables are constant in the steady state. Lower-case letters denote $\log$ deviations from steady state (e.g., $c_{t} \equiv \log C_{t}-\log \bar{C}$ ), and we normalize the nominal variables by the price level of final goods (e.g., $p_{t}(j) \equiv \log P_{t}(j) / P_{t}-\log (\overline{P(J) / P})$. We normalize commodity-specific productivity as $v_{t}(j) \equiv a_{t}(j)\left(1+\left(\varepsilon_{j} \theta_{c}\right)^{-1}\right)^{-1}\left(1+\varepsilon_{j}^{-1}\right)$ to simplify the aggregation across commodities, where $\varepsilon_{j} \equiv$ $\left(1-\alpha_{j}\right) / \alpha_{j} \cdot{ }^{4}$ We assume that the productivity process for each commodity sector has an idiosyncratic component

\footnotetext{
${ }^{3}$ One could allow the final goods sector to also use energy in its production process without changing any of the qualitative results in the factor structure of commodity prices.

${ }^{4}$ The rescaling of the commodity-specific productivity process ensures that a $1 \%$ increase in productivity in each commodity sector raises the equilibrium level of production of that commodity by equal amounts for each commodity. This would not be the case without the rescaling because each primary commodity sector's supply curve has a different slope.
} 
and a common component such that $v_{t}(j)=v_{t}^{a}+v_{t}^{j}$, which implies that the sum of productivity across commodities is $v_{t} \equiv \int_{0}^{1} v_{t}(j) d j=v_{t}^{a}$. The idiosyncratic components are orthogonal across commodity sectors, such that $E\left[v_{t}^{j} v_{t}^{k}\right]=0 \forall j \neq k$ and $E\left[v_{t}\right]=0$. The log deviation of $\alpha_{t}$ from its steady-state value of $\alpha$ is denoted by $\check{\alpha}_{t}$ and similarly for $\check{\Xi}$. Each of the exogenous processes $\left(v_{t}, v_{t}^{j}, \check{\alpha}_{t}, \check{\Xi}_{t}, \varepsilon_{t}^{n}\right)$ is stochastic, persistent, and assumed to be stationary, but we do not need to otherwise specify the specific process followed by each. ${ }^{5}$

As shown in Appendix 1, the aggregate level of production of final goods can be expressed in terms of exogenous forces:

$$
y_{t}=\omega_{y}\left[a_{t}+\delta_{n} \varepsilon_{t}^{n}+\delta_{\Xi} \check{\Xi}_{t}+\delta_{v} v_{t}+\delta_{\alpha} \check{\alpha}_{t}\right]
$$

where $\omega_{y}>0$ as long as $\sigma>1, \delta_{n}>0, \delta_{\Xi}>0$, and $\delta_{v}>0$ : output rises with aggregate productivity, positive variation in the household's willingness to supply land, as well as energy-specific and commodity-specific productivity shocks. Whether output rises when the relative demand for commodities increases $\left(\check{\alpha}_{t}\right)$ depends on specific parameter values.

\subsection{Comovement and the Factor Structure of Commodity Prices}

As shown in Appendix 1, the supply of commodity $j$ can be written in reduced form as:

$$
p_{t}(j)=\varepsilon_{j} y_{t}(j)+\alpha_{y} y_{t}+\alpha_{v} v_{t}^{a}+\alpha_{\Xi} \check{\Xi}_{t}++\alpha_{\breve{\alpha}} \check{\alpha}_{t}+\alpha_{v^{j}} v_{t}^{j}
$$

Because different commodities have different returns to energy in the production process, the slope of their supply curves (given by $\varepsilon_{j}$ ) will generally differ. The supply curve of each commodity shifts up with increases in aggregate income $y_{t}$ regardless of its source: greater aggregate production raises the price of energy and therefore the price of commodity $j\left(\alpha_{y}>0\right)$. The price of energy is higher when aggregate income rises because that higher income induces the household to reduce its supply of labor to the energy sector (which raises $W^{e}$ and therefore the price of energy) and because higher aggregate income implies a greater aggregate demand for energy which also causes the price of energy to rise. Hence, any shock that affects aggregate income in this model is a supply shock from the point of view of a given commodity. In addition, productivity shocks in the commodity sector or productivity shocks to the energy sector will induce an additional shift of the supply curve, holding constant their effect on aggregate production, as will shocks to the relative demand for commodities (which affect energy prices and therefore change cost of producing commodities). Hence, these shocks have a direct effect on the supply of commodities, above and beyond the general equilibrium effects that all shocks have on supply via their effects on aggregate income.

The demand for commodity $j$ can similarly be written in reduced form as:

$$
p_{t}(j)=-\frac{1}{\theta_{c}} y_{t}(j)+\beta_{y} y_{t}+\beta_{v} v_{t}^{a}+\beta_{\Xi} \check{\Xi}_{t}+\beta_{\alpha} \check{\alpha}_{t} .
$$

\footnotetext{
${ }^{5}$ Because we do not need to specify the specific time series process followed by each exogenous variable, we will frequently refer to these exogenous variables as "shocks" with obvious abuse of terminology, instead of referring explicitly to the innovations that generate variation in each exogenous variable.
} 
Given the setup of the model, all commodities have the same elasticity of demand. In addition, all commodities experience in rise in demand from any increase in aggregate production, regardless of its source $\left(\beta_{y}>0\right)$ which simply reflects the role of commodities as an input into the production of final goods. This term therefore captures general-equilibrium demand effects, and all macroeconomic shocks that affect aggregate production in the model result in an equal upward or downward shift in the demand for each commodity. Thus, all shocks in the model other than idiosyncratic shocks are both demand and supply shocks. However, in addition to these general-equilibrium shifts in commodity demand, the demand for commodity $j$ rises with changes in the relative demand for commodities $\left(\check{\alpha}_{t}\right)$, holding aggregate output constant. It also shifts, holding aggregate output constant, with exogenous common commodity productivity shocks (which increase the demand for all commodities on the part of the final goods sector) and exogenous shocks to energy (which affect the relative demand for all commodities).

As can be seen from the supply and demand curves above, there are two aggregate shocks that affect aggregate output but do not directly impact commodity prices other than through general equilibrium effects on output: $a_{t}$ and $\varepsilon_{t}^{n}$. We will refer to these variables as "indirect" shocks that affect commodity prices only through their general equilibrium effects on output. It's helpful to decompose movements in output coming from these variables vs other exogenous forces:

$$
y_{t}=y_{t}^{n c}\left(a_{t}, \varepsilon_{t}^{n}\right)+\omega_{y}\left[\delta_{\Xi} \check{\Xi}_{t}+\delta_{v} v_{t}^{a}+\delta_{\alpha} \check{\alpha}_{t}\right]
$$

where $y_{t}^{n c}=\omega_{y}\left[a_{t}+\delta_{n} \varepsilon_{t}^{n}\right]$ is the level of aggregate output coming exclusively from changes in aggregate productivity and changes in the willingness of households' to supply labor to the final goods sector.

As shown in Appendix A, we can then rewrite the equilibrium price of commodity $j$ as

$$
\begin{aligned}
p_{t}(j) & =\underbrace{\lambda_{j}^{y} y_{t}^{n c}\left(a_{t}, \varepsilon_{t}^{n}\right)}_{\text {indirect }(I C)}+\underbrace{\lambda_{j}^{\Xi} \breve{\Xi}_{t}+\lambda_{j}^{v} v_{t}^{a}+\lambda_{j}^{\alpha} \check{\alpha}_{t}}_{\text {direct }(D C)}-\underbrace{\frac{1}{\theta_{c}} v_{t}^{j}(j)}_{\text {idiosyncratic }} \\
& =\lambda_{j} F_{t}+\xi_{t}^{j}
\end{aligned}
$$

where $\lambda_{j}^{y}>0$ and $\frac{\partial \lambda_{j}^{\Xi}}{\partial\left(1-\alpha_{j}\right)}>0$ when $\sigma>1$ and $\theta_{c}(1-\alpha)-1>0$.

Equation (4) provides a factor structure for real commodity prices with three distinct and orthogonal components. ${ }^{6}$ The last term on the right-hand side reflects idiosyncratic shocks to commodity $j$ that have no aggregate real effects. The second set of terms on the right-hand side consist of a factor for each exogenous force that has both direct and indirect effects on the commodity market (i.e., that shifts the supply or demand for commodities, holding aggregate output constant, but also ultimately leads to changes in aggregate output). For this reason, we refer to these

\footnotetext{
${ }^{6}$ The differences in factor loadings across commodities in equation (4) stem only from differences in slopes of commodity supply curves, which are themselves a reflection of the different energy intensities of production across commodities. Appendix 2 considers a version of the model where industrial and agricultural commodities are aggregated into two different intermediate commodity bundles, both of which are used in final production, but in which the aggregation occurs with different elasticities of substitution. The factor structure is preserved, even though commodities now differ in both the slopes of their supply curves as well as their demand curves. This alternative representation of the model also illustrates that the aggregation of shocks underlying the factor structure of commodity prices does not hinge on the use of CES aggregation of all commodities into a single commodity intermediate input.
} 
factors as "direct common" (DC) factors. In this setup, there are three such factors: exogenous shocks to energy sector, a common productivity shock to commodities, and a shock to the relative demand for commodities in the production of final goods. Because these forces have both direct and indirect effects on the market for commodity $j$, there is, in general, no guarantee that their respective loadings have the same signs across commodities. However, it should be the case that commodities which are more intensive in energy (larger $\alpha_{j}$ ) should have prices which respond more strongly to exogenous energy price shocks.

The most interesting component of the factor structure is the first term on the right-hand side of (4), which reflects the combined contribution on the price of commodity $j$ from all shocks whose effects on commodity prices operate only indirectly through aggregate output (i.e., only through general-equilibrium effects). We refer to this common factor as the "indirect common" (IC) factor. It captures the fact that, because some shocks affect commodity markets only through changes in aggregate output, they all have identical implications for the price of a given commodity, conditional on the size of their effect on aggregate output, and induce the same comovement across different commodity prices. As a result, they can be represented as a single factor. Furthermore, this factor has a well-defined interpretation: it is the counterfactual level of global output that would have occurred in the absence of any direct commodity shocks. Thus, this common factor represents a way to reconstruct the counterfactual history of aggregate output without direct commodity shocks, as well as to decompose historical commodity price changes into those components reflecting direct commodity shocks versus all other aggregate economic forces captured by the IC factor. Unlike the DC factors, another key characteristic of the IC factor is that all the loadings on this factor must be positive $\left(\lambda_{j}^{y}>0 \forall j\right)$. This prediction reflects the fact that the shocks incorporated in the IC factor raise commodity demand when the shock is expansionary and simultaneously restrict the commodity supply through income effects, which unambiguously increases commodity prices. ${ }^{7}$ In short, this factor decomposition provides a new way to separate causality in the presence of simultaneously determined prices and production levels.

\subsection{Recovering a Structural Interpretation of the Factors}

A key limitation of factor structures is that, empirically, factors are identified only up to a rotation. For example, if one estimated a factor structure on commodity prices, one could not directly associate the extracted factors with the structural interpretation suggested by (4). However, the theory developed in this section has implications that can be used to identify the unique rotation consistent with those predictions and permits us to assign an economic interpretation to the factors driving commodity prices.

To see this, suppose that, as in the theory above, the $N$ variables in vector $X_{t}(N$ by 1$)$ of real commodity prices have a factor structure $X_{t}=L F_{t}+\varepsilon_{t}$ where $F_{t}$ is a $K$ by 1 vector of unobserved variables, and $L$ is an $N$ by $K$

\footnotetext{
${ }^{7}$ The prediction that all commodities have the same sign loading on the common factor is sensitive to the assumption of diminishing returns to scale in production of commodities, which generates upward-sloping supply curves. Downward sloping supply curves (coming from increasing returns) would imply that when global production is high, the increased demand would now reduce commodity prices (since supply slopes down), while the income effect would raise it (as before). Whether commodity prices went up would therefore depend on the relative strengths and slopes of each effect.
} 
matrix of factor loadings. Let the variance of $\varepsilon_{i}$ be given by $\varphi_{i}$ and the covariance matrix of $\varepsilon_{i}$ be $\operatorname{cov}(\varepsilon)=$ dia $\left(\varphi_{i}\right)=\Psi$ such that the $\varepsilon_{i}$ s are uncorrelated with one another. We make the typical assumptions underlying factor analysis: (a) $E(F)=0$, (b) $E\left(\varepsilon_{i}\right)=0$, (c) $E\left(F \varepsilon_{i}\right)=0$ and (d) $\operatorname{cov}(F)=I$, so that the factors are orthogonal to one another and have variance normalized to one. Then, letting $\Sigma \equiv \operatorname{cov}(X)$ be the covariance matrix of $X$, it follows that $\Sigma=L L^{\prime}+\Psi$. The identification problem is that for any $K$ by $K$ orthogonal matrix $T$ such that $T T^{\prime}=I$, we can define $\tilde{L}=L T$ and $\tilde{F}_{t}=T^{\prime} F_{t}$ such that $X_{t}=\tilde{L} \tilde{F}_{t}+\varepsilon_{t}$. As a result, an empirical estimate of the factors underlying $X_{t}$ do not, in general, permit the economic identification of the factors $F_{t}$ but rather some rotation $\tilde{F}_{t}$.

However, the model provides additional restrictions on the factor structure that can be used to assign an economic interpretation to the factors and identify the "structural" factors $F_{t}$ from the estimated factors $\tilde{F}_{t}$. For example, consider the factor structure of equation (4) in section 2.3 in which real commodity prices reflect two underlying factors, an exogenous energy shock $\left(\check{\Xi}_{t}\right)$ and the level of aggregate production that would have occurred in the absence of this shock $\left(y_{t}^{n c}\right)$, thus $F_{t}=\left[\begin{array}{lll}F_{t}^{1} & F_{t}^{2}\end{array}\right]^{\prime}=\left[\begin{array}{lll}y_{t}^{n c} & \breve{\Xi}_{t}\end{array}\right]^{\prime}$. As we discuss below, this two-factor structure is the most empirically relevant case. A factor decomposition of commodity prices would yield a rotation of these factors $\tilde{F}_{t}$ such that

$$
F_{t}=T^{\prime} \tilde{F}_{t}=\left[\begin{array}{ll}
t_{11} & t_{12} \\
t_{21} & t_{22}
\end{array}\right]^{\prime}\left[\tilde{F}_{t}^{1} \tilde{F}_{t}^{2}\right]^{\prime}=\left[\begin{array}{cc}
\cos \theta & \sin \theta \\
-\sin \theta & \cos \theta
\end{array}\right]\left[\tilde{F}_{t}^{1} \tilde{F}_{t}^{2}\right]^{\prime}
$$

where the last equality reflects the properties of rotation matrices. Recovering the "structural" factors $F_{t}$ corresponds to identifying the parameter $\theta$ and the rotation matrix $T$ such that $F_{t}=T^{\prime} \tilde{F}_{t}$.

The theory imposes three types of conditions that can be used to identify $\theta$. The first is that $y_{t}^{n c}$ (the IC factor) is orthogonal to commodity-related shocks (DC factors). Therefore, if one had a $S$ by 1 vector of instruments $z_{t}$ that is correlated with the energy shocks $\breve{\Xi}_{t}$, the orthogonality of $y_{t}^{n c}$ would deliver $S$ moment conditions $E\left[y_{t}^{n c} z_{t}\right]=0$. The conditions can be rewritten as

$$
E\left[y_{t}^{n c} z_{t}\right]=E\left[\left(\tilde{F}_{t}^{1} \cos \theta+\tilde{F}_{t}^{2} \sin \theta\right) z_{t}\right]=0 .
$$

If $S=1$, then $\theta$ would be uniquely identified. If $S>1$, then $\theta$ is overidentified, and one could estimate it using standard generalized method of moments GMM methods by writing the moment conditions as

$$
J(\theta)=E\left[y_{t}^{n c} z_{t}\right] W E\left[y_{t}^{n c} z_{t}\right]^{\prime}
$$

where $W$ is a weighting matrix, such that $\hat{\theta}=\operatorname{argmin} J(\theta)$. Letting $W$ be the inverse of the variance-covariance matrix associated with the moment conditions, standard GMM asymptotic results apply, including standard errors for $\theta$ and tests of the over-identifying conditions for $N$ and $T$ large enough for the factors to be considered as observed variables rather than generated (e.g., Stock and Watson 2002; and Bai and Ng 2002).

A second approach would be to make use of the theoretical prediction that $y_{t}^{n c}$ is a linear combination of exogenous variables that have only indirect effects on the commodity sector such as the productivity shocks or labor supply shocks considered in the model. If one had a $S$ by 1 vector of instruments $z_{t}$ for each period correlated with one or more of these exogenous drivers, then another set of orthogonality conditions imposed by the theory would 
be $E\left[F_{t}^{2} z_{t}\right]=0$. As in the previous case, one could estimate $\theta$ using GMM, given these orthogonality conditions, and test over-identifying restrictions if $S>1$.

In both of these cases, the econometrician must take a stand on whether the chosen instruments should be correlated with commodity-related shocks or with $y_{t}^{n c}$. While economic theory may provide clear guidance in some cases, this choice may be problematic when one is interested in whether an exogenous variable affects commodities only through general-equilibrium effects or more directly. Within our framework, this question amounts to whether the exogenous variable should be considered part of $y_{t}^{n c}$ or one of the commodity-related shocks. For example, in the case of commodity prices, monetary policy shocks could potentially have direct effects on commodity markets in the presence of storage motives but would otherwise not be expected to have direct effects on commodity markets if the speculative channel is absent or sufficiently small, as discussed in Appendix I.

A third approach is to make use of sign restrictions on the loadings. The theory predicts that the loadings on $y_{t}^{n c}$ must all be positive (since $\lambda_{j}^{y}>0 \forall j$ in equation (4)). Letting $\tilde{L}$ be the $N$ by 2 matrix of unrotated factor loadings, the rotated or "structural" loadings are $L=\tilde{L} T=\left[\tilde{L}^{1} \tilde{L}^{2}\right] T$. The loadings on the first rotated factor (corresponding to $y_{t}^{n c}$ ) are then $L^{1}=\tilde{L}^{1} \cos \theta+\tilde{L}^{2} \sin \theta$. Imposing that all of the elements of $L^{1}$ be positive would therefore correspond to identifying the range of values of $\theta \operatorname{such}$ that $\min \left(\tilde{L}^{1} \cos \theta+\tilde{L}^{2} \sin \theta\right)>0$. In general, this leads only to a set of admissible values of $\theta$ and associated rotation matrices without uniquely identifying the rotation matrix. This approach is conceptually similar to the set identification of VARs by sign restrictions (Uhlig 2002).

In short, the theoretical model of commodity prices yields not only a factor structure for commodity prices but also a set of conditions that can be used to identify (or, in the case of sign restrictions, limit the set of) the rotation matrix necessary to recover the underlying factors. Furthermore, the factors have economic interpretations. The IC factor corresponds to the level of production and income net of commodity-related shocks, while other factors correspond to one or more of these commodity-related shocks. The identification of the rotation matrix, and thus the underlying economic factors, follows from orthogonality conditions implied by the model, as well as sign restrictions on the loadings predicted by the theory. The implied factor structure of the model combined with the ability to recover an economic interpretation of the factors thus provides a new method for separating fluctuations in aggregate output into those driven by commodity-related shocks and those driven by non-commodity-related shocks.

\section{The Sources of Commodity Price Comovement: Empirical Evidence}

In this section, we implement the factor decomposition of real commodity prices suggested by the theory. We first construct a historical cross-section of real commodity prices for the commodities that conform to the theoretical structure of the model along several dimensions. We then implement a factor decomposition and identify the factors suggested by the theory. After considering a wide range of robustness checks, we argue that commodity-related shocks have contributed only modestly to fluctuations in global economic activity.

\subsection{Data}


Guided by the theoretical model, we use four criteria to decide which commodities to include in the data set and which to exclude. First, commodities must not be vertically integrated. ${ }^{8}$ Second, the main use of commodities must be directly related to the aggregate consumption bundle, and they should not be primarily used for the purposes of financial speculation. ${ }^{9}$ Third, commodities must not be jointly produced. ${ }^{10}$ Finally, the pricing of commodities must be determined freely in spot markets and must not display the price stickiness associated with the existence of longterm contractual agreements. ${ }^{11}$

Applying these criteria leaves us with 40 commodities in the sample. It includes 22 commodities that we refer to as agricultural or food commodities, five food oils, and 13 industrial commodities (see Appendix $\mathrm{C}$ for a detailed list). We compiled monthly data from January 1957 to January 2013 (as available) from a number of sources, including the CRB Commodity Yearbooks, the CRB InfoTech CD, the World Bank GEM Commodity Price Data, the IMF's Commodity Price Indices and the U.S. Bureau of Labor Statistics. While most of the data are consistently available from January 1968 until January 2013, in some cases, there are a number of missing observations in the underlying data, as well as periods when we treat the available data as missing because spot trading was limited. Appendix C provides details on the construction of each series, their availability and any periods over which we treat the data as missing because of infrequent price changes. Furthermore, while we can construct price data going back to at least 1957 for many commodities, we restrict the empirical analysis to the period since 1968, in light of the numerous price regulations and government price support mechanisms in place during the earlier period. ${ }^{12}$

\subsection{Common Factors in Commodity Prices}

Before conducting the factor analysis, we normalize each price series by the U.S. CPI, take logs of all series and normalize each series by its standard deviation. Because there are missing observations in the data, we use the expectation-maximization (EM) algorithm of Stock and Watson (2002). ${ }^{13}$ We follow Kilian (2009) in focusing on

\footnotetext{
${ }^{8}$ Vertically integrated commodities would introduce the possibility of price comovement resulting from idiosyncratic shocks to one commodity affecting prices in other commodities through the supply chain. For example, an exogenous shock to the production of sorghum would affect the price of non-grass-fed beef because sorghum is primarily used as feed. Thus, this shock could ultimately affect the price of milk and hides as well.

${ }^{9}$ Some commodities, such as precious metals, have long been recognized as behaving more like financial assets than normal commodities (Chinn and Coibion 2014). Thus, we exclude gold, silver, platinum and palladium from the cross-section of commodities.

${ }^{10}$ Some commodities are derivative products of the production of other commodities. This is particularly the case for minerals, which are commonly recovered during the mining for metal commodities, making the assumption of orthogonal productivity shocks clearly inapplicable. We drop any such commodities.

${ }^{11}$ While many commodities have long been traded on liquid international spot markets, this is not always the case. For example, the price measure of tung oil tracked by the Commodity Research Bureau (CRB) Commodity Yearbooks varies little over time and is often fixed for periods lasting as long as one year. Because we want to focus on commodities whose prices reflect contemporaneous economic conditions, we exclude commodities such as tung oil that systematically display long periods of price invariance. For some commodities in the sample, prices were not determined in flexible markets until much later than others; for these commodities, we treat early price data as missing values. For mercury, the reverse is true, since its use has declined over time and its price began to display long periods with no price changes starting in 1995 . We treat its prices after March 1995 as missing. Appendix B provides more details on these adjustments.

${ }^{12}$ Appendix D provides detail on the geographic variation in where commodities are produced and how they are used.

${ }^{13}$ Specifically, we first demean each series and replace missing values with zeroes before recovering the first $K$ factors. We use these $K$ factors to impute the value of missing observations, and then do the factor analysis again, iterating on this procedure
} 
the (log) level of real commodity prices but document in our robustness checks that our results are qualitatively unchanged if we take the first difference of real commodity prices or use linearly detrended series.

We consider several metrics to characterize the contribution of the first five factors in accounting for commodity price movements, summarized in Table $1 .{ }^{14}$ The first row presents the sum of eigenvalues associated with each number of factors normalized by the sum across all eigenvalues, a simple measure of variance explained by common factors. In addition, we present additional metrics based on $R^{2}$ s that explicitly take into account missing values associated with some commodities: the average across the individual $R^{2} \mathrm{~s}$ computed for each commodity, the median across these same commodity-specific $R^{2} \mathrm{~s}$, the $R^{2}$ constructed across all commodities. The key result from this table is that the first common factor explains a large share of the price variation across commodities, ranging from $60 \%$ to $70 \%$ depending on the specific measure used. In contrast, all of the additional factors explain smaller percentages of the variance in commodity prices. The second factor, for example, accounts for between $6 \%$ and $10 \%$, while the third factor contributes another $5 \%$ of the variance. Thus, the first two factors jointly account for approximately $70-75 \%$ of the variance in commodity prices. ${ }^{15}$

The ability of the first two factors, and the first common factor in particular, to account for so much of the variance holds across commodity groups. Table 1 includes the contribution of different factors to explaining the variance across the three subsets of commodities in the sample-agricultural/food, oils and industrials. Differences across subsets of commodities are quite small: the contribution of the first factor ranges from 55\% (pooled $R^{2}$ across all commodities in this subset) for industrial commodities to $64 \%$ for agricultural/food commodities and $72 \%$ for oils (see Appendix E for commodity-specific results). The decomposition does not suggest that one needs different factors for different types of commodities. This point is worth stressing because a common concern with factor analysis is that different factors are needed to explain different subsets of the data. As illustrated in Table 1, this is not the case for our data.

\subsection{Identification of the Rotation Matrix and the Underlying Economic Factors}

To implement a structural interpretation of the factors as suggested by the model, we interpret the results of Table 1 as indicating that a two-factor representation adequately characterizes the data. First, additional factors beyond the first two add relatively little in explanatory power and can be omitted. Second, under the null of the model, it is $a$ priori unlikely for there to be fewer than two factors. Indeed, such a finding would imply that there are no shocks that directly affect commodity prices and that all movements in commodity prices reflect either the level of aggregate economic activity or idiosyncratic commodity factors. We can rule this argument out immediately because there

until convergence. We use $K=5$ factors for the imputation; however, the results are not sensitive to the specific number of factors used.

${ }^{14}$ Following Connor and Korajczyk (1993) and Bai and $\mathrm{Ng}$ (2002), we use principal components on the variance-covariance matrix of commodity prices to estimate the approximate factors.

${ }^{15}$ Statistical tests of the number of factors point toward parsimonious factor specifications. For example, the PC2 and IC2 criteria of Bai and $\mathrm{Ng}$ (2002) each select one factor. The same result is obtained using the test suggested by Onatski (2010) or the two criteria proposed in Ahn and Horenstein (2013). 
exists at least one common shock to the supply of commodities: exogenous energy price movements. Because commodities require energy in production and distribution, exogenous shocks to energy prices necessarily induce some comovement in commodity prices, as commodities are produced in different parts of the world but consumption occurs disproportionately in advanced economies, thereby generating significant shipping and distribution costs.

To estimate the rotation matrix, our baseline is to impose orthogonality conditions on the indirect common factor $F_{t}^{1}$. Specifically, we take $\varepsilon_{t}^{o p e c}$, the measure of OPEC production shocks from Bastianin and Manera's (2014) updated version of the Kilian (2008) series and define the orthogonality conditions as $E\left[F_{t}^{1} z_{t}\right]$, where $z_{t} \equiv$

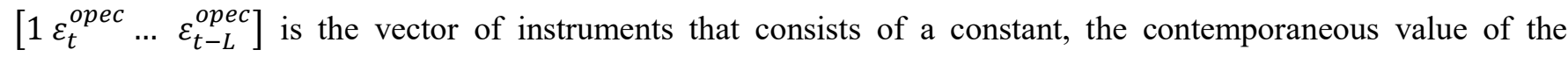
production shock series as well as $L$ lags of the shock. The IC factor $F_{t}^{1}\left(y_{t}^{n c}\right.$ in the model) is a rotation over the two estimated factors $\widehat{F}_{t}^{1}$ and $\widehat{F}_{t}^{2}$, i.e., $F_{t}^{1}=t_{11} \widehat{F}_{t}^{1}+t_{21} \hat{F}_{t}^{2}$ where the orthogonal rotation parameters $t_{11}$ and $t_{21}$ can be expressed as a function of a single underlying rotation parameter $\theta \operatorname{such}$ that $t_{11}=\cos \theta$ and $t_{21}=\sin \theta$. Given that there are more moment conditions $(L+2)$ than parameters $(\theta)$, we can estimate the rotation parameter $\theta$ using GMM by minimizing $J(\theta)$ :

$$
J(\theta)=\left[\frac{1}{T} \sum_{t}\left(F_{t}^{1}(\theta) z_{t}\right)\right] W\left[\frac{1}{T} \sum_{t}\left(F_{t}^{1}(\theta) z_{t}\right)\right]^{\prime}
$$

We set $L=36$ months for the baseline estimation to capture the fact that the OPEC production shocks have long-lived effects on commodity prices, although the results are robust to both shorter and longer lag specifications as well, as we document below. $W$ is the Newey-West (1987) heteroskedasticity and autocorrelation HAC robust estimate of the inverse of the variance-covariance matrix of moment conditions. We iterate over minimizing $J(\theta)$ and then computing the implied weighting matrix until the estimate of $\theta$ has converged ( $W=I$ in the first step). Table 2 presents the resulting estimate of $\theta$ and its associated standard error. With $\hat{\theta}=-0.10$ and a standard error of 0.31 , we cannot reject the null hypothesis that $\theta=0$. From this estimate of $\theta$, we construct estimates of the rotation parameters $t_{11}$ and $t_{21}: t_{11}$ is close to 1 , and we cannot reject the null hypothesis that $t_{21}=0$, so the estimated rotation matrix is not statistically different from the identity matrix. Furthermore, the over-identification conditions cannot be rejected.

The reason why the estimated rotation matrix is close to the identity matrix is that, while the first unrotated factor is largely uncorrelated with OPEC production shocks, this condition is not satisfied for the second unrotated factor, which responds strongly to OPEC production shocks. Because the unrotated factors are already largely consistent with the theoretically predicted orthogonality conditions (namely, that the first factor is orthogonal to commodity shocks, but the second is not), the estimation procedure yields only a slight rotation of the original factors.

While the fact that we cannot reject the over-identifying conditions is consistent with the theory, we can further assess the extent to which the estimated rotation satisfies the theoretical predictions of the model. For example, an additional theoretical prediction is that the loadings on the indirect factor will all be the same sign. To assess this prediction, we present in Table 3 the estimated factor loadings for each rotated factor. The loadings on the IC factor are positive for all commodities, as predicted by the theory. In contrast, the loadings on the commodity- 
related factor are of mixed signs. There are no systematic patterns across commodity groups, again confirming that the factors explaining commodity prices are common across commodity subsets. Without imposing any restrictions on the loadings as part of the identification strategy for the rotation matrix, we find that the estimated rotation satisfies theoretical predictions on the factor loadings and those implied by the over-identifying restrictions. ${ }^{16}$

Given the estimate of $\theta$ and the rotation matrix, we construct the rotated factor $F_{t}^{1}$ that, according to the model, corresponds to the level of aggregate output and income that would have occurred in the absence of commodity-related shocks. This factor is presented in Figure 2, after being detrended with a Hodrick-Prescott (HP) filter with $\lambda=129,600$, the typical value for monthly data, to highlight variation at business cycle frequencies. In addition, we draw from the estimated distribution of $\theta$, construct $F_{t}^{1}$ for each new draw and use this distribution to characterize the $99 \%$ confidence interval of the HP-filtered factor.

This factor displays a sharp rise in 1973-74 before falling sharply during the 1974-75 recession in the United States. This drop is followed by a progressive increase over the course of the mid- to late 1970s, with the factor peaking in 1979 before falling sharply during each of the "twin" recessions of 1980-82, and then rebounding sharply after the end of the Volcker disinflation. Thus, over the course of the 1970s, this structural factor displays a clear cyclical pattern. During the mid-1980s, the factor drops sharply before rebounding in the late 1980s, and then falls gradually through the 1990-91 U.S. recession before rebounding through the mid-1990s. It experiences a large decline in the late 1990s, before the 2000-01 U.S. recession and then rebounds shortly thereafter. After a brief decline in the mid-2000s, the factor displays a sharp increase from 2005 to 2008, the period when many commodity prices boomed, and then falls sharply in late 2008 and 2009 before rebounding strongly in 2010. In short, there is a clear procylical pattern to the IC factor relative to U.S. economic conditions.

\subsection{Robustness of the Estimation}

To assess the sensitivity of our results, we vary some of the specific choices made for the estimation of $\theta$. For example, we report in Table 2 results from using fewer moment conditions ( $L=12$ and 24 months) as well as more moment conditions ( $L=48$ months). Neither changes the estimates significantly. Similarly, we repeat the GMM estimates using a two-step procedure, in which $\theta$ is first estimated using a weighting matrix equal to the identity matrix with no subsequent iterations after updating the weighting matrix, and second using a continuously updated GMM in which we minimize over $\theta$ and $W$ jointly until convergence. In both cases, the results are qualitatively

\footnotetext{
16 The model developed in section 2 also predicts that commodities that are more energy intensive in production have larger (in absolute value) loadings on the DC factor. Using the 2007 benchmark input-output tables to characterize energy intensity of production for 13 commodity groupings (which jointly include 34 of the commodities in our cross-section), we find a positive relationship between the loadings and the energy intensity of production. These results are reported in Appendix K. This suggestive evidence is consistent with the model's predictions and lends credibility to the framework we use to characterize the common variation in commodity prices. Unfortunately, the input tables are not sufficiently detailed to allow us to test this prediction for a more differentiated set of commodities.
} 
similar. Finally, because non-linear GMM can be sensitive to normalizations, we replicate the baseline estimation after rewriting moment conditions as $E\left[\left(\hat{F}_{t}^{1}+\hat{F}_{t}^{2} \frac{\sin }{\cos \theta}\right) z_{t}\right]=0$, and the results are again unchanged. ${ }^{17}$

A more interesting robustness check is to consider the alternative identification strategy suggested in section 2.4, namely to exploit the theoretical predictions for signs of factor loadings: loadings on the IC factor should all be positive. Thus, one can characterize the set of admissible rotation matrices by restricting them to be consistent with the sign restrictions implied by the theory, in the spirit of Uhlig (2002). In our case, this procedure consists of identifying the set of $\theta$ such that $\min \left(\tilde{L}^{1} \cos \theta+\widetilde{L}^{2} \sin \theta\right)>0$, where $\tilde{L}^{i}$ for $i=\{1,2\}$ are the loading vectors associated with the unrotated factors and min is with respect to the elements of $L^{1}$. We consider values of $\theta \in[-\pi, \pi]$ (at increments of 0.001) and, for each $\theta$, determine whether the restriction is satisfied. This yields a set of admissible rotation matrices and therefore a set of possible IC factors. We apply the HP filter to each of these and plot the resulting minimum and maximum values for each month in Panel B of Figure 2, along with the 99\% confidence interval for the rotated IC factor from the baseline GMM estimation. There is significant overlap between the two approaches, with the minimum and maximum values from the sign restriction typically being within the $99 \%$ confidence interval of the GMM-estimated IC factor. Thus, despite the fact that the two identification strategies are quite different, they point toward a remarkably consistent characterization of the non-commodity-related structural factor.

In Appendix F, we provide a number of additional robustness checks on these results. For example, we replicate our results dropping either all commodities whose primary use is as food or as feed, or those commodities disproportionately produced in the U.S.S.R., China or India through much of the sample. We verify that our results are robust to alternative assumptions about stationarity and find similar results using first differences or linearly detrended real commodity prices (Appendix G). We also find little sensitivity to dropping commodities for which imputation was needed or to decomposing the correlation matrix rather than the covariance matrix for the factor analysis.

\subsection{Factor Contributions to Commodity Prices, Comovement and Global Real Activity}

We now turn to using the factor structure to better understand the historical sources of commodity price movements and global real activity. For prices, we decompose the average annual percentage change in commodity prices into the components driven by indirect and direct common factors. The decomposition follows directly from the rotated factor structure, yielding

$$
\overline{p_{t}-p_{t-12}}=\overline{L^{I C}}\left(F_{t}^{I C}-F_{t-12}^{I C}\right)+\overline{L^{D C}}\left(F_{t}^{D C}-F_{t-12}^{D C}\right)+\left(\overline{\varepsilon_{t}-\varepsilon_{t-12}}\right)
$$

where the bar denotes averages across all commodities in the cross-section. The first term on the right-hand side of the equation represents the contribution of the IC factor to average commodity price changes, the second represents

\footnotetext{
${ }^{17}$ While we rely on standard asymptotics which apply for large $\mathrm{N}$ and $\mathrm{T}$, adjusting standard errors to account for smaller $\mathrm{N}$ would only strengthen the main result that one cannot reject the null that the estimated rotation matrix is not different from the identity matrix.
} 
the contribution of the DC factor, and the third reflects average idiosyncratic effects. The results of this decomposition are presented in the top panel of Figure 3, in which we plot the contributions from the IC and DC factors each month as well as the actual annual average price change across commodities. The IC factor, which captures the endogenous response of prices to non-commodity shocks, explains the vast majority of historical commodity price changes. To the extent that income effects on inputs into the production of commodities are likely weak, the IC factor can be interpreted as primarily reflecting changing demand for commodities due to changes in global economic activity. During the commodity boom of 1973-74, for example, indirect shocks to commodity markets accounted for almost all of the rise in commodity prices, with the remainder reflecting direct commodityrelated shocks. Every other historical episode of large changes in average commodity prices is also accounted for by the indirect factor, i.e., as an endogenous response of commodity prices to global business cycle conditions not driven by commodity-related shocks.

We can also quantify how changes in each factor have contributed to the time variation in comovement among commodity prices. Specifically, we can decompose, each month, annual changes in real commodity prices as follows:

$$
p_{t}(j)-p_{t-12}(j)=\lambda_{j}^{I C}\left[F_{t}^{I C}-F_{t-12}^{I C}\right]+\lambda_{j}^{D C}\left[F_{t}^{D C}-F_{t-12}^{D C}\right]+\varepsilon_{t}^{j}-\varepsilon_{t-12}^{j}
$$

From this, we can construct each month the cross-sectional $R^{2}$ coming from both factors (i.e., the ability of changes in both factors to explain commodity price movements through common forces) as well as the partial $R^{2}$ coming from the IC factor. These series are plotted in Panel B of Figure 3. There is significant variation over time in the overall comovement of commodity prices, as captured by both factors, with the highest degrees of comovement in commodity prices occurring between 1973 and 1975, in the early to mid-1980s, in the late 1990s, and in the mid- to late 2000 s continuing to 2013 . The time variation in comovement is again primarily explained by changes in the indirect factor. Periods in which commodity prices co-move most strongly have also been periods in which commodity price changes have been driven by the endogenous response of commodity prices to non-commodity shocks.

We now assess the contribution of each factor to global economic activity, using the global industrial production (IP) constructed by Baumeister and Peersman (2011) from 1947Q1 until 2010Q4.

Unlike with commodity prices, the factor structure does not immediately lend itself to a decomposition of historical changes in global industrial production. To do so, we first rely on the theory presented in section 2 in which the IC factor corresponds to the level of global activity that would have occurred in the absence of direct commodity shocks $\left(y_{t}^{n c}\right)$. Because the scale of the IC factor is not identified, we normalize it such that the standard deviation of quarterly changes in the IC is equal to the standard deviation of quarterly percent changes in global IP and treat the resulting historical changes in the IC as the contribution of indirect shocks to global IP. The difference between the demeaned quarterly growth rate of global IP and the demeaned change in the IC (defined as $\delta_{t} \equiv \Delta y_{t}-\Delta y_{t}^{n c}$ ) should reflect the contribution of direct commodity shocks, potentially omitted factors, and mismeasurement in global production levels. To evaluate the contribution of direct commodity shocks to global IP, we regress $\delta_{t}$ on 4 lags of itself and 8 
lags of the direct commodity factor $\left(F_{t}^{D C}\right)$ at a quarterly frequency and construct the contribution of the DC factor to global IP net of the contribution of the IC factor. This approach leaves a component of global activity unaccounted for, potentially reflecting measurement error, omitted variables or model misspecification.

We plot the resulting contributions of the IC and DC factors to global IP growth in Panel C of Figure 3, again showing only the annual changes to filter out the high-frequency variation in the measurement of global IP. The correlation between the IC factor and global IP is high (0.59) so that historical changes in global IP are primarily attributed to indirect non-commodity shocks. This is particularly true from the early 1970s through the mid-1980s, although commodity-related shocks deepened the decline in global IP during late 1974 and early 1975. As was the case with the decomposition of commodity prices, the decline in economic activity during the Volcker disinflation is accounted for by the IC factor. The dynamics of global activity from the late 1980s to mid-1990s are also largely attributed to the IC factor, although actual changes in global IP exceeded those predicted by the two factors. Growth in the IC factor during the 2000 s also coincides with the growth in global IP during this time period, while commodity-related shocks in the DC contributed modest downward pressure on economic activity in 2002 and 2003 , then again in 2007-10. To the extent that the DC factor reflects exogenous energy price fluctuations, the negative contribution of the DC factor from late 2007 through 2010 (subtracting 1-2\% from the annual growth rate of global IP) is broadly consistent with Hamilton (2009), who argues that oil price shocks contributed to the severity of the Great Recession of 2007-09. Nonetheless, most of the decline in the growth rate of global IP from late 2007 to the depth of the recession can be attributed to declines in the IC factor.

\section{$4 \quad$ Forecasting Applications}

We examine whether the IC factor contains real-time information relevant for predicting commodity prices, broad commodity price indices and the price of oil in a recursive out-of-sample forecasting exercise. The forecasting model is a monthly linear bivariate $\operatorname{FAVAR}(p)$ model for the real price of commodity $j$ and the IC factor. ${ }^{18}$ The lag length $p$ is chosen recursively using the BIC. We assess the ability of the IC factor to forecast the 40 individual real commodity prices used to compute the IC factor, three widely used real commodity price indices - the CRB spot index, the World Bank non-energy index and the IMF non-fuel index - and the real price of oil. ${ }^{19}$ The forecast performance of the FAVAR is evaluated over two periods. One is commodity-specific and begins either in January 1968 or at the earliest possible date subject to the condition that the initial estimation window contains at least 48 observations. The second one begins in January 1984 and ends in December 2012, with the initial estimation window ending in December 1983. We evaluate the recursive mean-squared prediction error (MSPE) of the FAVAR-based

\footnotetext{
${ }^{18}$ Because we are unable to reject the null that the rotation matrix equals the identity matrix in section 3 , we use the unrotated first factor in the forecasting exercises.

${ }^{19}$ The IMF non-fuel commodity price index begins in February 1980. The price index was backcast to January 1957 using the IMF agricultural raw material, beverage, food and metals sub-indices with weights obtained from regressing the non-fuel index on the individual sub-indices. The real price of oil is the U.S. refiner's acquisition cost of imported oil. All variables are deflated by U.S. CPI. We apply the EM algorithm recursively to fill in the missing observations.
} 
forecast at the 1-, 3-, 6-, and 12-month horizons. All forecast accuracy comparisons are conducted relative to the nochange benchmark. Multiple step-ahead forecasts are computed iteratively using the FAVAR.

Table 4 summarizes the results obtained from the forecasting exercise for the commodity-specific and common sample periods. A summary measure across all commodities is given by the Aggregate MSPE Ratio $\equiv$ $\frac{\sum_{j=1}^{N} M S P E_{j}^{F A V A R}}{\sum_{j=1}^{N} M S P E_{j}^{R W}}$ where $M S P E_{j}^{F A V A R}$ is the mean-squared prediction error of the FAVAR-based forecast for commodity $j ; M S P E_{j}^{R W}$ is the mean-squared prediction error of the random walk forecast for commodity $j$.

For both the commodity-specific and the common forecast evaluation periods, forecasts based on a common factor generate improvements in forecast accuracy between $2 \%$ and $8 \%$ relative to the no-change forecast up to the 6-month horizon. The FAVAR-based forecasts improve on the no-change forecast for most commodities at shorthorizons but performance deteriorates over longer horizons. ${ }^{20}$ The FAVAR does best at predicting the World Bank non-energy index and the IMF non-fuel index, with improvements in forecast accuracy up to $17 \%$ over short horizons. It also delivers significant improvements relative to the random walk at predicting real oil prices at short horizons. $^{21}$

These findings show that the prices of internationally traded commodities are forecastable in a way suggested by the model presented in section 2. Improvements in forecast accuracy can be economically important at short horizons, and agricultural commodities and oils tend to be more predictable than industrial commodities. Thus, the factor structure in commodity prices serves a dual purpose for policy-makers and practitioners: it both provides a structural decomposition of the forces driving commodity prices and helps forecast commodity price fluctuations.

\section{Conclusion}

We propose a new empirical strategy, grounded in a microfounded business cycle model with commodities, to identify the driving forces of global economic activity and commodity prices. The model provides a set of orthogonality conditions and sign restrictions that can be used to identify the parameters of the rotation matrix that yield a structural interpretation of the common factors behind commodity prices, with the "indirect" factor representing the counterfactual level of global economic activity that would have occurred without direct shocks to commodity markets. The IC factor we identify accounts for about $60-70 \%$ of the variance in commodity prices, and we cannot reject the theoretical restrictions implied by the model. Its behavior during the 1970s and 1980s suggests that the macroeconomic fluctuations observed during that era were not driven primarily by commodity-related

\footnotetext{
${ }^{20}$ Appendix J provides commodity-specific results. FAVAR-based forecasts generate improvements in forecast accuracy for some agricultural commodities and oils up to 12 months ahead. For the common sample period, 10 (out of 15) of the agricultural commodities and 2 (out of 3) oils achieve improvements in forecast accuracy at the 12-month horizon. The improvements in forecast accuracy in the industrial commodities are concentrated at shorter horizons (i.e., 1- and 3-months).

${ }^{21}$ Additional results on the ability of the commodity price factor to forecast the real price of oil are in Appendix Table J.3. It compares the bivariate FAVAR with a VAR model of the global oil market that performs well at forecasting the real price of oil out of sample (Baumeister and Kilian 2012; Alquist et al. 2013). The FAVAR model based on the IC factor does well relative to the oil market VAR model at the 1- and 3-month horizons when the BIC is used but it is dominated by the VAR model when a fixed lag length of 12 is used, although the IC factor model still delivers improvements in forecast accuracy up to about $14 \%$ relative to the no-change forecast.
} 
shocks. Nevertheless, there are episodes during which the direct commodity shocks contributed negatively to global economic activity, particularly in the early 1990s and during the Great Recession.

The IC factor can also be used to forecast real commodity prices, some commonly used commodity price indices and the real price of crude oil with a bivariate FAVAR in real-time. Because our identification strategy relies only on commodity prices themselves, it can be implemented for commodities for which market fundamentals are unavailable in real time. In sum, we provide a new conceptual framework for identifying the sources and implications of commodity price comovement and its relationship to global macroeconomic conditions.

\section{References}

Ahn, Seung C. and Alex R. Horenstein, 2013. "Eigenvalue Ratio Test for the Number of Factors," Econometrica 81(3), 1203-1227.

Alquist, Ron, Lutz Kilian, and Robert Vigfusson, 2013. "Forecasting the Price of Oil,” in: G. Elliott and A. Timmermann (eds.), Handbook of Economic Forecasting, Amsterdam: North-Holland.

Bai, Jushan and Serena Ng, 2002. "Determining the Number of Factors in Approximate Factor Models," Econometrica, 70, 191-221.

Barsky, Robert B. and Lutz Kilian, 2002. "Do We Really Know that Oil Caused the Great Stagflation? A Monetary Alternative," in B. Bernanke and K. Rogoff (eds.), NBER Macroeconomics Annual 2001, May 2002, 137183.

Bastianin, Andrea and Manera, Matteo. 2014. "How does stock market volatility react to oil shocks?” FEEM Working Paper No. 70.2014

Baumeister, Christiane and Lutz Kilian, 2012. "Real-Time Forecasts of the Real Price of Oil," Journal of Business and Economic Statistics, 30(2), 326-336.

Baumeister, Christiane and Geert Peersman, 2011. "The Role of Time-Varying Price Elasticities in Accounting for Volatility Changes in the Crude Oil Market," Bank of Canada WP 11-28.

Blinder, Alan S. and Jeremy B. Rudd, 2012. "The Supply Shock Explanation of the Great Stagflation Revisited," in: The Great Inflation: The Rebirth of Modern Central Banking. NBER.

Bosworth, Barry P. and Robert Z. Lawrence, 1982. Commodity Prices and the New Inflation, The Brookings Institution, Washington D.C.

Chinn, Menzie and Olivier Coibion, 2014. "The Predictive Content of Commodity Futures," Journal of Futures Markets 34(7), 607-636.

Connor, Gregory, and Robert A. Korajczyk, 1993. "A Test for the Number of Factors in an Approximate Factor Model," Journal of Finance 48(4), 1263-1291.

Foerster, Andrew, Pierre-Daniel G. Sarte, and Mark Watson, 2011. "Sectoral versus Aggregate Shocks: A Structural Factor Analysis of Industrial Production,” Journal of Political Economy 119(1), 1-38. 
Forni, Mario and Lucrezia Reichlin, 1998. "Let's Get Real: A Factor Analytical Approach to Disaggregated Business Cycle Dynamics,” Review of Economic Studies 65(3), 453-473.

Gospodinov, Nikolay and Serena Ng, 2013. “Commodity Prices, Convenience Yields, and Inflation,” The Review of Economics and Statistics 95(1), 206-219.

Hamilton, James D., 1983. “Oil and the Macroeconomy since World War II,” Journal of Political Economy 91(2), 228-248.

Hamilton, James D. 2009. “Causes and Consequences of the Oil Shock of 2007-2008,” Brookings Papers on Economic Activity 2009(2): 215-259.

Kilian, Lutz. 2008. "Exogenous Oil Supply Shocks: How Big Are They and How Much Do They Matter for the U.S. Economy?" Review of Economics and Statistics, 90(2), 216-240.

Kilian, Lutz. 2009. "Not All Oil Price Shocks Are Alike: Disentangling Demand and Supply Shocks in the Crude Oil Market," American Economic Review, 99(3), June 2009, 1053-1069.

Kose, M. Ayan, Christopher Otrok, and Eswar Prasad, 2012. "Global Business Cycles: Convergence or Decoupling?" International Economic Review 53(2), 511-538.

Newey, Whitney K; West, Kenneth D (1987). "A Simple, Positive Semi-definite, Heteroskedasticity and Autocorrelation Consistent Covariance Matrix". Econometrica 55 (3): 703-708.

Onatski. Alexei. 2010. "Determining the Number of Factors From Empirical Distribution of Eigenvalues," Review of Economics and Statistics, 92(4), 1004-1016.

Pindyck, Robert S., Julio J. Rotemberg (1990). “The Excess Comovement of Commodity Prices,” The Economic Journal, 100(403), 1173-1189.

Reis, Ricardo and Mark W. Watson, 2010. "Relative Goods' Prices, Pure Inflation, and the Phililips Correlation," American Economic Journal: Macroeconomics 2 (July), 128-157.

Stock, James and Mark W. Watson. 2002. "Macroeconomic Forecasting Using Diffusion Indexes,” Journal of Business and Economic Statistics, 20, 147-162.

Stock, James and Mark W. Watson. 2005. "Understanding Changes in International Business Cycle Dynamics," Journal of the European Economic Association 3(5), 968-1006.

Stuermer, Martin. 2017. "Industrialization and the Demand for Mineral Commodities," Journal of International Money and Finance 46, 16-27.

Uhlig, Harald, 2002. "What are the Effects of Monetary Policy on Output? Results from an Agnostic Identification Procedure," Journal of Monetary Economics 52(2), 381-419.

West, Kenneth D. and Ka-Fu Wong. 2014. “A Factor Model for Comovements of Commodity Prices," Journal of International Money and Finance, 42, 289-309. 
TABle 1: CONTRIBUTION OF COMMON FACTORS TO COMMODITY PRICES

\begin{tabular}{lccccc}
\hline \hline & \multicolumn{7}{c}{ Cumulative Variance Explained by Common Factors } \\
\cline { 2 - 6 } Number of Common Factors: & 1 & 2 & 3 & 4 & 5 \\
\hline Complete Sample: & & & & & \\
$\quad$ Cumulative eigenvalue shares & 0.59 & 0.69 & 0.75 & 0.79 & 0.82 \\
Mean across commodity-specific $R^{2} \mathrm{~s}$ & 0.60 & 0.69 & 0.74 & 0.78 & 0.81 \\
Median across commodity-specific $R^{2} \mathrm{~s}$ & 0.70 & 0.76 & 0.78 & 0.84 & 0.85 \\
$R^{2}$ across all commodities & 0.62 & 0.71 & 0.75 & 0.79 & 0.82 \\
& & & & & \\
Subset of Commodities: & & & & & 0.77 \\
$R^{2}$ across agricultural/food commodities & 0.64 & 0.72 & 0.75 & 0.80 \\
$R^{2}$ across oils & 0.72 & 0.74 & 0.76 & 0.82 & 0.85 \\
$R^{2}$ across industrial commodities & 0.55 & 0.68 & 0.75 & 0.80 & 0.83 \\
\hline \hline
\end{tabular}

Notes: The table provides metrics of the cumulative variance associated with using additional factors, as indicated by each column. The first row provides the cumulative sum of eigenvalues associated with each factor normalized by the sum of all eigenvalues. The second row provides the mean across the $R^{2}$ of each commodity for each given factor, using the specific sample associated with each commodity. The third row provides the median $R^{2}$ across all commodity-specific $R^{2}$ s. The fourth row provides the joint $R^{2}$ constructed using all commodities. In addition, the top panel presents joint $R^{2}$ s for subsets of commodities (as defined in Table 1). Each $R^{2}$ omits imputed values. See section 3.2 for details. 
TABLE 2: GMM ESTIMATES OF THE ROTATION MATRIX

\begin{tabular}{|c|c|c|c|c|c|c|c|c|}
\hline & \multicolumn{4}{|c|}{ GMM Estimates of Rotation Parameter } & \multicolumn{4}{|c|}{ Implied Rotation Coefficients } \\
\hline & $\theta$ & $\operatorname{se}(\theta)$ & $p$ (over-id) & $\mathrm{N}$ & $t_{11}$ & $95 \% \mathrm{CI}\left(t_{11}\right)$ & $t_{21}$ & $95 \% \mathrm{CI}\left(t_{21}\right)$ \\
\hline $\begin{array}{l}\text { Baseline GMM Estimates: } \\
\quad \text { (Iterative GMM, } L=36 \text { ) }\end{array}$ & -0.10 & $(0.31)$ & 1.00 & 505 & 1.00 & {$\left[\begin{array}{lll}0.75 & 1.00\end{array}\right]$} & -0.10 & {$\left[\begin{array}{lll}-0.65 & 0.49\end{array}\right]$} \\
\hline Robustness of GMM Estimates: & & & & & & & & \\
\hline More moments: $(L=48)$ & -0.15 & $(0.27)$ & 1.00 & 493 & 0.99 & {$[0.77$ 1.00] } & -0.15 & {$\left[\begin{array}{lll}-0.63 & 0.39\end{array}\right]$} \\
\hline Fewer moments: $(L=24)$ & -0.13 & $(0.35)$ & 1.00 & 517 & 0.99 & {$\left[\begin{array}{lll}0.67 & 1.00]\end{array}\right.$} & -0.13 & {$\left[\begin{array}{lll}-0.73 & 0.54\end{array}\right]$} \\
\hline Fewer moments: $(L=12)$ & -0.23 & $(0.50)$ & 1.00 & 529 & 0.97 & {$\left[\begin{array}{lll}0.32 & 1.00\end{array}\right]$} & -0.23 & {$\left[\begin{array}{lll}-0.94 & 0.69\end{array}\right]$} \\
\hline Two-step GMM & -0.10 & $(0.31)$ & 1.00 & 505 & 1.00 & {$\left[\begin{array}{ll}0.75 & 1.00\end{array}\right]$} & -0.10 & {$\left[\begin{array}{lll}-0.65 & 0.47\end{array}\right]$} \\
\hline Continuous GMM & -0.07 & $(0.31)$ & 1.00 & 505 & 1.00 & {$\left[\begin{array}{lll}0.76 & 1.00]\end{array}\right]$} & -0.07 & {$\left[\begin{array}{ll}-0.62 & 0.52\end{array}\right]$} \\
\hline Alternative normalization & -0.08 & $(0.31)$ & 1.00 & 505 & 1.00 & {$\left[\begin{array}{ll}0.75 & 1.00\end{array}\right]$} & -0.08 & {$\left[\begin{array}{lll}-0.64 & 0.50\end{array}\right]$} \\
\hline
\end{tabular}

Notes: The table presents nonlinear GMM estimates of parameter $\theta$ from equation (7) in the text, along with NeweyWest (1987) standard errors $(\operatorname{se}(\theta))$, the $p$-value for over-identifying restrictions ( $p$ (over-id)), and the number of observations used in the estimation $(N)$. The panel on the right presents the implied parameters of the first row of the rotation matrix, along with the $95 \%$ confidence interval implied from the estimated distribution of $\theta$. The baseline estimates are based on iterative GMM until convergence, using a constant as well as the contemporaneous value and 36 lags of OPEC production shocks for moment conditions. Subsequent rows present robustness to using more or fewer lags of OPEC production shocks as moment conditions, a two-step GMM procedure, a continuously updated GMM procedure and an alternative normalization of moment conditions. See section 3.3 for details. 
TABLE 3: ROTATED COMMODITY-SPECIFIC FACTOR LOADINGS

\begin{tabular}{|c|c|c|c|c|c|}
\hline \multirow[b]{2}{*}{ Commodity } & \multicolumn{2}{|c|}{ Factor Loadings } & \multirow[b]{2}{*}{ Commodity } & \multicolumn{2}{|c|}{ Factor Loadings } \\
\hline & IC & $\mathrm{DC}$ & & $\mathrm{IC}$ & $\mathrm{DC}$ \\
\hline Agr./Food Commodities & & & Oils & & \\
\hline Apples & 0.46 & 0.13 & Coconut oil & 0.82 & 0.02 \\
\hline Bananas & 0.57 & 0.22 & Groundnut oil & 0.86 & 0.13 \\
\hline Barley & 0.75 & 0.41 & Palm oil & 0.89 & 0.13 \\
\hline Beef & 0.87 & -0.09 & Rapeseed oil & 0.53 & 0.39 \\
\hline Cocoa & 0.89 & -0.12 & Sun/Safflower oil & 0.83 & 0.22 \\
\hline Coffee & 0.85 & -0.17 & & & \\
\hline Corn & 0.95 & 0.09 & Industrial Commodities & & \\
\hline Fishmeal & 0.91 & 0.15 & Aluminum & 0.80 & 0.05 \\
\hline Hay & 0.86 & -0.04 & Burlap & 0.85 & -0.00 \\
\hline Oats & 0.88 & 0.11 & Cement & 0.21 & 0.06 \\
\hline Orange juice & 0.74 & -0.22 & Copper & 0.60 & 0.69 \\
\hline Onions & 0.53 & -0.39 & Cotton & 0.92 & -0.20 \\
\hline Pepper & 0.56 & -0.62 & Lead & 0.73 & 0.58 \\
\hline Potatoes & 0.73 & -0.05 & Lumber & 0.53 & -0.23 \\
\hline Rice & 0.93 & 0.09 & Mercury & 0.46 & 0.75 \\
\hline Shrimp & 0.44 & -0.75 & Nickel & 0.20 & 0.74 \\
\hline Sorghums & 0.95 & 0.08 & Rubber & 0.79 & 0.45 \\
\hline Soybeans & 0.95 & 0.02 & Tin & 0.90 & 0.18 \\
\hline Sugar & 0.78 & 0.11 & Wool & 0.87 & 0.16 \\
\hline Tea & 0.87 & -0.22 & Zinc & 0.60 & 0.36 \\
\hline Tobacco & 0.84 & -0.33 & & & \\
\hline Wheat & 0.92 & 0.13 & & & \\
\hline
\end{tabular}

Notes: The table presents the rotated loadings from factor analysis using the GMM estimates of the rotation matrix. See section 3.3 for details. 


\begin{tabular}{|c|c|c|c|c|c|c|c|c|c|c|}
\hline & \multicolumn{10}{|c|}{ Forecast Evaluation Period: Commodity-Specific } \\
\hline & Aggregate MSPE Ratio & \multicolumn{5}{|c|}{ Distribution of MSPE Ratios } & \multirow[b]{2}{*}{$\underline{\mathrm{CRB}}$} & \multirow[b]{2}{*}{$\underline{\mathrm{WB}}$} & \multirow[b]{2}{*}{$\underline{\mathrm{IMF}}$} & \multirow[b]{2}{*}{ Crude Oil } \\
\hline & & {$[0,0.9)$} & {$[0.9,0.95)$} & {$[0.95,1)$} & {$[0,1)$} & {$[1, \infty)$} & & & & \\
\hline 1 month & 0.921 & 10 & 11 & 11 & 32 & 8 & $\overline{0.974}$ & $\overline{0.834}$ & $\overline{0.874}$ & 0.805 \\
\hline 3 months & 0.922 & 4 & 5 & 11 & 20 & 20 & 1.057 & 1.023 & 0.990 & 0.977 \\
\hline 6 months & 0.938 & 5 & 4 & 4 & 13 & 27 & 1.127 & 1.125 & 1.072 & 1.143 \\
\hline 12 months & 1.096 & 5 & 6 & 5 & 16 & 24 & 1.187 & 1.214 & 1.155 & 1.324 \\
\hline No. of commodities & 40 & & & & & & $24(15)$ & $39(17)$ & $45(17)$ & \\
\hline
\end{tabular}

Forecast Evaluation Period: January 1984—December 2012

Aggregate MSPE Ratio

$\begin{array}{ll}1 \text { month } & 0.931 \\ 3 \text { months } & 0.944 \\ 6 \text { months } & 0.985 \\ 12 \text { months } & 1.106\end{array}$

Distribution of MSPE Ratios

\begin{tabular}{|c|c|c|c|c|c|c|c|c|}
\hline$[0,0.9)$ & {$[0.9,0.95)$} & {$[0.95,1)$} & {$[0,1)$} & {$[1, \infty)$} & CRB & $\underline{\mathrm{WB}}$ & IMF & Crude Oil \\
\hline 8 & 7 & 8 & 23 & 5 & 0.964 & $\overline{0.863}$ & 0.888 & 0.790 \\
\hline 7 & 5 & 6 & 18 & 10 & 0.991 & 0.982 & 0.928 & 0.951 \\
\hline 8 & 3 & 3 & 14 & 14 & 1.068 & 1.106 & 1.008 & 1.114 \\
\hline 9 & 2 & 5 & 16 & 12 & 1.128 & 1.256 & 1.112 & 1.314 \\
\hline & & & & & $24(15)$ & $39(17)$ & $45(17)$ & \\
\hline
\end{tabular}

No. of commodities

28

Notes: For the commodity-specific forecast evaluation period, the initial estimation window depends on the commodity. It begins either in January 1968 or at the earliest date that allows the initial estimation window to contain at least 48 observations. The maximum length of the recursive sample is restricted by the end of the data sample for each commodity and the forecast horizon. The "Aggregate MSPE Ratio" is the ratio of the sum of the MSPEs for the bivariate FAVAR forecasts of the real commodity prices relative to the sum of the MSPEs for the no-change forecast. The MSPE ratios of the individual forecasts of real commodity prices are also computed relative to the benchmark no-change forecast. For the FAVAR-based forecasts, the lag length is chosen recursively using the BIC. The number of commodities included in the commodity price indices but not in the cross-section of 40 commodities used to extract the factor is in parentheses. 


\section{FIGURE 1: INDIRECT COMMON FACTOR IN COMMODITY PRICES}

Panel A: Indirect Common Factor (GMM Approach)

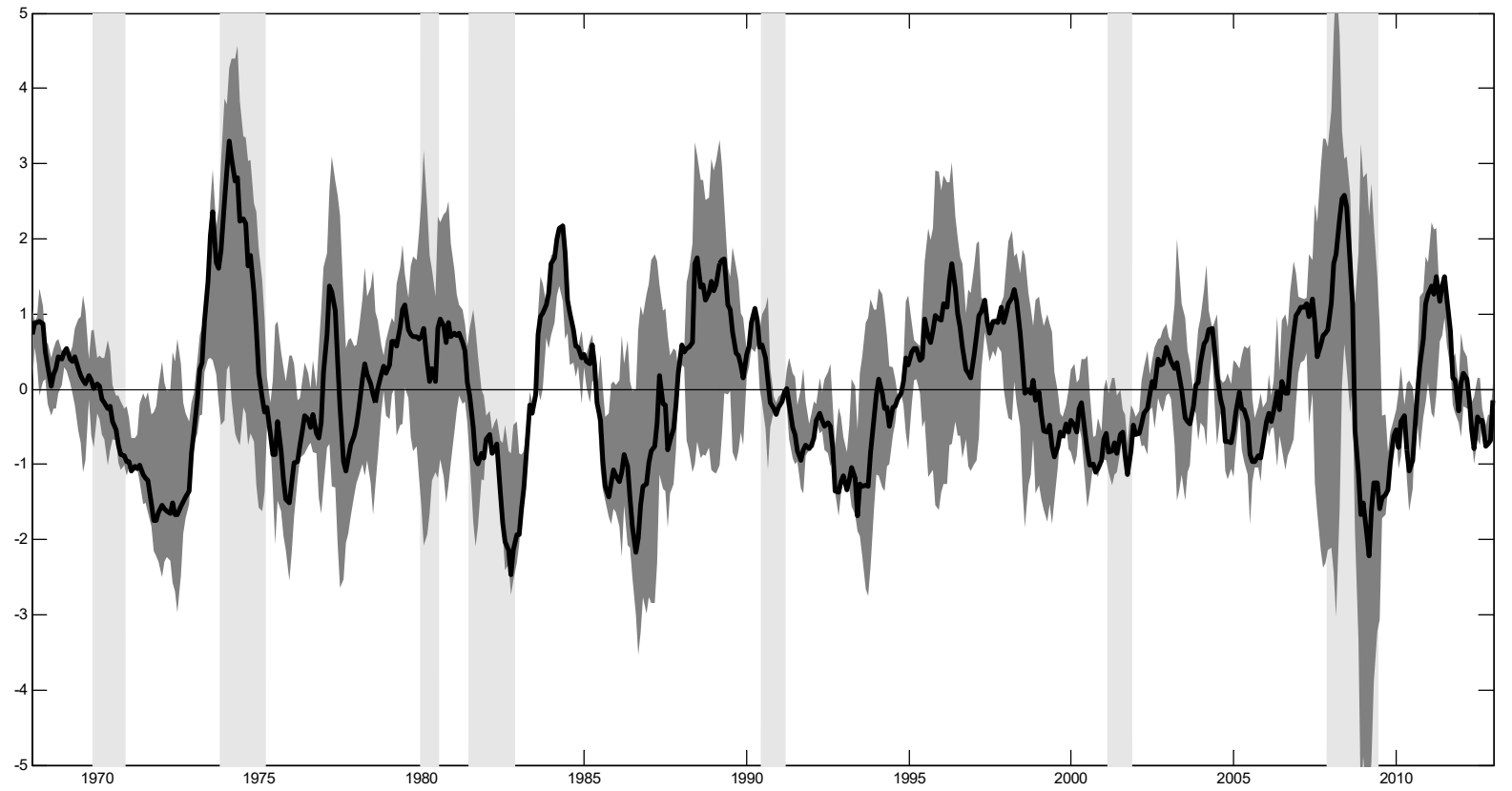

Panel B: Indirect Common Factor (Factor Loading Sign Restrictions)

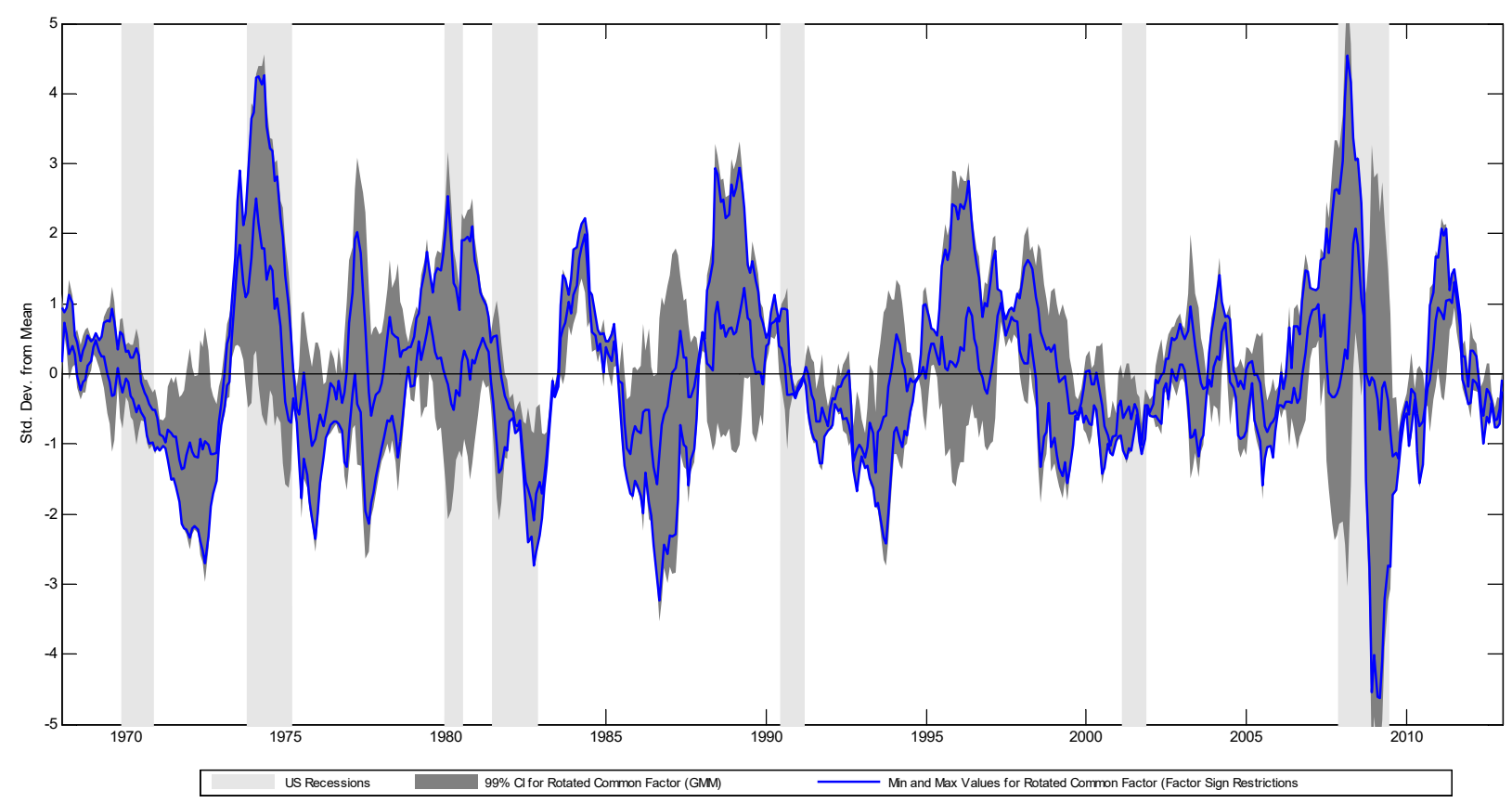

Notes: The figure in Panel A presents the IC factor from the factor analysis in section 3.3. The IC factor is HP-filtered $(\lambda=129,600)$ in the figure. The light grey shaded areas are recessions dated by the National Bureau of Economic Research. The dark grey shaded areas are $99 \%$ confidence intervals of HP-filtered rotated factors constructed from the estimated distribution of rotation parameters. The figure in Panel B plots the $99 \%$ confidence interval of the IC factor as estimated by GMM (shaded areas), and the minimum and maximum range for admissible values of the IC factor using sign restrictions on factor loadings (solid blue lines). See section 3.3 for details. 


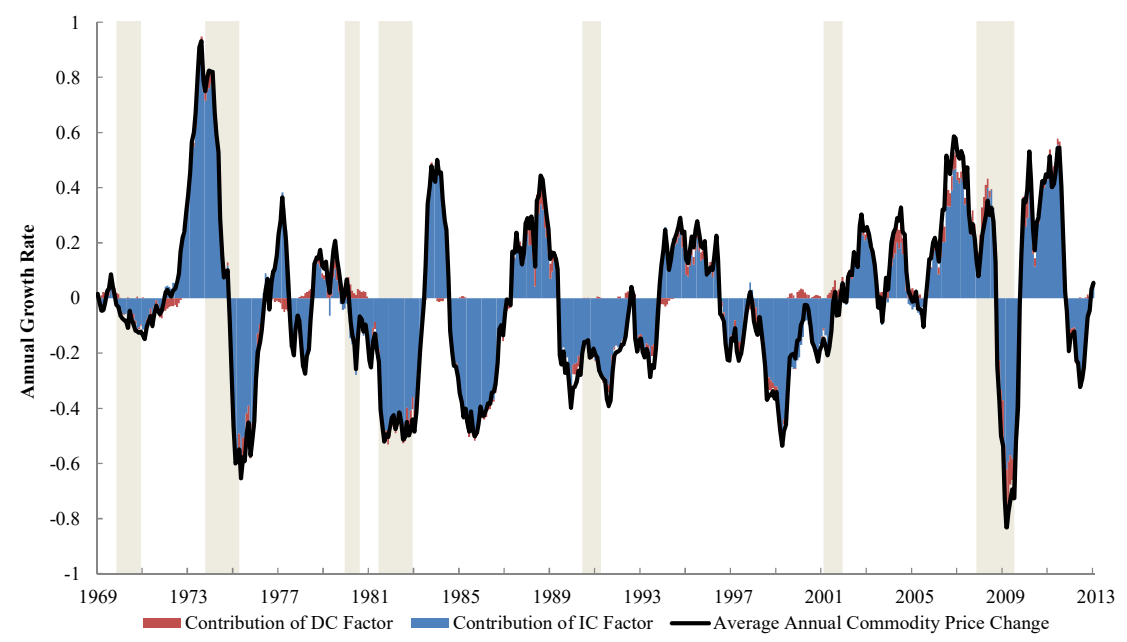

Panel B: Contributions to Comovement in Commodity Price Changes

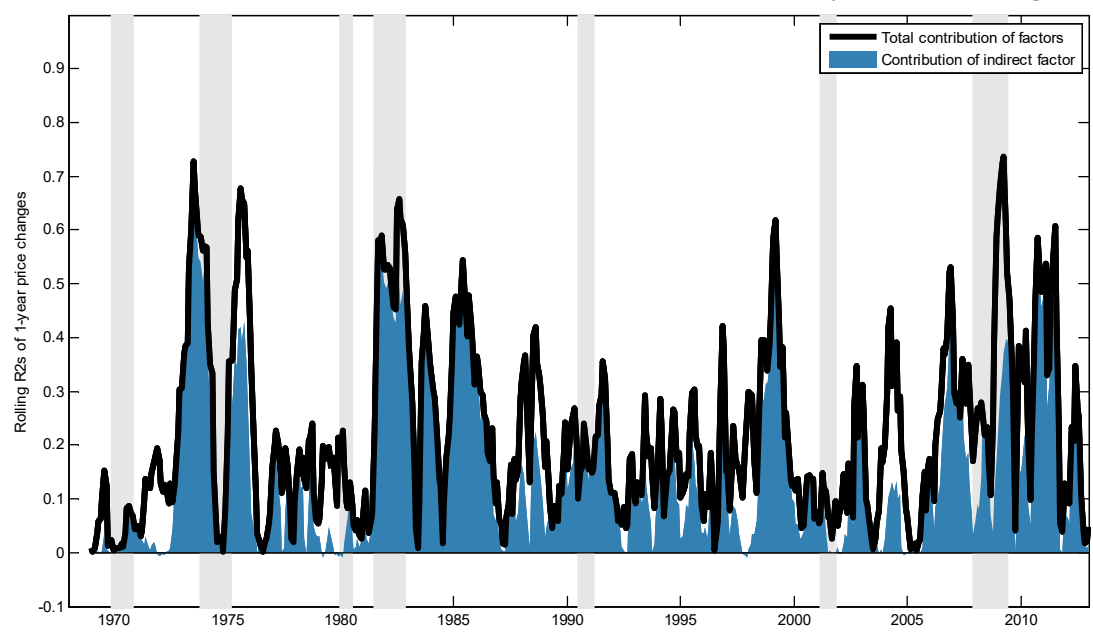

Panel C: Contributions to Annual Changes in Global Industrial Production

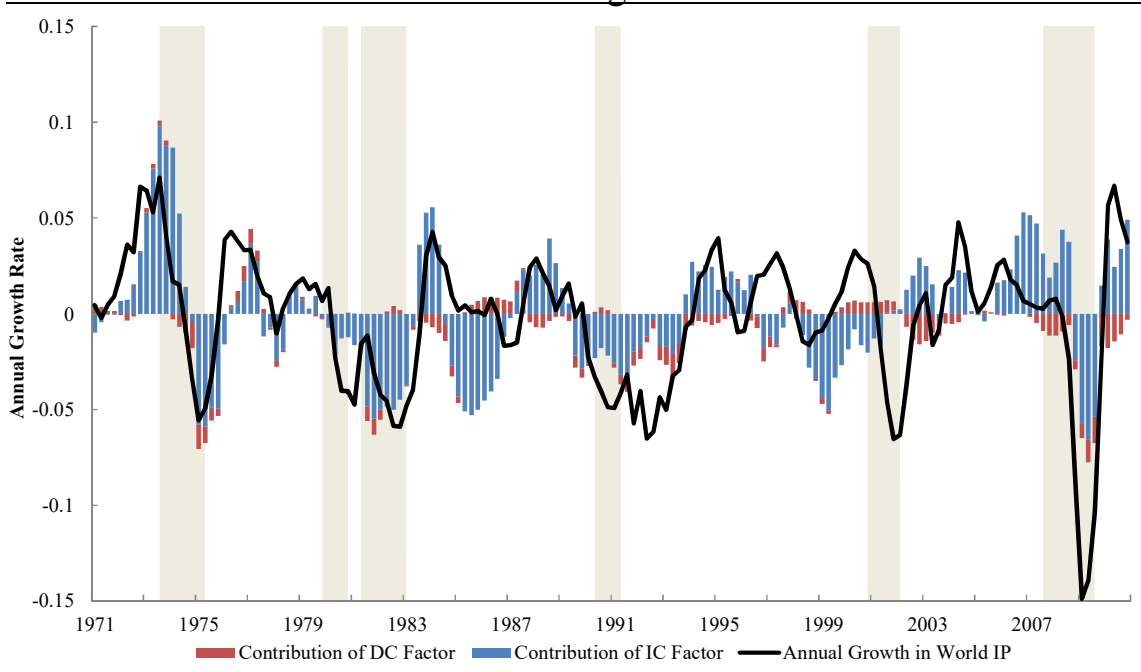

Notes: Panel A plots the contributions of the direct and indirect factors (DC and IC, respectively) to the average annual price changes across all commodities. Panel B plots the contribution of the two factors to cross-sectional variation in 1 -year commodity price changes (black line) and that coming solely from IC factor (blue shaded area). See section 3.4 for details. Panel $\mathrm{C}$ plots the equivalent contributions to the annual growth rate of global industrial production. 


\section{APPENDIX A.1: BASELINE MODEL}

\section{$1 \quad$ Model}

We present the model in detail below.

\subsection{Household}

Household maximizes

$$
E_{t} \sum_{i=0}^{\infty} \beta^{i}\left[\frac{C_{t+i}^{1-\sigma}}{1-\sigma}-e^{-\varepsilon_{t+i}^{n}} \varphi_{n} \frac{N_{t+i}^{s^{1+\frac{1}{\eta}}}}{1+\frac{1}{\eta}}-\varphi_{e} \frac{N_{t+i}^{s, e^{1+\frac{1}{\eta}}}}{1+\frac{1}{\eta}}\right]
$$

where $C_{t}$ is consumption and the household supplies labor to the final good $\left(N_{t}^{s}\right)$ and the energy sectors $\left(N_{t}^{s, e}\right)$. The nominal flow budget constraint faced by the household is

$$
P_{t} C_{t}+B_{t}=B_{t-1} R_{t-1}+W_{t} N_{t}^{s}+W_{t}^{e} N_{t}^{s, e}+T_{t}
$$

where $P_{t}$ is aggregate price, $B_{t}$ is nominal bond holdings with $R_{t-1}$ the interest rate, $W_{t}$ the wage in the final good sector, $W_{t}^{e}$ the wage in the energy sector and $T_{t}$ lump-sum profits from firms.

The first order conditions are standard and given by

$$
\begin{gathered}
\varphi_{n} C_{t}^{\sigma} N_{t}^{s \frac{1}{\eta}}=e^{\varepsilon_{t}^{n}} \frac{W_{t}}{P_{t}}, \\
\varphi_{e} C_{t}^{\sigma} N_{t}^{s, e \frac{1}{\eta}}=\frac{W_{t}^{e}}{P_{t}}, \\
C_{t}^{-\sigma}=\beta E_{t}\left[C_{t+1}^{-\sigma} R_{t} \frac{P_{t}}{P_{t+1}}\right] .
\end{gathered}
$$

\subsection{Energy Sector}

The energy sector's total supply of the energy good $\left(\Sigma_{t}\right)$ is endogenous, with exogenous productivity shock $\Xi_{t}$ and the firm faces a decreasing returns to scale (determined by $\gamma$ ) production function that uses labor

$$
\Sigma_{t}=\Xi_{t}\left(N_{t}^{d, e}\right)^{1-\gamma} .
$$

The energy sector firm maximizes

$$
S_{t} \Xi_{t}\left(N_{t}^{d, e}\right)^{1-\gamma}-W_{t}^{e} N_{t}^{d, e}
$$

while taking productivity and wages as given, where $S_{t}$ is the price of the energy good. The first-order condition can we written in real terms as

$$
(1-\gamma) \frac{S_{t}}{P_{t}} \Sigma_{t}=N_{t}^{d, e} \frac{W_{t}^{e}}{P_{t}} .
$$


The market clearing condition for labor is

$$
N_{t}^{s, e}=N_{t}^{d, e}=N_{t}^{e}
$$

while the market clearing condition for the energy good is

$$
\Sigma_{t}=\int_{0}^{1} \Sigma_{t}(j) d j
$$

where as we explain below, a continuum of primary-commodity producing firms use the energy good in production.

\subsection{Primary Commodity-Production Sector}

There are a continuum of primary commodity producing firms. The energy good is used in the production of the primary commodity $\left(Q_{t}(j)\right)$, with a decreasing returns to scale (determined by $\alpha_{j}$ ) production function

$$
Q_{t}(j)=A_{t}(j) \Sigma_{t}(j)^{1-\alpha_{j}}
$$

where $A_{t}(j)$ is the productivity shock. Let $P_{t}(j)$ be the price of the commodity $j$. Then the firm's problem is to maximize profits

$$
P_{t}(j) A_{t}(j) \Sigma_{t}(j)^{1-\alpha_{j}}-S_{t} \Sigma_{t}(j)
$$

while taking productivity and prices as given. The first-order condition can be written in real terms as

$$
\left(1-\alpha_{j}\right)\left(\frac{P_{t}(j)}{P_{t}}\right) Q_{t}(j)=\Sigma_{t}(j) \frac{S_{t}}{P_{t}}
$$

\subsection{The Intermediate Commodity}

The production function for the intermediate commodity $\left(Q_{t}^{C}\right)$, which is simply a CES aggregator with elasticity of substitution $\theta_{c}$ across the primary commodities, is given by

$$
Q_{t}^{C}=\left[\int_{0}^{1} Y_{t}(j)^{\frac{\theta_{c}-1}{\theta_{c}}} d j\right]^{\frac{\theta_{c}}{\theta_{c}-1}}
$$

which gives the standard price index

$$
P_{t}^{C}=\left[\int_{0}^{1} P_{t}(j)^{1-\theta_{c}} d j\right]^{\frac{1}{1-\theta_{c}}}
$$

and the standard demand curve

$$
\frac{Y_{t}(j)}{Q_{t}^{C}}=\left(\frac{P_{t}(j)}{P_{t}^{C}}\right)^{-\theta_{c}}
$$

Market clearing is then given by

$$
Y_{t}(j)=Q_{t}(j)
$$




\subsection{The Final Goods Sector}

The production function for the final good $\left(Y_{t}\right)$ sector is given by

$$
Y_{t}=A_{t} Y_{t}^{C^{\alpha_{t}}} N_{t}^{d^{1-\alpha_{t}}}
$$

where $A_{t}$ is the productivity shock and the share parameter $\alpha_{t}$ is exogenous. Let $P_{t}$ be the price of the final good. The firm's problem is to maximize profits

$$
P_{t} A_{t} Y_{t}^{C^{\alpha_{t}}} N_{t}^{d^{1-\alpha_{t}}}-W_{t} N_{t}^{d}-P_{t}^{C} Y_{t}^{C}
$$

while taking productivity and prices as given.

The first order conditions are given by

$$
\begin{gathered}
\alpha_{t}=\left(\frac{P_{t}^{C}}{P_{t}}\right)\left(\frac{Y_{t}^{C}}{Y_{t}}\right), \\
1-\alpha_{t}=\left(\frac{W_{t}}{P_{t}}\right)\left(\frac{N_{t}^{d}}{Y_{t}}\right) .
\end{gathered}
$$

Market clearing for good is

$$
Y_{t}=C_{t}
$$

while for labor is

$$
N_{t}^{d}=N_{t}^{s}=N_{t}
$$

and for the commodity input is

$$
Q_{t}^{C}=Y_{t}^{C}
$$

\subsection{Equilibrium}

We now present the equilibrium conditions of the model.

\subsubsection{Non-linear equilibrium conditions}

The following non-linear optimality and market clearing conditions determine the equilibrium

$$
\begin{gathered}
\varphi_{n} Y_{t}^{\sigma} N_{t}^{\frac{1}{\eta}}=e^{\varepsilon_{t}^{n}} \frac{W_{t}}{P_{t}} \\
Y_{t}^{-\sigma}=\beta E_{t}\left[Y_{t+1}^{-\sigma} R_{t} \frac{P_{t}}{P_{t+1}}\right] \\
\varphi_{e} Y_{t}^{\sigma} N_{t}^{e \frac{1}{\eta}}=\frac{W_{t}^{e}}{P_{t}} \\
(1-\gamma) \frac{S_{t}}{P_{t}} \Sigma_{t}=N_{t}^{e} \frac{W_{t}^{e}}{P_{t}} \\
\Sigma_{t}=\Xi_{t}\left(N_{t}^{e}\right)^{1-\gamma} \\
\Sigma_{t}=\int_{0}^{1} \Sigma_{t}(j) d j
\end{gathered}
$$




$$
\begin{gathered}
Y_{t}(j)=A_{t}(j) \Sigma_{t}(j)^{1-\alpha_{j}} \\
\left(1-\alpha_{j}\right)\left(\frac{P_{t}(j)}{P_{t}}\right) Y_{t}(j)=\Sigma_{t}(j) \frac{S_{t}}{P_{t}} \\
Y_{t}^{C}=\left[\int_{0}^{1} Y_{t}(j)^{\frac{\theta_{c}-1}{\theta_{c}}} d j\right]^{\frac{\theta_{c}}{\theta_{c}-1}} \\
\frac{Y_{t}(j)}{Y_{t}^{C}}=\left(\frac{P_{t}(j)}{P_{t}^{C}}\right)^{-\theta_{c}} \\
P_{t}^{C}=\left[\int_{0}^{1} P_{t}(j)^{1-\theta_{c}} d j\right]^{\frac{1}{1-\theta_{c}}} \\
Y_{t}=A_{t} Y_{t}^{C^{\alpha_{t}}} N_{t}^{1-\alpha_{t}} \\
\alpha_{t}=\left(\frac{P_{t}^{C}}{P_{t}}\right)\left(\frac{Y_{t}^{C}}{Y_{t}}\right) \\
1-\alpha_{t}=\left(\frac{W_{t}}{P_{t}}\right)\left(\frac{N_{t}}{Y_{t}}\right)
\end{gathered}
$$

where the following are exogenous processes $\left\{A_{t}, \alpha_{t}, A_{t}(j), \varepsilon_{t}^{n}, \Xi_{t}\right\}$.

\subsubsection{Log-linear approximation}

We now consider a first-order approximation around a non-stochastic steady-state. We use the notation with lower case variables denoting $\log$ deviations of real variables (except for $\Sigma_{t}(j)$ and $\Sigma_{t}$, which are deviations from steady-state) and variables without a $t$ subscript to denote steadystate values of respective variables. We normalize, without loss of generality, equal production in steady-state across commodity producers. The log-linear equilibrium is determined by

$$
\begin{gathered}
\sigma y_{t}+\frac{1}{\eta} n_{t}=w_{t}+\varepsilon_{t}^{n} \\
y_{t}=E_{t}\left[y_{t+1}-\frac{1}{\sigma} r_{t}\right] \\
\sigma y_{t}+\frac{1}{\eta} n_{t}^{e}=w_{t}^{e} \\
s_{t}+\frac{\Sigma_{t}}{\Sigma}=n_{t}^{e}+w_{t}^{e} \\
\frac{\Sigma_{t}}{\Sigma}=\Xi_{t}+(1-\gamma) n_{t}^{e} \\
\Sigma_{t}=\int_{0}^{1} \Sigma_{t}(j) d j \\
y_{t}(j)=a_{t}(j)+\frac{\left(1-\alpha_{j}\right)}{\Sigma_{j}} \Sigma_{t}(j)
\end{gathered}
$$




$$
\begin{gathered}
p_{t}(j)=s_{t}+\frac{1}{\Sigma_{j}} \Sigma_{t}(j)-y_{t}(j) \\
y_{c, t}=\int_{0}^{1} y_{t}(j) d j \\
p_{t}(j)=p_{c, t}-\frac{1}{\theta_{c}}\left(y_{t}(j)-y_{c, t}\right) \\
y_{t}=a_{t}+\alpha y_{c, t}+(1-\alpha) n_{t}+\varphi_{\alpha} \tilde{\alpha}_{t} \\
p_{c, t}=y_{t}-y_{c, t}+\tilde{\alpha}_{t} \\
w_{t}=y_{t}-n_{t}-\frac{\alpha}{1-\alpha} \tilde{\alpha}_{t}
\end{gathered}
$$

where note that $\tilde{\alpha}_{t}$ is $\log$-deviation of $\alpha_{t}$ and $\varphi_{\alpha} \equiv \alpha\left(\ln \overline{Y^{C}}-\ln \bar{N}\right)$.

\subsubsection{Solution}

We now present the solution of the model.

Primary commodity sector We start with the primary commodity sector. We have, from the production function and substitution of the energy good input, the following

$$
\begin{aligned}
y_{t}(j) & =a_{t}(j)+\frac{\left(1-\alpha_{j}\right)}{\Sigma_{j}} \Sigma_{t}(j) \\
& =a_{t}(j)+\left(1-\alpha_{j}\right)\left[p_{t}(j)-s_{t}+y_{t}(j)\right]
\end{aligned}
$$

which gives, after defining

$$
\begin{gathered}
\left(\frac{\alpha_{j}}{1-\alpha_{j}}\right) \equiv \varepsilon_{j}, \\
y_{t}(j)=\left(1+\varepsilon_{j}^{-1}\right) a_{t}(j)+\varepsilon_{j}^{-1}\left(p_{t}(j)-s_{t}\right) .
\end{gathered}
$$

(1) above gives the supply curve of commodity $j$. Next, plug in the relative demand expression

$$
p_{t}(j)=p_{c, t}-\frac{1}{\theta_{c}}\left(y_{t}(j)-y_{c, t}\right)
$$

to (1) in order to eliminate the commodity price $p_{t}(j)$, which gives, after defining a re-scaled productivity shock for commodity $j$ as

$$
\left(1+\frac{1}{\varepsilon_{j} \theta_{c}}\right)^{-1}\left(1+\varepsilon_{j}^{-1}\right) a_{t}(j) \equiv v_{t}(j)
$$

the solution as

$$
y_{t}(j)=v_{t}(j)+\left(1+\frac{1}{\varepsilon_{j} \theta_{c}}\right)^{-1}\left(\varepsilon_{j}^{-1}\left(p_{c, t}+\frac{1}{\theta_{c}} y_{c, t}-s_{t}\right)\right) .
$$


To determine the aggregate supply of commodities, integrate (2) over all $j$, which gives

$$
\begin{aligned}
& y_{c, t}=\int_{0}^{1} v_{t}(j) d j+p_{c, t} \int_{0}^{1}\left(1+\frac{1}{\varepsilon_{j} \theta_{c}}\right)^{-1} \varepsilon_{j}^{-1} d j+ \\
& \frac{1}{\theta_{c}} y_{c, t} \int_{0}^{1}\left(1+\frac{1}{\varepsilon_{j} \theta_{c}}\right)^{-1} \varepsilon_{j}^{-1} d j-s_{t} \int_{0}^{1}\left(1+\frac{1}{\varepsilon_{j} \theta_{c}}\right)^{-1} \varepsilon_{j}^{-1} d j .
\end{aligned}
$$

Define

$$
\begin{gathered}
\int_{0}^{1} v_{t}(j) d j \equiv v_{t} \\
\varphi \equiv \int_{0}^{1}\left(1+\varepsilon_{j} \theta_{c}\right)^{-1} d j
\end{gathered}
$$

and rewrite as

$$
p_{c, t}=\frac{1}{\theta_{c}}\left(\frac{1}{\varphi}-1\right) y_{c, t}+s_{t}-\frac{1}{\varphi \theta_{c}} v_{t} .
$$

Next, we have the aggregate demand for commodity given by

$$
p_{c, t}=y_{t}-y_{c, t}+\tilde{\alpha}_{t}
$$

which we use with (3) to derive the production of the intermediate commodity bundle, which is

$$
y_{c, t}=\frac{\theta_{c} \varphi}{1+\left(\theta_{c}-1\right) \varphi} y_{t}+\frac{1}{1+\left(\theta_{c}-1\right) \varphi} v_{t}-\frac{\theta_{c} \varphi}{1+\left(\theta_{c}-1\right) \varphi} s_{t}+\frac{\theta_{c} \varphi}{1+\left(\theta_{c}-1\right) \varphi} \tilde{\alpha}_{t} .
$$

For future reference, we also derive the solution for $p_{c, t}$. We can use the aggregate demand for the commodity sector to derive, after plugging in for (4)

$$
p_{c, t}=\frac{1-\varphi}{1+\left(\theta_{c}-1\right) \varphi} y_{t}-\frac{1}{1+\left(\theta_{c}-1\right) \varphi} v_{t}+\frac{\theta_{c} \varphi}{1+\left(\theta_{c}-1\right) \varphi} s_{t}+\frac{1-\varphi}{1+\left(\theta_{c}-1\right) \varphi} \tilde{\alpha}_{t}
$$

with (5) above giving the solution for $p_{c, t}$.

Energy sector price We now move to the energy sector. We can use market clearing condition to pin down the (aggregate) price of the energy sector $s_{t}$. Using the production function and (2) we get

$$
a_{t}(j)+\frac{\left(1-\alpha_{j}\right)}{\Sigma_{j}} \Sigma_{t}(j)=v_{t}(j)+\left(1+\frac{1}{\varepsilon_{j} \theta_{c}}\right)^{-1}\left(\varepsilon_{j}^{-1}\left(p_{c, t}+\frac{1}{\theta_{c}} y_{c, t}-s_{t}\right)\right)
$$

which can be written as

$$
\begin{aligned}
\Sigma_{t}(j) & =\left(\frac{1-\alpha_{j}}{\Sigma_{j}}\right)^{-1} v_{t}(j)-\left(\frac{1-\alpha_{j}}{\Sigma_{j}}\right)^{-1} a_{t}(j)+ \\
& \left(\frac{1-\alpha_{j}}{\Sigma_{j}}\right)^{-1}\left(1+\frac{1}{\varepsilon_{j} \theta_{c}}\right)^{-1}\left(\varepsilon_{j}^{-1}\left(p_{c, t}+\frac{1}{\theta_{c}} y_{c, t}-s_{t}\right)\right) .
\end{aligned}
$$

Define

$$
\frac{1-\alpha_{j}}{\Sigma_{j}} \equiv \varsigma_{j}
$$


and get

$$
\Sigma_{t}(j)=\varsigma_{j}^{-1} v_{t}(j)-\varsigma_{j}^{-1} a_{t}(j)+\varsigma_{j}^{-1}\left(1+\frac{1}{\varepsilon_{j} \theta_{c}}\right)^{-1}\left(\varepsilon_{j}^{-1}\left(p_{c, t}+\frac{1}{\theta_{c}} y_{c, t}-s_{t}\right)\right) .
$$

Then we use (6) in the market clearing condition to get a solution for $s_{t}$

$$
\Sigma_{t}=\int_{0}^{1} \varsigma_{j}^{-1} v_{t}(j) d j-\int_{0}^{1} \varsigma_{j}^{-1} a_{t}(j) d j+\left(p_{c, t}+\frac{1}{\theta_{c}} y_{c, t}-s_{t}\right) \int_{0}^{1} \varsigma_{j}^{-1}\left(1+\frac{1}{\varepsilon_{j} \theta_{c}}\right)^{-1} \varepsilon_{j}^{-1} d j .
$$

Lets define,

$$
\begin{gathered}
\int_{0}^{1} \varsigma_{j}^{-1} v_{t}(j) d j \equiv \tilde{v}_{t} \\
\int_{0}^{1} \varsigma_{j}^{-1} a_{t}(j) d j \equiv \tilde{a}_{t} \\
\int_{0}^{1} \varsigma_{j}^{-1}\left(1+\frac{1}{\varepsilon_{j} \theta_{c}}\right)^{-1} \varepsilon_{j}^{-1} d j \equiv \tilde{\varphi} .
\end{gathered}
$$

For future reference, note that if $\frac{1-\alpha_{j}}{\Sigma_{j}} \equiv \varsigma_{j}=1$, then $\tilde{v}_{t}=v_{t}$ and $\tilde{\varphi}=\theta_{c} \varphi$.

Then we can write the solution for $s_{t}$ as

$$
s_{t}=\tilde{\varphi}^{-1} \tilde{v}_{t}-\tilde{\varphi}^{-1} \tilde{a}_{t}-\tilde{\varphi}^{-1} \Sigma_{t}+p_{c, t}+\frac{1}{\theta_{c}} y_{c, t}
$$

where (7) gives the solution for $s_{t}$ as a function of the total supply in the energy sector, the two averages over commodity specific productivity shocks, and $p_{c, t}$ and $y_{c, t}$. We have expressions for $p_{c, t}$ and $y_{c, t}$ in (5) and (4), which we can later combine for solutions of all aggregate variables as a function of various aggregate shocks and total supply in the energy sector.

Moreover, given the equilibrium conditions from the supply side of the firms, we can derive

$$
\frac{\Sigma_{t}}{\Sigma}=\frac{1}{\left(1-(1-\gamma)\left(1+\frac{1}{\eta}\right)^{-1}\right)} \Xi_{t}+\frac{(1-\gamma)\left(1+\frac{1}{\eta}\right)^{-1}}{\left(1-(1-\gamma)\left(1+\frac{1}{\eta}\right)^{-1}\right)}\left[s_{t}-\sigma y_{t}\right],
$$

which we will use later for equating demand and supply of $\frac{\Sigma_{t}}{\Sigma}$.

Final good sector We now use the equilibrium conditions of the final good sector to determine labor supply and output, which are given by

$$
\begin{gathered}
n_{t}=\frac{(1-\sigma)}{\left(1+\frac{1}{\eta}\right)} y_{t}-\frac{\frac{\alpha}{1-\alpha}}{\left(1+\frac{1}{\eta}\right)} \tilde{\alpha}_{t}+\frac{1}{\left(1+\frac{1}{\eta}\right)} \varepsilon_{t}^{n}, \\
{\left[\frac{1}{(1-\alpha)}-\frac{(1-\sigma)}{\left(1+\frac{1}{\eta}\right)}\right] y_{t}=-\left[\frac{\frac{\alpha}{1-\alpha}}{\left(1+\frac{1}{\eta}\right)}-\frac{\varphi_{\alpha}}{(1-\alpha)}\right] \tilde{\alpha}_{t}+\frac{1}{\left(1+\frac{1}{\eta}\right)} \varepsilon_{t}^{n}+\frac{1}{(1-\alpha)} a_{t}+\frac{\alpha}{(1-\alpha)} y_{c, t} .}
\end{gathered}
$$


First, we can plug in the solution for $y_{c, t}$ from (4) to eliminate it. Moreover, we can later in turn write all aggregate variables as a function of aggregate shocks and averages of commodity specific productivity shocks. Lets define

$$
\left[\frac{1}{(1-\alpha)}-\frac{(1-\sigma)}{\left(1+\frac{1}{\eta}\right)}\right] \equiv \chi
$$

Then, we have

$$
y_{t}=-\chi^{-1}\left[\frac{\frac{\alpha}{1-\alpha}}{\left(1+\frac{1}{\eta}\right)}-\frac{\varphi_{\alpha}}{(1-\alpha)}\right] \tilde{\alpha}_{t}+\frac{\chi^{-1}}{\left(1+\frac{1}{\eta}\right)} \varepsilon_{t}^{n}+\frac{\chi^{-1}}{(1-\alpha)} a_{t}+\chi^{-1} \frac{\alpha}{(1-\alpha)} y_{c, t} .
$$

which gives the expression for final output.

Aggregate equilibrium The aggregate equilibrium is now given by the following four conditions (4), (5), (7), and (9) that give the solution for $\left\{y_{t}, y_{c, t}, s_{t}, p_{c, t}\right\}$,

$$
\begin{gathered}
y_{c, t}=\frac{\theta_{c} \varphi}{1+\left(\theta_{c}-1\right) \varphi} y_{t}+\frac{1}{1+\left(\theta_{c}-1\right) \varphi} v_{t}-\frac{\theta_{c} \varphi}{1+\left(\theta_{c}-1\right) \varphi} s_{t}+\frac{\theta_{c} \varphi}{1+\left(\theta_{c}-1\right) \varphi} \tilde{\alpha}_{t} \\
p_{c, t}=\frac{1-\varphi}{1+\left(\theta_{c}-1\right) \varphi} y_{t}-\frac{1}{1+\left(\theta_{c}-1\right) \varphi} v_{t}+\frac{\theta_{c} \varphi}{1+\left(\theta_{c}-1\right) \varphi} s_{t}+\frac{1-\varphi}{1+\left(\theta_{c}-1\right) \varphi} \tilde{\alpha}_{t} \\
s_{t}=\tilde{\varphi}^{-1} \tilde{v}_{t}-\tilde{\varphi}^{-1} \tilde{a}_{t}-\tilde{\varphi}^{-1} \Sigma_{t}+p_{c, t}+\frac{1}{\theta_{c}} y_{c, t} \\
y_{t}=-\chi^{-1}\left[\frac{\frac{\alpha}{1-\alpha}}{\left(1+\frac{1}{\eta}\right)}-\frac{\varphi_{\alpha}}{(1-\alpha)}\right] \tilde{\alpha}_{t}+\frac{\chi^{-1}}{\left(1+\frac{1}{\eta}\right)} \varepsilon_{t}^{n}+\frac{\chi^{-1}}{(1-\alpha)} a_{t}+\chi^{-1} \frac{\alpha}{(1-\alpha)} y_{c, t}
\end{gathered}
$$

and we can write them eventually as a function of shocks. Note that $\left\{a_{t}, \varepsilon_{t}^{n}\right\}$ only show up in the expression for $y_{t}$, as given in (9), while $\left\{\Sigma_{t}\right\}$ only shows up in the expression for $s_{t}$ as given in (7).

At this point, lets express the aggregate energy price $s_{t}$ as a function of shocks and $y_{t}$. So lets replace for $p_{c, t}+\frac{1}{\theta_{c}} y_{c, t}$ to get

$$
s_{t}=\left(1+\left(\theta_{c}-1\right) \varphi\right)\left[\tilde{\varphi}^{-1} \tilde{v}_{t}-\tilde{\varphi}^{-1} \tilde{a}_{t}-\tilde{\varphi}^{-1} \Sigma_{t}\right]+y_{t}-\left(\frac{\theta_{c}-1}{\theta_{c}}\right) v_{t}+\tilde{\alpha}_{t}
$$

This solution for $s_{t}$ in (10) will be used below in discussing the direct and indirect determinants of commodity supply and demand.

Finally, we can also write down the solution for $y_{t}$ by plugging in for $y_{c, t}$ and $s_{t}$. That is, after manipulations and plugging in, get

$$
\begin{aligned}
y_{t} & =-\chi^{-1}\left[\frac{\frac{\alpha}{1-\alpha}}{\left(1+\frac{1}{\eta}\right)}-\frac{\varphi_{\alpha}}{(1-\alpha)}\right] \tilde{\alpha}_{t}+\frac{\chi^{-1}}{\left(1+\frac{1}{\eta}\right)} \varepsilon_{t}^{n}+\frac{\chi^{-1}}{(1-\alpha)} a_{t} \\
& +\chi^{-1} \frac{\alpha}{(1-\alpha)} v_{t}-\left[\chi^{-1} \frac{\alpha}{(1-\alpha)} \frac{\theta_{c} \varphi}{1+\left(\theta_{c}-1\right) \varphi}\right]\left[\left(1+\left(\theta_{c}-1\right) \varphi\right)\left(\tilde{\varphi}^{-1} \tilde{v}_{t}-\tilde{\varphi}^{-1} \tilde{a}_{t}-\tilde{\varphi}^{-1} \Sigma_{t}\right)\right]
\end{aligned}
$$


with (11) above giving a solution for $y_{t}$ as a function of all aggregate shocks and the supply of energy good.

Next, lets impose, without loss of generality, the normalization on steady-state that

$$
\frac{1-\alpha_{j}}{\Sigma_{j}} \equiv \varsigma_{j}=1
$$

Then we have

$$
\begin{gathered}
\tilde{v}_{t}=v_{t} \text { and } \tilde{\varphi}=\theta_{c} \varphi \\
\int_{0}^{1} \varsigma_{j}^{-1} v_{t}(j) d j \equiv \tilde{v}_{t}=v_{t} \equiv \int_{0}^{1} v_{t}(j) d j \\
\int_{0}^{1} \varsigma_{j}^{-1} a_{t}(j) d j=\int_{0}^{1} a_{t}(j) d j \equiv \tilde{a}_{t} \\
\int_{0}^{1} \varsigma_{j}^{-1}\left(1+\frac{1}{\varepsilon_{j} \theta_{c}}\right)^{-1} \varepsilon_{j}^{-1} d j \equiv \tilde{\varphi}=\theta_{c} \varphi
\end{gathered}
$$

So we can further simplify (11) as

$$
y_{t}=\varphi_{y}\left[a_{t}+\kappa_{n} \varepsilon_{t}^{n}+\kappa_{\tilde{a}} \tilde{a}_{t}+\kappa_{\Sigma} \Sigma_{t}-\kappa_{\alpha} \tilde{\alpha}_{t}\right]
$$

where

$$
\begin{aligned}
\varphi_{y} & \equiv \frac{\left(1+\frac{1}{\eta}\right)}{\left(1+\frac{1}{\eta}\right)-(1-\sigma)(1-\alpha)} \\
\kappa_{n} & \equiv\left(\frac{1-\alpha}{1+\frac{1}{\eta}}\right) \\
\kappa_{\tilde{a}} & \equiv \alpha \\
\kappa_{\Sigma} & \equiv \alpha \\
\kappa_{\alpha} & =\left(\frac{\alpha}{1+\frac{1}{\eta}}-\varphi_{\alpha}\right) .
\end{aligned}
$$

Comovement in Commodity Prices First, lets write out the supply curve for commodity $j$, which can be derived from (1) and reproduced here

$$
y_{t}(j)=\left(1+\varepsilon_{j}^{-1}\right) a_{t}(j)+\varepsilon_{j}^{-1}\left(p_{t}(j)-s_{t}\right)
$$

and where we will use the definition

$$
\left(1+\frac{1}{\varepsilon_{j} \theta_{c}}\right)^{-1}\left(1+\varepsilon_{j}^{-1}\right) a_{t}(j) \equiv v_{t}(j) .
$$

That is, write (1) as

$$
p_{t}(j)=\varepsilon_{j} y_{t}(j)+s_{t}-\frac{\left(1+\varepsilon_{j} \theta_{c}\right)}{\theta_{c}} v_{t}(j)
$$


where $s_{t}$ appears.

Next, we can write out the demand curve for commodity $j$ from the relative demand equation and final good input share equation, as well as the solution for $y_{c, t}$ as given in (4). That is, we get

$$
\begin{aligned}
p_{t}(j) & =-\frac{1}{\theta_{c}} y_{t}(j)+\left(\frac{1}{1+\left(\theta_{c}-1\right) \varphi}\right) y_{t}-\left(\frac{\theta_{c}-1}{\theta_{c}}\right)\left(\frac{1}{1+\left(\theta_{c}-1\right) \varphi}\right) v_{t} \\
& +\left(\frac{\left(\theta_{c}-1\right) \varphi}{1+\left(\theta_{c}-1\right) \varphi}\right) s_{t}+\left(\frac{1}{1+\left(\theta_{c}-1\right) \varphi}\right) \tilde{\alpha}_{t}
\end{aligned}
$$

where there is a dependence not just on $s_{t}$, but now also on $y_{t}$ directly.

Lets simplify the above further by replacing for the solution for $s_{t}$ from (10). Start with (13), to get

$$
\begin{aligned}
p_{t}(j) & =\varepsilon_{j} y_{t}(j)-\frac{\left(1+\varepsilon_{j} \theta_{c}\right)}{\theta_{c}} v_{t}(j) \\
& +\left(\theta_{c} \varphi\right)^{-1} v_{t}-\left(1+\left(\theta_{c}-1\right) \varphi\right)\left(\theta_{c} \varphi\right)^{-1} \tilde{a}_{t}-\left(1+\left(\theta_{c}-1\right) \varphi\right)\left(\theta_{c} \varphi\right)^{-1} \Sigma_{t}+\tilde{\alpha}_{t}+y_{t} .
\end{aligned}
$$

Next, do the same manipulation for (14), to get

$$
p_{t}(j)=-\frac{1}{\theta_{c}} y_{t}(j)+y_{t}+\tilde{\alpha}_{t}-\left(\frac{\theta_{c}-1}{\theta_{c}}\right) \tilde{a}_{t}-\left(\frac{\theta_{c}-1}{\theta_{c}}\right) \Sigma_{t} .
$$

These intermediate derivations for the commodity demand and supply are useful for intuition. We will later derive the final formulations after we determine the solution for $\Sigma_{t}$, the level of energy good produced in this economy.

Commodity Prices Next, we can solve for commodity prices, by combining (15) and (16) above

$$
\begin{aligned}
p_{t}(j)\left(1+\varepsilon_{j} \theta_{c}\right) & =\left(1+\varepsilon_{j} \theta_{c}\right) y_{t}+\left(1+\varepsilon_{j} \theta_{c}\right) \tilde{\alpha}_{t}-\left[\varepsilon_{j} \theta_{c}\left(\frac{\theta_{c}-1}{\theta_{c}}\right)+\frac{\left(1+\left(\theta_{c}-1\right) \varphi\right)}{\theta_{c} \varphi}\right] \tilde{a}_{t} \\
& -\left[\varepsilon_{j} \theta_{c}\left(\frac{\theta_{c}-1}{\theta_{c}}\right)+\frac{\left(1+\left(\theta_{c}-1\right) \varphi\right)}{\theta_{c} \varphi}\right] \Sigma_{t}-\frac{\left(1+\varepsilon_{j} \theta_{c}\right)}{\theta_{c}} v_{t}(j)+\left(\theta_{c} \varphi\right)^{-1} v_{t}
\end{aligned}
$$

where we have two averages of commodity producer productivity that appear in (17). We have defined them as

$$
\begin{gathered}
\left(1+\frac{1}{\varepsilon_{j} \theta_{c}}\right)^{-1}\left(1+\varepsilon_{j}^{-1}\right) a_{t}(j) \equiv v_{t}(j) \\
v_{t} \equiv \int_{0}^{1} v_{t}(j) d j \\
\tilde{a}_{t} \equiv \int_{0}^{1} a_{t}(j) d j .
\end{gathered}
$$

Lets assume then that there is a common and idiosyncratic component to the commodity producer productivity $a_{t}(j)$ (with the idiosyncratic components orthogonal across commodity producers)

$$
a_{t}(j)=a_{t}^{a}+a_{t}^{j}
$$


which also means, multiplying by $\left(1+\frac{1}{\varepsilon_{j} \theta_{c}}\right)^{-1}\left(1+\varepsilon_{j}^{-1}\right)$ on both sides

$$
v_{t}(j)=v_{t}^{a}+v_{t}^{j}
$$

where we define

$$
\begin{aligned}
v_{t}^{j} & \equiv\left(1+\frac{1}{\varepsilon_{j} \theta_{c}}\right)^{-1}\left(1+\varepsilon_{j}^{-1}\right) a_{t}^{j} \\
v_{t}^{a} & \equiv\left(1+\frac{1}{\varepsilon_{j} \theta_{c}}\right)^{-1}\left(1+\varepsilon_{j}^{-1}\right) a_{t}^{a} .
\end{aligned}
$$

Then, this implies that

$$
\begin{aligned}
\tilde{a}_{t} & \equiv \int_{0}^{1} a_{t}(j) d j=a_{t}^{a} \\
v_{t} & \equiv \int_{0}^{1} v_{t}(j) d j=v_{t}^{a} \\
v_{t}^{a} & \equiv\left(1+\frac{1}{\varepsilon_{j} \theta_{c}}\right)^{-1}\left(1+\varepsilon_{j}^{-1}\right) a_{t}^{a} \\
v_{t}^{j} & \equiv\left(1+\frac{1}{\varepsilon_{j} \theta_{c}}\right)^{-1}\left(1+\varepsilon_{j}^{-1}\right) a_{t}^{j} .
\end{aligned}
$$

Now lets substitute these in (17) above to get

$$
\begin{aligned}
p_{t}(j) & =y_{t}+\tilde{\alpha}_{t}-\left(1+\varepsilon_{j} \theta_{c}\right)^{-1}\left[\varepsilon_{j} \theta_{c}\left(\frac{\theta_{c}-1}{\theta_{c}}\right)+\frac{\left(1+\left(\theta_{c}-1\right) \varphi\right)}{\theta_{c} \varphi}\right] \Sigma_{t} \\
& -\left(\left(1+\varepsilon_{j}\right) \theta_{c}\right)^{-1}\left[\left(\frac{\theta_{c}-1}{\theta_{c}}\right)\left(\left(1+\varepsilon_{j} \theta_{c}\right)-\frac{1}{\varphi\left(1+\varepsilon_{j} \theta_{c}\right)}\right)+\left(1+\varepsilon_{j}\right)\right] v_{t}^{a}-\frac{1}{\theta_{c}} v_{t}^{j} .
\end{aligned}
$$

Given the endogenous determination of $\Sigma_{t}$ however, we need to do further manipulations to write this solution in terms of $y_{t}$ and aggregate shocks. Moreover, we need to further manipulate to find a solution for the energy price $s_{t}$. For this purpose, lets first simplify the current solution for $s_{t}$ given in (10) to

$$
\begin{aligned}
s_{t} & =\left[\frac{1}{\theta_{c} \varphi}-\left(\frac{1+\left(\theta_{c}-1\right) \varphi}{\theta_{c} \varphi}\right)\left(1+\frac{1}{\varepsilon_{j} \theta_{c}}\right)\left(1+\varepsilon_{j}^{-1}\right)^{-1}\right] v_{t}^{a} \\
& -\left(\frac{1+\left(\theta_{c}-1\right) \varphi}{\theta_{c} \varphi}\right) \Sigma_{t}+y_{t}+\tilde{\alpha}_{t} .
\end{aligned}
$$

Next, we have from the firm/supply side of the energy sector given in (8)

$$
\frac{\Sigma_{t}}{\Sigma}=\frac{1}{\left(1-(1-\gamma)\left(1+\frac{1}{\eta}\right)^{-1}\right)} \Xi_{t}+\frac{(1-\gamma)\left(1+\frac{1}{\eta}\right)^{-1}}{\left(1-(1-\gamma)\left(1+\frac{1}{\eta}\right)^{-1}\right)}\left[s_{t}-\sigma y_{t}\right] .
$$


Lets use the two expressions above to solve for $\Sigma_{t}$ as a function of $y_{t}$ and aggregate shocks. We substitute for $s_{t}$ and get

$$
\begin{aligned}
\Sigma^{-1} \Sigma_{t} & =\frac{1}{\left(1-(1-\gamma)\left(1+\frac{1}{\eta}\right)^{-1}\right)} \Xi_{t} \\
& +\frac{(1-\gamma)\left(1+\frac{1}{\eta}\right)^{-1}}{\left(1-(1-\gamma)\left(1+\frac{1}{\eta}\right)^{-1}\right)}\left(\left[\frac{1}{\theta_{c} \varphi}-\left(\frac{1+\left(\theta_{c}-1\right) \varphi}{\theta_{c} \varphi}\right)\left(1+\frac{1}{\varepsilon_{j} \theta_{c}}\right)\left(1+\varepsilon_{j}^{-1}\right)^{-1}\right] v_{t}^{a}\right) \\
& +\frac{(1-\gamma)\left(1+\frac{1}{\eta}\right)^{-1}}{\left(1-(1-\gamma)\left(1+\frac{1}{\eta}\right)^{-1}\right)}\left(-\left(\frac{1+\left(\theta_{c}-1\right) \varphi}{\theta_{c} \varphi}\right) \Sigma_{t}+y_{t}+\tilde{\alpha}_{t}\right) \\
& +\frac{(1-\gamma)\left(1+\frac{1}{\eta}\right)^{-1}}{\left(1-(1-\gamma)\left(1+\frac{1}{\eta}\right)^{-1}\right)}\left(-\sigma y_{t}\right) .
\end{aligned}
$$

For ease of notation, we define

$$
\gamma_{\eta} \equiv(1-\gamma)\left(1+\frac{1}{\eta}\right)^{-1}
$$

where note that $\gamma_{\eta}=0$ when $\gamma=1$, the case where energy good supply is exogenous. Then,

$$
\begin{aligned}
\left(\Sigma^{-1}+\frac{\gamma_{\eta}}{\left(1-\gamma_{\eta}\right)}\left(\frac{1+\left(\theta_{c}-1\right) \varphi}{\theta_{c} \varphi}\right)\right) \Sigma_{t} & =\frac{1}{\left(1-\gamma_{\eta}\right)} \Xi_{t}+\frac{\gamma_{\eta}}{\left(1-\gamma_{\eta}\right)}\left((1-\sigma) y_{t}+\tilde{\alpha}_{t}\right) \\
& +\frac{\gamma_{\eta}}{\left(1-\gamma_{\eta}\right)}\left(\left[\frac{1}{\theta_{c} \varphi}-\left(\frac{1+\left(\theta_{c}-1\right) \varphi}{\theta_{c} \varphi}\right)\left(1+\frac{1}{\varepsilon_{j} \theta_{c}}\right)\left(1+\varepsilon_{j}^{-1}\right)^{-1}\right] v_{t}^{a}\right) .
\end{aligned}
$$

Here, (19) is important so that we can plug this back into the earlier solution for commodity prices. In particular, for ease of notation lets define

$$
\left[\varepsilon_{j} \theta_{c}\left(\frac{\theta_{c}-1}{\theta_{c}}\right)+\frac{\left(1+\left(\theta_{c}-1\right) \varphi\right)}{\theta_{c} \varphi}\right] \equiv \Sigma_{j, c}
$$

and lets define the following for use in (19)

$$
\Sigma_{\eta} \equiv\left(\Sigma^{-1}+\frac{\gamma_{\eta}}{\left(1-\gamma_{\eta}\right)}\left(\frac{1+\left(\theta_{c}-1\right) \varphi}{\theta_{c} \varphi}\right)\right)
$$


where note that $\Sigma_{\eta}=\Sigma^{-1}$ when $\gamma=1$ as then $\gamma_{\eta}=0$. Then, plugging in (19) gives

$$
\begin{aligned}
p_{t}(j) & =\left(1-\left(1+\varepsilon_{j} \theta_{c}\right)^{-1} \Sigma_{j, c} \Sigma_{\eta}^{-1} \frac{\gamma_{\eta}}{\left(1-\gamma_{\eta}\right)}(1-\sigma)\right) y_{t} \\
& +\left(1-\left(1+\varepsilon_{j} \theta_{c}\right)^{-1} \Sigma_{j, c} \Sigma_{\eta}^{-1} \frac{\gamma_{\eta}}{\left(1-\gamma_{\eta}\right)}\right) \tilde{\alpha}_{t} \\
& -\left(1+\varepsilon_{j} \theta_{c}\right)^{-1} \Sigma_{j, c} \Sigma_{\eta}^{-1} \frac{1}{\left(1-\gamma_{\eta}\right)} \Xi_{t} \\
& -\left(1+\varepsilon_{j} \theta_{c}\right)^{-1} \Sigma_{j, c} \Sigma_{\eta}^{-1}\left(\frac{\gamma_{\eta}}{\left(1-\gamma_{\eta}\right)}\right)\left[\frac{1}{\theta_{c} \varphi}-\left(\frac{1+\left(\theta_{c}-1\right) \varphi}{\theta_{c} \varphi}\right)\left(1+\frac{1}{\varepsilon_{j} \theta_{c}}\right)\left(1+\varepsilon_{j}^{-1}\right)^{-1}\right] v_{t}^{a} \\
& -\left(\left(1+\varepsilon_{j}\right) \theta_{c}\right)^{-1}\left[\left(\frac{\theta_{c}-1}{\theta_{c}}\right)\left(\left(1+\varepsilon_{j} \theta_{c}\right)-\frac{1}{\varphi\left(1+\varepsilon_{j} \theta_{c}\right)}\right)+\left(1+\varepsilon_{j}\right)\right] v_{t}^{a}-\frac{1}{\theta_{c}} v_{t}^{j}
\end{aligned}
$$

where (20) now gives a version of the solution for commodity prices.

Aggregate output solution in terms of shocks We can also now give the final solution for

aggregate output. Currently, we have (12), where we now substitute in for the solution to $\Sigma_{t}$, to get

$$
\begin{aligned}
y_{t} & =\Omega^{-1} \varphi_{y}\left(a_{t}+\kappa_{n} \varepsilon_{t}^{n}+\Sigma_{\eta}^{-1} \kappa_{\Sigma}\left[\frac{1}{\left(1-\gamma_{\eta}\right)} \Xi_{t}\right]\right) \\
& -\Omega^{-1} \varphi_{y}\left(\kappa_{\alpha}-\Sigma_{\eta}^{-1} \kappa_{\Sigma} \frac{\gamma_{\eta}}{\left(1-\gamma_{\eta}\right)}\right) \tilde{\alpha}_{t} \\
& +\Omega^{-1} \varphi_{y}\left(\kappa_{\tilde{a}} \frac{1+\varepsilon_{j} \theta_{c}}{\theta_{c}\left(1+\varepsilon_{j}\right)}+\Sigma_{\eta}^{-1} \kappa_{\Sigma} \frac{\gamma_{\eta}}{\left(1-\gamma_{\eta}\right)}\left[\frac{1}{\theta_{c} \varphi}-\left(\frac{1+\left(\theta_{c}-1\right) \varphi}{\theta_{c} \varphi}\right) \frac{1+\varepsilon_{j} \theta_{c}}{\theta_{c}\left(1+\varepsilon_{j}\right)}\right]\right) v_{t}^{a}
\end{aligned}
$$

where

$$
\Omega=1-\Sigma_{\eta}^{-1} \varphi_{y} \kappa_{\Sigma} \frac{\gamma_{\eta}}{\left(1-\gamma_{\eta}\right)}(1-\sigma)
$$

which means that the coefficients just for $a_{t}, \varepsilon_{t}^{n}$ are

$$
\begin{aligned}
& \Omega^{-1} \varphi_{y} \\
& \Omega^{-1} \varphi_{y} \kappa_{n}
\end{aligned}
$$

respectively.

This solution given in (21) above for aggregate output is the version that appears in the text in Equation (1), where we use reduced form coefficients in the text to represent the solution in (21). Then as in the text, we can define,

$$
\begin{aligned}
y_{t} & =y_{t}^{n c}\left(a_{t}, \varepsilon_{t}^{n}\right)+\Omega^{-1} \varphi_{y}\left(\Sigma_{\eta}^{-1} \kappa_{\Sigma}\left[\frac{1}{\left(1-\gamma_{\eta}\right)} \Xi_{t}\right]\right) \\
& -\Omega^{-1} \varphi_{y}\left(\kappa_{\alpha}-\Sigma_{\eta}^{-1} \kappa_{\Sigma} \frac{\gamma_{\eta}}{\left(1-\gamma_{\eta}\right)}\right) \tilde{\alpha}_{t} \\
& +\Omega^{-1} \varphi_{y}\left(\kappa_{\tilde{a}} \frac{1+\varepsilon_{j} \theta_{c}}{\theta_{c}\left(1+\varepsilon_{j}\right)}+\Sigma_{\eta}^{-1} \kappa_{\Sigma} \frac{\gamma_{\eta}}{\left(1-\gamma_{\eta}\right)}\left[\frac{1}{\theta_{c} \varphi}-\left(\frac{1+\left(\theta_{c}-1\right) \varphi}{\theta_{c} \varphi}\right) \frac{1+\varepsilon_{j} \theta_{c}}{\theta_{c}\left(1+\varepsilon_{j}\right)}\right]\right) v_{t}^{a}
\end{aligned}
$$


where we have defined

$$
y_{t}^{n c}\left(a_{t}, \varepsilon_{t}^{n}\right)=\Omega^{-1} \varphi_{y}\left(a_{t}+\kappa_{n} \varepsilon_{t}^{n}\right) .
$$

This expression given in (22) above for aggregate output and $y_{t}^{n c}\left(a_{t}, \varepsilon_{t}^{n}\right)$ is the version that appears in the text of the paper, where we use reduced form coefficients in the text to represent the solution in $(22)$.

Solution for commodity prices Consider the solution for commodity prices above in (20), where below we sign the coefficient only on aggregate output

$$
p_{t}(j)=\left(1-\left(1+\varepsilon_{j} \theta_{c}\right)^{-1} \Sigma_{j, c} \Sigma_{\eta}^{-1} \frac{\gamma_{\eta}}{\left(1-\gamma_{\eta}\right)}(1-\sigma)\right) y_{t}
$$

where we have

$$
\begin{aligned}
& \Sigma_{j, c} \equiv\left[\varepsilon_{j} \theta_{c}\left(\frac{\theta_{c}-1}{\theta_{c}}\right)+\frac{\left(1+\left(\theta_{c}-1\right) \varphi\right)}{\theta_{c} \varphi}\right] \\
& \varepsilon_{j} \equiv\left(\frac{\alpha_{j}}{1-\alpha_{j}}\right) \\
& \varphi \equiv \int_{0}^{1}\left(1+\varepsilon_{j} \theta_{c}\right)^{-1} d j \\
& \Sigma_{\eta} \equiv\left(\Sigma^{-1}+\frac{\gamma_{\eta}}{\left(1-\gamma_{\eta}\right)}\left(\frac{1+\left(\theta_{c}-1\right) \varphi}{\theta_{c} \varphi}\right)\right) \\
& \Sigma=\int_{0}^{1}\left(1-\alpha_{j}\right) d j \\
& \gamma_{\eta} \equiv(1-\gamma)\left(1+\frac{1}{\eta}\right)^{-1}
\end{aligned}
$$

and $0 \leq \gamma<1 ; 0 \leq \alpha_{j}<1 ; \eta>0 ; \theta_{c}>1$. Given this, we have

$$
\begin{aligned}
\varepsilon_{j} & \equiv\left(\frac{\alpha_{j}}{1-\alpha_{j}}\right)>0 \\
\varphi & \equiv \int_{0}^{1}\left(1+\varepsilon_{j} \theta_{c}\right)^{-1} d j>0 \\
\Sigma_{j, c} & \equiv\left[\varepsilon_{j} \theta_{c}\left(\frac{\theta_{c}-1}{\theta_{c}}\right)+\frac{\left(1+\left(\theta_{c}-1\right) \varphi\right)}{\theta_{c} \varphi}\right]>0 \\
\Sigma & =\int_{0}^{1}\left(1-\alpha_{j}\right) d j>0 \\
\gamma_{\eta} & \equiv(1-\gamma)\left(1+\frac{1}{\eta}\right)^{-1}>0 \text { and } \gamma_{\eta}<1 \\
\Sigma_{\eta} & \equiv\left(\Sigma^{-1}+\frac{\gamma_{\eta}}{\left(1-\gamma_{\eta}\right)}\left(\frac{1+\left(\theta_{c}-1\right) \varphi}{\theta_{c} \varphi}\right)\right)>0
\end{aligned}
$$


which means that a sufficient condition for

$$
\left(1-\left(1+\varepsilon_{j} \theta_{c}\right)^{-1} \Sigma_{j, c} \Sigma_{\eta}^{-1} \frac{\gamma_{\eta}}{\left(1-\gamma_{\eta}\right)}(1-\sigma)\right)>0
$$

is that

$$
\sigma>1
$$

Moreover, note that the two shocks that only affect aggregate $y_{t}$ have the following coefficients in the final solution for $y_{t}$

$$
\begin{aligned}
& {\left[\left(1-\Sigma_{\eta}^{-1} \varphi_{y} \kappa_{\Sigma} \frac{\gamma_{\eta}}{\left(1-\gamma_{\eta}\right)}(1-\sigma)\right)^{-1} \varphi_{y}\right] a_{t}} \\
& {\left[\left(1-\Sigma_{\eta}^{-1} \varphi_{y} \kappa_{\Sigma} \frac{\gamma_{\eta}}{\left(1-\gamma_{\eta}\right)}(1-\sigma)\right)^{-1} \varphi_{y} \kappa_{n}\right] \varepsilon_{t}^{n}}
\end{aligned}
$$

respectively. That is, here, we are trying to sign the coefficients on $y_{t}^{n c}\left(a_{t}, \varepsilon_{t}^{n}\right)$ that we have defined in (23). Then, when $\sigma>1$, we have

$$
\begin{aligned}
\varphi_{y} & \equiv \frac{\left(1+\frac{1}{\eta}\right)}{\left(1+\frac{1}{\eta}\right)-(1-\sigma)(1-\alpha)}>0 \\
\kappa_{n} & \equiv\left(\frac{1-\alpha}{1+\frac{1}{\eta}}\right)>0 \\
\kappa_{\Sigma} & \equiv \alpha>0
\end{aligned}
$$

which implies that

$$
\begin{aligned}
& \Omega^{-1} \varphi_{y}>0 \\
& \Omega^{-1} \varphi_{y} \kappa_{n}>0
\end{aligned}
$$

where

$$
\Omega=1-\Sigma_{\eta}^{-1} \varphi_{y} \kappa_{\Sigma} \frac{\gamma_{\eta}}{\left(1-\gamma_{\eta}\right)}(1-\sigma) .
$$

Next, consider the solution for commodity prices again, where we now look at the coefficient on the energy shock

$$
p_{t}(j)=-\left(1+\varepsilon_{j} \theta_{c}\right)^{-1} \Sigma_{j, c} \Sigma_{\eta}^{-1} \frac{1}{\left(1-\gamma_{\eta}\right)} \Xi_{t}
$$


and where we now want to check how the coefficient depends on $1-\alpha_{j}$. From before, note the various definitions of the parameters above

$$
\begin{aligned}
\Sigma_{j, c} & \equiv\left[\varepsilon_{j} \theta_{c}\left(\frac{\theta_{c}-1}{\theta_{c}}\right)+\frac{\left(1+\left(\theta_{c}-1\right) \varphi\right)}{\theta_{c} \varphi}\right] \\
\varepsilon_{j} & \equiv\left(\frac{\alpha_{j}}{1-\alpha_{j}}\right) \\
\varphi & \equiv \int_{0}^{1}\left(1+\varepsilon_{j} \theta_{c}\right)^{-1} d j \\
\Sigma_{\eta} & \equiv\left(\Sigma^{-1}+\frac{\gamma_{\eta}}{\left(1-\gamma_{\eta}\right)}\left(\frac{1+\left(\theta_{c}-1\right) \varphi}{\theta_{c} \varphi}\right)\right) \\
\Sigma & =\int_{0}^{1}\left(1-\alpha_{j}\right) d j \\
\gamma_{\eta} & \equiv(1-\gamma)\left(1+\frac{1}{\eta}\right)^{-1} .
\end{aligned}
$$

Thus, first, we can manipulate the component that depends on $1-\alpha_{j}$

$$
\left(1+\varepsilon_{j} \theta_{c}\right)^{-1} \Sigma_{j, c}=\left(1+\varepsilon_{j} \theta_{c}\right)^{-1}\left[\varepsilon_{j} \theta_{c}\left(\frac{\theta_{c}-1}{\theta_{c}}\right)+\frac{\left(1+\left(\theta_{c}-1\right) \varphi\right)}{\theta_{c} \varphi}\right] .
$$

We have $\varepsilon_{j}$ is increasing $\alpha_{j}$. Then, it is the case that $\left(1+\varepsilon_{j} \theta_{c}\right)^{-1} \Sigma_{j, c}$ is decreasing in $\alpha_{j}$. Then it is also the case that

$$
\left(1+\varepsilon_{j} \theta_{c}\right)^{-1} \Sigma_{j, c} \Sigma_{\eta}^{-1} \frac{1}{\left(1-\gamma_{\eta}\right)}
$$

is decreasing in $\alpha_{j}$. In other words, when the share of energy in the commodity production, which is given by $\left(1-\alpha_{j}\right)$ increases, then the coefficient in the solution of commodity prices on the energy shock also increases:

$$
\frac{\partial\left[\left(1+\varepsilon_{j} \theta_{c}\right)^{-1} \Sigma_{j, c}\right]}{\partial \varepsilon_{j}}=-\frac{1}{\varphi}\left(1+\varepsilon_{j} \theta_{c}\right)^{-2}<0 .
$$

Factor structure of commodity prices Finally, note that we use the definition of $y_{t}^{n c}\left(a_{t}, \varepsilon_{t}^{n}\right)$ given in (23) in (20) to derive the factor structure of prices in the form presented in the text. That 
is

$$
\begin{aligned}
p_{t}(j) & =\left(1-\left(1+\varepsilon_{j} \theta_{c}\right)^{-1} \Sigma_{j, c} \Sigma_{\eta}^{-1} \frac{\gamma_{\eta}}{\left(1-\gamma_{\eta}\right)}(1-\sigma)\right) y_{t}^{n c}\left(a_{t}, \varepsilon_{t}^{n}\right) \\
& +\Omega^{-1}\left(1-\left(1+\varepsilon_{j} \theta_{c}\right)^{-1} \Sigma_{j, c} \Sigma_{\eta}^{-1} \frac{\gamma_{\eta}}{\left(1-\gamma_{\eta}\right)}(1-\sigma)\right) \varphi_{y}\left(\Sigma_{\eta}^{-1} \kappa_{\Sigma}\left[\frac{1}{\left(1-\gamma_{\eta}\right)} \Xi_{t}\right]\right) \\
& -\Omega^{-1} \varphi_{y}\left(\kappa_{\alpha}-\Sigma_{\eta}^{-1} \kappa_{\Sigma} \frac{\gamma_{\eta}}{\left(1-\gamma_{\eta}\right)}\right) \tilde{\alpha}_{t} \\
& +\Omega^{-1} \varphi_{y}\left(\kappa_{\tilde{a}} \frac{1+\varepsilon_{j} \theta_{c}}{\theta_{c}\left(1+\varepsilon_{j}\right)}+\Sigma_{\eta}^{-1} \kappa_{\Sigma} \frac{\gamma_{\eta}}{\left(1-\gamma_{\eta}\right)}\left[\frac{1}{\theta_{c} \varphi}-\left(\frac{1+\left(\theta_{c}-1\right) \varphi}{\theta_{c} \varphi}\right) \frac{1+\varepsilon_{j} \theta_{c}}{\theta_{c}\left(1+\varepsilon_{j}\right)}\right]\right) v_{t}^{a} \\
& +\left(1-\left(1+\varepsilon_{j} \theta_{c}\right)^{-1} \Sigma_{j, c} \Sigma_{\eta}^{-1} \frac{\gamma_{\eta}}{\left(1-\gamma_{\eta}\right)}\right) \tilde{\alpha}_{t} \\
& -\left(1+\varepsilon_{j} \theta_{c}\right)^{-1} \Sigma_{j, c} \Sigma_{\eta}^{-1} \frac{1}{\left(1-\gamma_{\eta}\right)} \Xi_{t} \\
& -\left(1+\varepsilon_{j} \theta_{c}\right)^{-1} \Sigma_{j, c} \Sigma_{\eta}^{-1}\left(\frac{\gamma_{\eta}}{\left(1-\gamma_{\eta}\right)}\right)\left[\frac{1}{\theta_{c} \varphi}-\left(\frac{1+\left(\theta_{c}-1\right) \varphi}{\theta_{c} \varphi}\right)\left(1+\frac{1}{\varepsilon_{j} \theta_{c}}\right)\left(1+\varepsilon_{j}^{-1}\right)^{-1}\right] v_{t}^{a} \\
& -\left(\left(1+\varepsilon_{j}\right)_{c}\right)^{-1}\left[\left(\frac{\theta_{c}-1}{\theta_{c}}\right)\left(\left(1+\varepsilon_{j} \theta_{c}\right)-\frac{1}{\varphi\left(1+\varepsilon_{j} \theta_{c}\right)}\right)+\left(1+\varepsilon_{j}\right)\right] v_{t}^{a}-\frac{1}{\theta_{c}} v_{t}^{j}
\end{aligned}
$$

This (24) above is the expression that appears in Equation (4) in the text of the paper, where we use reduced form coefficients in the text to represent the solution in (24).

Now consider the coefficient on $\Xi_{t}$

$$
\begin{aligned}
p_{t}(j) & =-\frac{\left(1+\varepsilon_{j} \theta_{c}\right)^{-1}}{\left(1-\gamma_{\eta}\right)}\left[\Sigma_{j, c} \Sigma_{\eta}^{-1}-\Omega^{-1}\left(\left(1+\varepsilon_{j} \theta_{c}\right)-\Sigma_{j, c} \Sigma_{\eta}^{-1} \frac{\gamma_{\eta}}{\left(1-\gamma_{\eta}\right)}(1-\sigma)\right) \varphi_{y} \Sigma_{\eta}^{-1} \kappa_{\Sigma}\right] \Xi_{t} \\
& =-\frac{\left(\left(1-\gamma_{\eta}\right) \Sigma_{\eta} \theta\right)^{-1}}{1-\Sigma_{\eta}^{-1} \varphi_{y} \kappa_{\Sigma} \frac{\gamma_{\eta}}{\left(1-\gamma_{\eta}\right)}(1-\sigma)}\left[\frac{\left(\theta_{c}(1-\alpha)-1\right)\left(1+\frac{1}{\eta}\right)-\left(\theta_{c}-1\right)(1-\sigma)(1-\alpha)}{\left(1+\frac{1}{\eta}\right)-(1-\sigma)(1-\alpha)}+\frac{\left(1+\varepsilon_{j} \theta_{c}\right)^{-1}}{\varphi}\right] \Xi_{t}
\end{aligned}
$$

where

$$
\varphi \equiv \int_{0}^{1}\left(1+\varepsilon_{j} \theta_{c}\right)^{-1} d j
$$

Thus, if

$$
\begin{aligned}
\theta_{c}(1-\alpha)-1 & >0 \\
\sigma & >1
\end{aligned}
$$

then the coefficient on $\Xi_{t}$ is negative. Also, the coefficient is always decreasing (in absolute term) in $\varepsilon_{j}$. Moreover, as shown above, the coefficient on $y_{t}^{n c}\left(a_{t}, \varepsilon_{t}^{n}\right)$ in $(24)$ above is positive when $\sigma>1$.

Commodity demand and supply final solutions Now we re-write after relevant substitutions the commodity demand and supply curves. For this, first combine (15) and (19) to get 


$$
\begin{aligned}
p_{t}(j)= & \varepsilon_{j} y_{t}(j)-\frac{\left(1+\varepsilon_{j} \theta_{c}\right)}{\theta_{c}} v_{t}^{j}-\frac{1+\left(\theta_{c}-1\right) \varphi}{\theta_{c} \varphi} \Sigma_{\eta}^{-1} \frac{1}{\left(1-\gamma_{\eta}\right)} \Xi_{t} \\
& +\left(1-\frac{1+\left(\theta_{c}-1\right) \varphi}{\theta_{c} \varphi} \Sigma_{\eta}^{-1} \frac{\gamma_{\eta}}{\left(1-\gamma_{\eta}\right)}(1-\sigma)\right) y_{t} \\
& +\left(1-\frac{1+\left(\theta_{c}-1\right) \varphi}{\theta_{c} \varphi} \Sigma_{\eta}^{-1} \frac{\gamma_{\eta}}{\left(1-\gamma_{\eta}\right)}\right) \tilde{\alpha}_{t} \\
& +\left(\left(1-\frac{1+\left(\theta_{c}-1\right) \varphi}{\theta_{c} \varphi} \Sigma_{\eta}^{-1} \frac{\gamma_{\eta}}{\left(1-\gamma_{\eta}\right)}\right)\left[\frac{1}{\theta_{c} \varphi}-\left(\frac{1+\left(\theta_{c}-1\right) \varphi}{\theta_{c} \varphi}\right) \frac{1+\varepsilon_{j} \theta_{c}}{\theta_{c}\left(1+\varepsilon_{j}\right)}\right]-\frac{\left(1+\varepsilon_{j} \theta_{c}\right)}{\theta_{c}}\right) v_{t}^{a},
\end{aligned}
$$

and (25) above is the expression that appears in Equation (2) in the text of the paper, where we use reduced form coefficients in the text to represent the solution in (25).

Second, combine (16) and (19) to get,

$$
\begin{aligned}
p_{t}(j)= & -\frac{1}{\theta_{c}} y_{t}(j)-\left(\frac{\theta_{c}-1}{\theta_{c}}\right) \Sigma_{\eta}^{-1} \frac{1}{\left(1-\gamma_{\eta}\right)} \Xi_{t} \\
& +\left(1-\left(\frac{\theta_{c}-1}{\theta_{c}}\right) \Sigma_{\eta}^{-1} \frac{\gamma_{\eta}}{\left(1-\gamma_{\eta}\right)}(1-\sigma)\right) y_{t} \\
& +\left(1-\left(\frac{\theta_{c}-1}{\theta_{c}}\right) \Sigma_{\eta}^{-1} \frac{\gamma_{\eta}}{\left(1-\gamma_{\eta}\right)}\right) \tilde{\alpha}_{t} \\
& -\left(\frac{\theta_{c}-1}{\theta_{c}}\right)\left(\frac{1+\varepsilon_{j} \theta_{c}}{\theta_{c}\left(1+\varepsilon_{j}\right)}+\Sigma_{\eta}^{-1} \frac{\gamma_{\eta}}{\left(1-\gamma_{\eta}\right)}\left[\frac{1}{\theta_{c} \varphi}-\left(\frac{1+\left(\theta_{c}-1\right) \varphi}{\theta_{c} \varphi}\right) \frac{1+\varepsilon_{j} \theta_{c}}{\theta_{c}\left(1+\varepsilon_{j}\right)}\right]\right) v_{t}^{a}
\end{aligned}
$$

and (26) above is the expression that appears in Equation (3) in the text of the paper, where we use reduced form coefficients in the text to represent the solution in (26). 


\section{APPENDIX A.2: TWO-SECTOR MODEL}

\section{$1 \quad$ Model}

We now present the two-commodity-sectors extension of our baseline model.

\subsection{Household}

Household maximizes

$$
E_{t} \sum_{i=0}^{\infty} \beta^{i}\left[\frac{C_{t+i}^{1-\sigma}}{1-\sigma}-e^{-\varepsilon_{t+i}^{n}} \varphi_{n} \frac{N_{t+i}^{s^{1+\frac{1}{\eta}}}}{1+\frac{1}{\eta}}-\varphi_{e} \frac{N_{t+i}^{s, e^{1+\frac{1}{\eta}}}}{1+\frac{1}{\eta}}\right]
$$

where $C_{t}$ is consumption and the household supplies labor to the final good $\left(N_{t}^{s}\right)$ and the energy sectors $\left(N_{t}^{s, e}\right)$. The nominal flow budget constraint faced by the household is

$$
P_{t} C_{t}+B_{t}=B_{t-1} R_{t-1}+W_{t} N_{t}^{s}+W_{t}^{e} N_{t}^{s, e}+T_{t}
$$

where $P_{t}$ is aggregate price, $B_{t}$ is nominal bond holdings with $R_{t-1}$ the interest rate, $W_{t}$ the wage in the final good sector, $W_{t}^{e}$ the wage in the energy sector and $T_{t}$ lump-sum profits from firms.

The first order conditions are standard and given by

$$
\begin{gathered}
\varphi_{n} C_{t}^{\sigma} N_{t}^{s \frac{1}{\eta}}=e^{\varepsilon_{t}^{n}} \frac{W_{t}}{P_{t}}, \\
\varphi_{e} C_{t}^{\sigma} N_{t}^{s, e \frac{1}{\eta}}=\frac{W_{t}^{e}}{P_{t}}, \\
C_{t}^{-\sigma}=\beta E_{t}\left[C_{t+1}^{-\sigma} R_{t} \frac{P_{t}}{P_{t+1}}\right] .
\end{gathered}
$$

\subsection{Energy Sector}

The energy sector's total supply of the energy good $\left(\Sigma_{t}\right)$ is endogenous, with exogenous productivity shock $\Xi_{t}$ and the firm faces a decreasing returns to scale (determined by $\gamma$ ) production function that uses labor

$$
\Sigma_{t}=\Xi_{t}\left(N_{t}^{d, e}\right)^{1-\gamma}
$$

The energy sector firm maximizes

$$
S_{t} \Xi_{t}\left(N_{t}^{d, e}\right)^{1-\gamma}-W_{t}^{e} N_{t}^{d, e}
$$

while taking productivity and wages as given, where $S_{t}$ is the price of the energy good. The first-order condition can we written in real terms as

$$
(1-\gamma) \frac{S_{t}}{P_{t}} \Sigma_{t}=N_{t}^{d, e} \frac{W_{t}^{e}}{P_{t}}
$$


The market clearing condition for labor is

$$
N_{t}^{s, e}=N_{t}^{d, e}=N_{t}^{e .}
$$

The market clearing condition for the energy good remains the same as before, but as we discuss below, there will be two sectors using it, $a g$ and ind, and so we have

$$
\Sigma_{t}=\int_{0}^{1} \Sigma_{t}^{a g}(j) d j+\int_{0}^{1} \Sigma_{t}^{i n d}(j) d j
$$

where we use the notation for total supply.

\subsection{Primary Commodity-Production Sector}

There are two types of "commodity sectors/goods", say agriculture and industrial, denoted by $k$. Here, $k=a g$, ind. There are a continuum of primary commodity producing firms in each sector. The energy good is used in the production of the primary commodity $\left(Q_{t}^{k}(j)\right)$, with a decreasing returns to scale (determined by $\alpha_{k, j}$ ) production function

$$
Q_{t}^{k}(j)=A_{t}^{k}(j) \Sigma_{t}^{k}(j)^{1-\alpha_{k, j}}
$$

where $A_{t}^{k}(j)$ is the productivity shock. Let $P_{t}^{k}(j)$ be the price of the commodity $j$ in sector $k$. Then the firm's problem is to maximize profits

$$
P_{t}^{k}(j) A_{t}^{k}(j) \Sigma_{t}^{k}(j)^{1-\alpha_{k, j}}-S_{t} \Sigma_{t}^{k}(j)
$$

while taking productivity and prices as given. The first-order condition can be written in real terms as

$$
\left(1-\alpha_{k, j}\right)\left(\frac{P_{t}^{k}(j)}{P_{t}}\right) Q_{t}^{k}(j)=\Sigma_{t}^{k}(j) \frac{S_{t}}{P_{t}} .
$$

\subsection{The Intermediate Commodity}

This production function remains the same as before, as a CES aggregator, but now we have the two sectors for commodity producers given above, where we allow different elasticity of substitutions across varieties in a given sector $\theta_{k, c}$

$$
Q_{t}^{k, C}=\left[\int_{0}^{1} Y_{t}^{k}(j)^{\frac{\theta_{k, c}-1}{\theta_{k, c}}} d j\right]^{\frac{\theta_{k, c}}{\theta_{k, c}-1}}
$$

which gives the standard price index

$$
P_{t}^{k, C}=\left[\int_{0}^{1} P_{t}^{k}(j)^{1-\theta_{k, c}} d j\right]^{\frac{1}{1-\theta_{k, c}}}
$$

and the standard demand curve

$$
\frac{Y_{t}^{k}(j)}{Q_{t}^{k, C}}=\left(\frac{P_{t}^{k}(j)}{P_{t}^{k, C}}\right)^{-\theta_{k, c}} .
$$

Market clearing is then given by

$$
Y_{t}^{k}(j)=Q_{t}^{k}(j) .
$$




\subsection{The Final Goods Sector}

The production function for the final good $\left(Y_{t}\right)$ sector is similar to the baseline model, but now with these two different aggregate of commodity goods serving as inputs

$$
Y_{t}=A_{t} Y_{t}^{a g, C_{t}^{\alpha_{t}^{a g}}} Y_{t}^{i n d, C_{t}^{\alpha_{t}^{i n d}}} N_{t}^{d^{1-\alpha_{t}^{a g}-\alpha_{t}^{i n d}}}
$$

where $A_{t}$ is the productivity shock and the share parameters $\alpha_{t}^{k}$ are exogenous. Let $P_{t}$ be the price of the final good. Then the firm's problem is to maximize profits

$$
P_{t} A_{t} Y_{t}^{a g, C^{\alpha_{t}^{a g}}} Y_{t}^{i n d, C^{\alpha_{t}^{i n d}}} N_{t}^{d^{1-\alpha_{t}^{a g}-\alpha_{t}^{i n d}}}-W_{t} N_{t}^{d}-P_{t}^{a g, C} Y_{t}^{a g, C}-P_{t}^{i n d, C} Y_{t}^{i n d, C}
$$

while taking productivity and prices as given.

The first order conditions are given by

$$
\begin{gathered}
\alpha_{t}^{k}=\left(\frac{P_{t}^{k, C}}{P_{t}}\right)\left(\frac{Y_{t}^{k, C}}{Y_{t}}\right) \\
1-\alpha_{t}^{a g}-\alpha_{t}^{i n d}=\left(\frac{W_{t}}{P_{t}}\right)\left(\frac{N_{t}^{d}}{Y_{t}}\right) .
\end{gathered}
$$

Market clearing for good is

$$
Y_{t}=C_{t}
$$

while for labor is

$$
N_{t}^{d}=N_{t}^{s}=N_{t}
$$

and for the commodity input is

$$
Q_{t}^{k, C}=Y_{t}^{k, C}
$$

\subsection{Equilibrium}

We now present the equilibrium conditions of the model.

\subsubsection{Non-linear equilibrium conditions}

The following non-linear optimality and market clearing conditions determine the equilibrium

$$
\begin{gathered}
\varphi_{n} Y_{t}^{\sigma} N_{t}^{\frac{1}{\eta}}=e^{\varepsilon_{t}^{n}} \frac{W_{t}}{P_{t}} \\
Y_{t}^{-\sigma}=\beta E_{t}\left[Y_{t+1}^{-\sigma} R_{t} \frac{P_{t}}{P_{t+1}}\right] \\
\varphi_{e} Y_{t}^{\sigma} N_{t}^{e \frac{1}{\eta}}=\frac{W_{t}^{e}}{P_{t}} \\
(1-\gamma) \frac{S_{t}}{P_{t}} \Sigma_{t}=N_{t}^{e} \frac{W_{t}^{e}}{P_{t}} \\
\Sigma_{t}=\Xi_{t}\left(N_{t}^{e}\right)^{1-\gamma}
\end{gathered}
$$




$$
\begin{aligned}
& \Sigma_{t}=\int_{0}^{1} \Sigma_{t}^{a g}(j) d j+\int_{0}^{1} \Sigma_{t}^{i n d}(j) d j \\
& Y_{t}^{k}(j)=A_{t}^{k}(j) \Sigma_{t}^{k}(j)^{1-\alpha_{k, j}} \\
& \left(1-\alpha_{k, j}\right)\left(\frac{P_{t}^{k}(j)}{P_{t}}\right) Y_{t}^{k}(j)=\Sigma_{t}^{k}(j) \frac{S_{t}}{P_{t}} \\
& Y_{t}^{k, C}=\left[\int_{0}^{1} Y_{t}^{k}(j)^{\frac{\theta_{k, c}-1}{\theta_{k, c}}} d j\right]^{\frac{\theta_{k, c}}{\theta_{k, c}-1}} \\
& \frac{Y_{t}^{k}(j)}{Y_{t}^{k, C}}=\left(\frac{P_{t}^{k}(j)}{P_{t}^{k, C}}\right)^{-\theta_{k, c}} \\
& P_{t}^{k, C}=\left[\int_{0}^{1} P_{t}^{k}(j)^{1-\theta_{k, c}} d j\right]^{\frac{1}{1-\theta_{k, c}}} \\
& Y_{t}=A_{t} Y_{t}^{a g, C^{\alpha_{t}^{\alpha g}}} Y_{t}^{i n d, C^{\alpha_{t}^{i n d}}} N_{t}^{1-\alpha_{t}^{a g}-\alpha_{t}^{i n d}} \\
& \alpha_{t}^{k}=\left(\frac{P_{t}^{k, C}}{P_{t}}\right)\left(\frac{Y_{t}^{k, C}}{Y_{t}}\right) \\
& 1-\alpha_{t}^{a g}-\alpha_{t}^{i n d}=\left(\frac{W_{t}}{P_{t}}\right)\left(\frac{N_{t}}{Y_{t}}\right)
\end{aligned}
$$

where the following are exogenous processes $\left\{A_{t}, \alpha_{t}^{k}, A_{t}^{k}(j), \varepsilon_{t}^{n}, \Xi_{t}\right\}$.

\subsubsection{Log-linear approximation}

We now consider a first-order approximation around a non-stochastic steady-state. We use the notation with lower case variables denoting $\log$ deviations of real variables (except for $\Sigma_{t}^{k}(j)$ and $\Sigma_{t}$, which are deviations from steady-state) and variables without a $t$ subscript to denote steadystate values of respective variables. We normalize, without loss of generality, equal production in steady-state across commodity producers. The log-linear equilibrium is determined by

$$
\begin{gathered}
\sigma y_{t}+\frac{1}{\eta} n_{t}=w_{t}+\varepsilon_{t}^{n} \\
y_{t}=E_{t}\left[y_{t+1}-\frac{1}{\sigma} r_{t}\right] \\
\sigma y_{t}+\frac{1}{\eta} n_{t}^{e}=w_{t}^{e}+\varepsilon_{t}^{e} \\
s_{t}+\frac{\Sigma_{t}}{\Sigma}=n_{t}^{e}+w_{t}^{e} \\
\frac{\Sigma_{t}}{\Sigma}=\Xi_{t}+(1-\gamma) n_{t}^{e}
\end{gathered}
$$




$$
\begin{gathered}
\Sigma_{t}=\int_{0}^{1} \Sigma_{t}^{a g}(j) d j+\int_{0}^{1} \Sigma_{t}^{i n d}(j) d j \\
y_{t}^{k}(j)=a_{t}^{k}(j)+\frac{\left(1-\alpha_{k, j}\right)}{\Sigma_{j}^{k}} \Sigma_{t}^{k}(j) \\
p_{t}^{k}(j)=s_{t}+\frac{1}{\sum_{j}^{k}} \Sigma_{t}^{k}(j)-y_{t}^{k}(j) \\
y_{t}^{k, c}=\int_{0}^{1} y_{t}^{k}(j) d j \\
y_{t}=a_{t}+\alpha^{a g} y_{t}^{a g, c}+\alpha^{i n d} y_{t}^{i n d, c}+\left(1-\alpha^{a g}-\alpha^{i n d}\right) n_{t} \\
+\varphi_{\alpha}^{a g} \tilde{\alpha}_{t}^{a g}+\varphi_{\alpha}^{i n d} \tilde{\alpha}_{t}^{i n d}(j)=\frac{1}{\theta_{k, c}}\left(y_{t}^{k}(j)-y_{t}^{k, c}\right) \\
p_{t}^{k, c}=y_{t}-y_{t}^{k, c}+\tilde{\alpha}_{t}^{k} \\
w_{t}=y_{t}-n_{t}-\frac{\alpha^{a g}}{1-\alpha^{a g}} \tilde{\alpha}_{t}^{a g}-\frac{\alpha^{i n d}}{1-\alpha^{i n d}} \tilde{\alpha}_{t}^{i n d}
\end{gathered}
$$

where note that $\tilde{\alpha}_{t}^{k}$ is $\log$-deviation of $\alpha_{t}^{k}$ and $\varphi_{\alpha}^{k} \equiv \alpha\left(\ln \overline{Y^{k, C}}-\ln \bar{N}\right)$.

\subsubsection{Solution}

We now present the solution of the model.

Primary commodity sector We start with the (two) primary commodity sectors. We have, from the production function and substitution of the energy good input, the following

$$
\begin{aligned}
y_{t}^{k}(j) & =a_{t}^{k}(j)+\frac{\left(1-\alpha_{k, j}\right)}{\Sigma_{j}^{k}} \Sigma_{t}^{k}(j) \\
& =a_{t}^{k}(j)+\left(1-\alpha_{k, j}\right)\left[p_{t}^{k}(j)-s_{t}+y_{t}^{k}(j)\right]
\end{aligned}
$$

which gives, after defining

$$
\begin{gathered}
\left(\frac{\alpha_{k, j}}{1-\alpha_{k, j}}\right) \equiv \varepsilon_{k, j} \\
y_{t}^{k}(j)=\left(1+\varepsilon_{k, j}^{-1}\right) a_{t}^{k}(j)+\varepsilon_{k, j}^{-1}\left(p_{t}^{k}(j)-s_{t}\right)
\end{gathered}
$$

(1) above gives the supply curve of commodity $j$. Next, plug in the relative demand expression

$$
p_{t}^{k}(j)=p_{t}^{k, c}-\frac{1}{\theta_{k, c}}\left(y_{t}^{k}(j)-y_{t}^{k, c}\right)
$$


to (1) in order to eliminate the commodity price $p_{t}^{k}(j)$, which gives, after defining a re-scaled productivity shock for commodity $j$ as

$$
\left(1+\frac{1}{\varepsilon_{k, j} \theta_{k, c}}\right)^{-1}\left(1+\varepsilon_{k, j}^{-1}\right) a_{t}^{k}(j) \equiv v_{t}^{k}(j)
$$

the solution as

$$
y_{t}^{k}(j)=v_{t}^{k}(j)+\left(1+\frac{1}{\varepsilon_{k, j} \theta_{k, c}}\right)^{-1}\left(\varepsilon_{k, j}^{-1}\left(p_{t}^{k, c}+\frac{1}{\theta_{k, c}} y_{t}^{k, c}-s_{t}\right)\right) .
$$

To pin down the aggregate supply of commodities for each sector, lets integrate (2) over all $j$, which gives

$$
\begin{aligned}
y_{t}^{k, c}= & \int_{0}^{1} v_{t}^{k}(j) d j+p_{t}^{k, c} \int_{0}^{1}\left(1+\frac{1}{\varepsilon_{k, j} \theta_{k, c}}\right)^{-1} \varepsilon_{k, j}^{-1} d j+ \\
& \frac{1}{\theta_{k, c}} y_{t}^{k, c} \int_{0}^{1}\left(1+\frac{1}{\varepsilon_{k, j} \theta_{k, c}}\right)^{-1} \varepsilon_{k, j}^{-1} d j-s_{t} \int_{0}^{1}\left(1+\frac{1}{\varepsilon_{k, j} \theta_{k, c}}\right)^{-1} \varepsilon_{k, j}^{-1} d j .
\end{aligned}
$$

Define

$$
\begin{gathered}
\int_{0}^{1} v_{t}^{k}(j) d j \equiv v_{t}^{k} \\
\varphi^{k} \equiv \int_{0}^{1}\left(1+\varepsilon_{k, j} \theta_{k, c}\right)^{-1} d j
\end{gathered}
$$

and rewrite as

$$
p_{t}^{k, c}=\frac{1}{\theta_{k, c}}\left(\frac{1}{\varphi^{k}}-1\right) y_{t}^{k, c}+s_{t}-\frac{1}{\varphi^{k} \theta_{k, c}} v_{t}^{k} .
$$

Next, we have the aggregate demand for commodity of a sector given by

$$
p_{t}^{k, c}=y_{t}-y_{t}^{k, c}+\tilde{\alpha}_{t}^{k}
$$

which we use with (3) to derive the production of the intermediate commodity bundle, which is

$$
y_{t}^{k, c}=\frac{\theta_{k, c} \varphi^{k}}{1+\left(\theta_{k, c}-1\right) \varphi^{k}} y_{t}+\frac{1}{1+\left(\theta_{k, c}-1\right) \varphi^{k}} v_{t}^{k}-\frac{\theta_{k, c} \varphi^{k}}{1+\left(\theta_{k, c}-1\right) \varphi^{k}} s_{t}+\frac{\theta_{k, c} \varphi^{k}}{1+\left(\theta_{k, c}-1\right) \varphi^{k}} \tilde{\alpha}_{t}^{k}
$$

For future reference, lets also derive the solution for $p_{t}^{k, c}$. We can use the aggregate demand for the commodity sector to write, after plugging in for (4)

$$
p_{t}^{k, c}=\frac{1-\varphi^{k}}{1+\left(\theta_{k, c}-1\right) \varphi^{k}} y_{t}-\frac{1}{1+\left(\theta_{k, c}-1\right) \varphi^{k}} v_{t}^{k}+\frac{\theta_{k, c} \varphi^{k}}{1+\left(\theta_{k, c}-1\right) \varphi^{k}} s_{t}+\frac{1-\varphi^{k}}{1+\left(\theta_{k, c}-1\right) \varphi^{k}} \tilde{\alpha}_{t}^{k}
$$

with (5) above giving the solution for $p_{t}^{k, c}$. 
Energy sector price Now lets move to the energy sector. We can use market clearing condition to pin down the (aggregate) price of the energy sector $s_{t}$. Using the production function and (2) we get

$$
a_{t}^{k}(j)+\frac{\left(1-\alpha_{k, j}\right)}{\Sigma_{j}^{k}} \Sigma_{t}^{k}(j)=v_{t}^{k}(j)+\left(1+\frac{1}{\varepsilon_{k, j} \theta_{k, c}}\right)^{-1}\left(\varepsilon_{k, j}^{-1}\left(p_{t}^{k, c}+\frac{1}{\theta_{k, c}} y_{t}^{k, c}-s_{t}\right)\right)
$$

which can be written as

$$
\begin{aligned}
\Sigma_{t}^{k}(j)= & \left(\frac{1-\alpha_{k, j}}{\Sigma_{j}^{k}}\right)^{-1} v_{t}^{k}(j)-\left(\frac{1-\alpha_{k, j}}{\Sigma_{j}^{k}}\right)^{-1} a_{t}^{k}(j)+ \\
& \left(\frac{1-\alpha_{k, j}}{\Sigma_{j}^{k}}\right)^{-1}\left(1+\frac{1}{\varepsilon_{k, j} \theta_{k, c}}\right)^{-1}\left(\varepsilon_{k, j}^{-1}\left(p_{t}^{k, c}+\frac{1}{\theta_{k, c}} y_{t}^{k, c}-s_{t}\right)\right)
\end{aligned}
$$

Define

$$
\frac{1-\alpha_{k, j}}{\Sigma_{j}^{k}} \equiv \varsigma_{k, j}
$$

and get

$$
\Sigma_{t}^{k}(j)=\varsigma_{k, j}^{-1} v_{t}^{k}(j)-\varsigma_{k, j}^{-1} a_{t}^{k}(j)+\varsigma_{k, j}^{-1}\left(1+\frac{1}{\varepsilon_{k, j} \theta_{k, c}}\right)^{-1}\left(\varepsilon_{k, j}^{-1}\left(p_{t}^{k, c}+\frac{1}{\theta_{k, c}} y_{t}^{k, c}-s_{t}\right)\right) .
$$

Then we use (6) in the market clearing condition to get a solution for $s_{t}$

$\Sigma_{t}=\sum_{k=a g, \text { ind }}\left[\int_{0}^{1} \varsigma_{k, j}^{-1} v_{t}^{k}(j) d j-\int_{0}^{1} \varsigma_{k, j}^{-1} a_{t}^{k}(j) d j+\left(p_{t}^{k, c}+\frac{1}{\theta_{k, c}} y_{t}^{k, c}-s_{t}\right) \int_{0}^{1} \varsigma_{k, j}^{-1}\left(1+\frac{1}{\varepsilon_{k, j} \theta_{k, c}}\right)^{-1} \varepsilon_{k, j}^{-1} d j\right]$.

Lets define,

$$
\begin{gathered}
\int_{0}^{1} \varsigma_{k, j}^{-1} v_{t}^{k}(j) d j \equiv \tilde{v}_{t}^{k} \\
\int_{0}^{1} \varsigma_{k, j}^{-1} a_{t}^{k}(j) d j \equiv \tilde{a}_{t}^{k} \\
\int_{0}^{1} \varsigma_{k, j}^{-1}\left(1+\frac{1}{\varepsilon_{k, j} \theta_{k, c}}\right)^{-1} \varepsilon_{k, j}^{-1} d j \equiv \tilde{\varphi}^{k} .
\end{gathered}
$$

For future reference, note that if $\frac{1-\alpha_{k, j}}{\Sigma_{k, j}} \equiv \varsigma_{k, j}=1$, then $\tilde{v}_{t}^{k}=v_{t}^{k}$ and $\tilde{\varphi}^{k}=\theta_{k, c} \varphi^{k}$.

Then we can write the solution $s_{t}$ as

$$
\begin{aligned}
s_{t}= & \left(\tilde{\varphi}^{a g}+\tilde{\varphi}^{i n d}\right)^{-1} \sum_{k=a g, \text { ind }} \tilde{v}_{t}^{k}-\left(\tilde{\varphi}^{a g}+\tilde{\varphi}^{i n d}\right)^{-1} \sum_{k=a g, \text { ind }} \tilde{a}_{t}^{k} \\
& -\left(\tilde{\varphi}^{a g}+\tilde{\varphi}^{i n d}\right)^{-1} \Sigma_{t}+\left(\tilde{\varphi}^{a g}+\tilde{\varphi}^{i n d}\right)^{-1} \sum_{k=a g, \text { ind }} \tilde{\varphi}^{k} p_{t}^{k, c}+\left(\tilde{\varphi}^{a g}+\tilde{\varphi}^{i n d}\right)^{-1} \sum_{k=a g, \text { ind }} \tilde{\varphi}^{k} \frac{1}{\theta_{k, c}} y_{t}^{k, c}
\end{aligned}
$$

where (7) gives the solution for $s_{t}$ as a function of the total supply in the energy sector, the two averages over commodity specific productivity shocks over sectors, and $p_{t}^{k, c}$ and $y_{t}^{k, c}$. We have 
expressions for $p_{t}^{k, c}$ and $y_{t}^{k, c}$ in (5) and (4), which we can later combine for solutions of all aggregate variables as a function of various aggregate shocks and total supply in the energy sector.

For future, note the following in terms of the firm/supply side FOC, we can derive

$$
\frac{\Sigma_{t}}{\Sigma}=\frac{1}{\left(1-(1-\gamma)\left(1+\frac{1}{\eta}\right)^{-1}\right)} \Xi_{t}+\frac{(1-\gamma)\left(1+\frac{1}{\eta}\right)^{-1}}{\left(1-(1-\gamma)\left(1+\frac{1}{\eta}\right)^{-1}\right)}\left[s_{t}-\sigma y_{t}\right]
$$

which we will use later for equating demand and supply of $\frac{\Sigma_{t}}{\Sigma}$.

Final good sector We now use the equilibrium conditions of the final good sector to determine labor supply and output, which are given by

$$
\begin{aligned}
& n_{t}=\frac{(1-\sigma)}{\left(1+\frac{1}{\eta}\right)} y_{t}-\frac{\frac{\alpha^{a g}}{1-\alpha^{a g}}}{\left(1+\frac{1}{\eta}\right)} \tilde{\alpha}_{t}^{a g}-\frac{\frac{\alpha^{i n d}}{1-\alpha^{i n d}}}{\left(1+\frac{1}{\eta}\right)} \tilde{\alpha}_{t}^{i n d}+\frac{1}{\left(1+\frac{1}{\eta}\right)} \varepsilon_{t}^{n} \\
& {\left[\frac{1}{\left(1-\alpha^{a g}-\alpha^{i n d}\right)}-\frac{(1-\sigma)}{\left(1+\frac{1}{\eta}\right)}\right] y_{t}=\frac{1}{\left(1+\frac{1}{\eta}\right)} \varepsilon_{t}^{n}+\frac{1}{\left(1-\alpha^{a g}-\alpha^{i n d}\right)} a_{t}+\frac{\alpha^{a g}}{\left(1-\alpha^{a g}-\alpha^{i n d}\right)} y_{t}^{a g, c}} \\
& +\frac{\alpha^{i n d}}{\left(1-\alpha^{a g}-\alpha^{i n d}\right)} y_{t}^{i n d, c}+\left(\frac{\varphi_{\alpha}^{a g}}{\left(1-\alpha^{a g}-\alpha^{i n d}\right)}-\frac{\alpha^{a g}}{1-\alpha^{a g}}\right) \tilde{\alpha}_{t}^{a g} \\
& +\left(\frac{\varphi_{\alpha}^{i n d}}{\left(1-\alpha^{a g}-\alpha^{i n d}\right)}-\frac{\alpha^{i n d}}{1-\alpha^{i n d}}\right) \tilde{\alpha}_{t}^{i n d}
\end{aligned}
$$

First, we can plug in the solution for $y_{c, t}$ from (4) to eliminate it. Moreover, we can later in turn write all aggregate variables as a function of aggregate shocks and averages of commodity specific productivity shocks. Lets define

$$
\left[\frac{1}{\left(1-\alpha^{a g}-\alpha^{i n d}\right)}-\frac{(1-\sigma)}{\left(1+\frac{1}{\eta}\right)}\right] \equiv \chi .
$$

Then, we have

$$
\begin{aligned}
y_{t}= & -\chi^{-1}\left[\frac{\frac{\alpha^{a g}}{1-\alpha^{a g}}}{\left(1+\frac{1}{\eta}\right)}-\frac{\varphi_{\alpha}^{a g}}{\left(1-\alpha^{a g}-\alpha^{i n d}\right)}\right] \tilde{\alpha}_{t}^{a g}-\chi^{-1}\left[\frac{\alpha^{i n d}}{1-\alpha^{i n d}}-\frac{\varphi_{\alpha}^{i n d}}{\left(1+\frac{1}{\eta}\right)}\right] \tilde{\alpha}_{t}^{\text {ind }} \\
& +\frac{\chi^{-1}}{\left(1+\frac{1}{\eta}\right)} \varepsilon_{t}^{n}+\frac{\chi^{-1}}{\left(1-\alpha^{a g}-\alpha^{i n d}\right)} a_{t}+\chi^{-1} \frac{\alpha^{a g}}{\left(1-\alpha^{a g}-\alpha^{i n d}\right)} y_{t}^{a g, c}+\chi^{-1} \frac{\alpha^{i n d}}{\left(1-\alpha^{a g}-\alpha^{i n d}\right)} y_{t}^{\text {ind,c }} .
\end{aligned}
$$

which gives the expression for final output. 
Aggregate equilibrium We then have the aggregate equilibrium given by the following four conditions (4), (5), (7), and (9) that give the solution for $\left\{y_{t}, y_{t}^{k, c}, s_{t}, p_{t}^{k, c}\right\}$, which are reproduced here

$$
\begin{aligned}
& y_{t}^{k, c}=\frac{\theta_{k, c} \varphi^{k}}{1+\left(\theta_{k, c}-1\right) \varphi^{k}} y_{t}+\frac{1}{1+\left(\theta_{k, c}-1\right) \varphi^{k}} v_{t}^{k}-\frac{\theta_{k, c} \varphi^{k}}{1+\left(\theta_{k, c}-1\right) \varphi^{k}} s_{t}+\frac{\theta_{k, c} \varphi^{k}}{1+\left(\theta_{k, c}-1\right) \varphi^{k}} \tilde{\alpha}_{t}^{k} \\
& p_{t}^{k, c}=\frac{1-\varphi^{k}}{1+\left(\theta_{k, c}-1\right) \varphi^{k}} y_{t}-\frac{1}{1+\left(\theta_{k, c}-1\right) \varphi^{k}} v_{t}^{k}+\frac{\theta_{k, c} \varphi^{k}}{1+\left(\theta_{k, c}-1\right) \varphi^{k}} s_{t}+\frac{1-\varphi^{k}}{1+\left(\theta_{k, c}-1\right) \varphi^{k}} \tilde{\alpha}_{t}^{k} \\
& s_{t}=\left(\tilde{\varphi}^{a g}+\tilde{\varphi}^{i n d}\right)^{-1} \sum_{k=a g, \text { ind }} \tilde{v}_{t}^{k}-\left(\tilde{\varphi}^{a g}+\tilde{\varphi}^{i n d}\right)^{-1} \sum_{k=a g, \text { ind }} \tilde{a}_{t}^{k} \\
& -\left(\tilde{\varphi}^{a g}+\tilde{\varphi}^{i n d}\right)^{-1} \Sigma_{t}+\left(\tilde{\varphi}^{a g}+\tilde{\varphi}^{i n d}\right)^{-1} \sum_{k=a g, \text { ind }} \tilde{\varphi}^{k} p_{t}^{k, c}+\left(\tilde{\varphi}^{a g}+\tilde{\varphi}^{i n d}\right)^{-1} \sum_{k=a g, \text { ind }} \tilde{\varphi}^{k} \frac{1}{\theta_{k, c}} y_{t}^{k, c} \\
& y_{t}=-\chi^{-1}\left[\frac{\frac{\alpha^{a g}}{1-\alpha^{a g}}}{\left(1+\frac{1}{\eta}\right)}-\frac{\varphi_{\alpha}^{a g}}{\left(1-\alpha^{a g}-\alpha^{i n d}\right)}\right] \tilde{\alpha}_{t}^{a g}-\chi^{-1}\left[\frac{\alpha^{i n d}}{1-\alpha^{i n d}}-\frac{\varphi_{\alpha}^{i n d}}{\left(1+\frac{1}{\eta}\right)}-\frac{\left.\alpha^{a g}-\alpha^{i n d}\right)}{\left(1-\tilde{\alpha}_{t}^{i n d}\right.}\right. \\
& +\frac{\chi^{-1}}{\left(1+\frac{1}{\eta}\right)} \varepsilon_{t}^{n}+\frac{\chi^{-1}}{\left(1-\alpha^{a g}-\alpha^{i n d}\right)} a_{t}+\chi^{-1} \frac{\alpha^{a g}}{\left(1-\alpha^{a g}-\alpha^{i n d}\right)} y_{t}^{a g, c}+\chi^{-1} \frac{\alpha^{i n d}}{\left(1-\alpha^{a g}-\alpha^{i n d}\right)} y_{t}^{i n d, c}
\end{aligned}
$$

and we can write them as a function of shocks. Note that $\left\{a_{t}, \varepsilon_{t}^{n}\right\}$ only show up in the expression for $y_{t}$, as given in (9), while $\left\{\Sigma_{t}\right\}$ only shows up in the expression for $s_{t}$ as given in (7). Also from here on, lets define a parameter that is the sum across sectors as follows

$$
\tilde{\varphi}^{-1} \equiv\left(\tilde{\varphi}^{a g}+\tilde{\varphi}^{i n d}\right)^{-1} .
$$

At this point, lets express the aggregate energy price $s_{t}$ as a function of shocks and $y_{t}$. So lets replace for $p_{t}^{k, c}+\frac{1}{\theta_{k, c}} y_{t}^{k, c}$ to get

$$
\begin{aligned}
s_{t}= & \Lambda\left[\tilde{\varphi}^{-1} \sum_{k=a g, \text { ind }} \tilde{v}_{t}^{k}-\tilde{\varphi}^{-1} \sum_{k=a g, \text { ind }} \tilde{a}_{t}^{k}-\tilde{\varphi}^{-1} \Sigma_{t}\right]+y_{t} \\
& -\Lambda \tilde{\varphi}^{-1} \sum_{k=a g, \text { ind }}\left[\tilde{\varphi}^{k}\left(\frac{\theta_{k, c}-1}{\theta_{k, c}}\right)\left(\frac{1}{1+\left(\theta_{k, c}-1\right) \varphi^{k}}\right) v_{t}^{k}\right] \\
& +\Lambda \tilde{\varphi}^{-1} \sum_{k=a g, \text { ind }}\left[\tilde{\varphi}^{k}\left(\frac{1}{1+\left(\theta_{k, c}-1\right) \varphi^{k}}\right) \tilde{\alpha}_{t}^{k}\right]
\end{aligned}
$$

where we define

$$
\Lambda \equiv \frac{\tilde{\varphi}}{\sum_{k=a g, i n d}\left(\frac{\tilde{\varphi}^{k}}{1+\left(\theta_{k, c}-1\right) \varphi^{k}}\right)}
$$


This solution for $s_{t}$ in (10) can be used below in discussing the direct and indirect determinants of commodity supply and demand.

Finally, we can also write down the solution for $y_{t}$ by plugging in for $y_{t}^{k, c}$ and $s_{t}$. That is, after manipulations and plugging in, get

$$
\begin{aligned}
y_{t}= & -\chi^{-1} \sum_{k=a g, \text { ind }}\left[\left(\frac{\frac{\alpha^{k}}{1-\alpha^{k}}}{\left(1+\frac{1}{\eta}\right)}-\frac{1}{\left(1-\alpha^{a g}-\alpha^{i n d}\right)}\left(\varphi_{\alpha}^{k}-\frac{\alpha^{k} \theta_{k, c} \varphi^{k}-\Phi \Lambda \tilde{\varphi}^{-1} \tilde{\varphi}^{k}}{1+\left(\theta_{k, c}-1\right) \varphi^{k}}\right)\right) \tilde{\alpha}_{t}^{k}\right](11) \\
& +\frac{\chi^{-1}}{\left(1+\frac{1}{\eta}\right)} \varepsilon_{t}^{n}+\frac{\chi^{-1}}{\left(1-\alpha^{a g}-\alpha^{i n d}\right)} a_{t} \\
& +\frac{\chi^{-1}}{\left(1-\alpha^{a g}-\alpha^{i n d}\right)} \sum_{k=a g, \text { ind }}\left[\frac{\alpha^{k}+\Phi \Lambda \tilde{\varphi}^{-1} \tilde{\varphi}^{k}\left(\frac{\theta_{k, c}-1}{\theta_{k, c}}\right)}{1+\left(\theta_{k, c}-1\right) \varphi^{k}} v_{t}^{k}\right] \\
& -\frac{\chi^{-1} \Phi \Lambda \tilde{\varphi}^{-1}}{\left(1-\alpha^{a g}-\alpha^{i n d}\right)}\left[\sum_{k=a g, \text { ind }} \tilde{v}_{t}^{k}-\sum_{k=a g, \text { ind }} \tilde{a}_{t}^{k}-\Sigma_{t}\right]
\end{aligned}
$$

where we define

$$
\Phi \equiv \sum_{k=a g, \text { ind }} \alpha^{k}\left(\frac{\theta_{k, c} \varphi^{k}}{1+\left(\theta_{k, c}-1\right) \varphi^{k}}\right) .
$$

Here, (11) above gives a solution for $y_{t}$ as a function of all aggregate shocks and the supply of energy good.

Next, lets impose, without loss of generality, the normalization on steady-state that

$$
\frac{1-\alpha_{k, j}}{\Sigma_{j}^{k}} \equiv \varsigma_{k, j}=1
$$

Then we have

$$
\begin{gathered}
\int_{0}^{1} \varsigma_{k, j}^{-1} v_{t}^{k}(j) d j \equiv \tilde{v}_{t}^{k}=v_{t}^{k}=\int_{0}^{1} v_{t}^{k}(j) d j=\int_{0}^{1}\left(1+\frac{1}{\varepsilon_{k, j} \theta_{k, c}}\right)^{-1}\left(1+\varepsilon_{k, j}^{-1}\right) a_{t}^{k}(j) d j \\
\int_{0}^{1} \varsigma_{k, j}^{-1} a_{t}^{k}(j) d j \equiv \tilde{a}_{t}^{k} \\
\int_{0}^{1} \varsigma_{k, j}^{-1}\left(1+\frac{1}{\varepsilon_{k, j} \theta_{k, c}}\right)^{-1} \varepsilon_{k, j}^{-1} d j \equiv \tilde{\varphi}^{k}=\theta_{k, c} \varphi^{k} \\
\tilde{\varphi}=\sum_{k=a g, \text { ind }} \tilde{\varphi}^{k}=\sum_{k=a g, \text { ind }} \theta_{k, c} \varphi^{k} \\
\Lambda \equiv \frac{\tilde{\varphi}}{\sum_{k=a g, \text { ind }}\left(\frac{\tilde{\varphi}^{k}}{1+\left(\theta_{k, c}-1\right) \varphi^{k}}\right)}=\frac{\tilde{\varphi}}{\sum_{k=a g, i n d}\left(\frac{\theta_{k, c} \varphi^{k}}{1+\left(\theta_{k, c}-1\right) \varphi^{k}}\right)} .
\end{gathered}
$$


So we can further simplify (11) as

$$
\begin{aligned}
y_{t}= & -\frac{\chi^{-1}}{\left(1-\alpha^{a g}-\alpha^{i n d}\right)} \sum_{k=a g, \text { ind }}\left[\left(\frac{\alpha^{k}}{1-\alpha^{k}} \frac{\left(1-\alpha^{a g}-\alpha^{i n d}\right)}{\left(1+\frac{1}{\eta}\right)}-\left(\varphi_{\alpha}^{k}-\theta_{k, c} \varphi^{k}\left(\frac{\alpha^{k}-\Phi \Lambda \tilde{\varphi}^{-1}}{1+\left(\theta_{k, c}-1\right) \varphi^{k}}\right)\right)\right) \tilde{\alpha}_{t}^{k}\right] \\
& +\frac{\chi^{-1}}{\left(1-\alpha^{a g}-\alpha^{i n d}\right)}\left(\frac{\left(1-\alpha^{a g}-\alpha^{i n d}\right)}{\left(1+\frac{1}{\eta}\right)} \varepsilon_{t}^{n}+a_{t}\right) \\
& +\frac{\chi^{-1}}{\left(1-\alpha^{a g}-\alpha^{i n d}\right)} \sum_{k=a g, \text { ind }}\left[\left(\frac{\alpha^{k}-\Phi \Lambda \tilde{\varphi}^{-1}}{1+\left(\theta_{k, c}-1\right) \varphi^{k}}\right) v_{t}^{k}\right] \\
& +\frac{\chi^{-1}}{\left(1-\alpha^{a g}-\alpha^{i n d}\right)} \Phi \Lambda \tilde{\varphi}^{-1}\left(\sum_{k=a g, \text { ind }} \tilde{a}_{t}^{k}+\Sigma_{t}\right)
\end{aligned}
$$

where

$$
\Phi \Lambda \tilde{\varphi}^{-1}=\frac{\sum_{k=a g, \text { ind }} \alpha^{k}\left(\frac{\theta_{k, c} \varphi^{k}}{1+\left(\theta_{k, c}-1\right) \varphi^{k}}\right)}{\sum_{k=a g, \text { ind }}\left(\frac{\theta_{k, c} \varphi^{k}}{1+\left(\theta_{k, c}-1\right) \varphi^{k}}\right)} .
$$

We have

$$
\begin{aligned}
\frac{\chi^{-1}}{\left(1-\alpha^{a g}-\alpha^{i n d}\right)} & =\left[\frac{1}{\left(1-\alpha^{a g}-\alpha^{i n d}\right)}-\frac{(1-\sigma)}{\left(1+\frac{1}{\eta}\right)}\right]^{-1}\left(1-\alpha^{a g}-\alpha^{i n d}\right)^{-1} \\
& =\frac{\left(1+\frac{1}{\eta}\right)}{\left(1+\frac{1}{\eta}\right)-(1-\sigma)\left(1-\alpha^{a g}-\alpha^{i n d}\right)}
\end{aligned}
$$

Then we can write

$$
y_{t}=\varphi_{y}\left(a_{t}+\kappa_{n} \varepsilon_{t}^{n}+\kappa_{\Sigma} \Sigma_{t}+\sum_{k=a g, \text { ind }}\left(\kappa_{v}^{k} v_{t}^{k}+\kappa_{\tilde{a}} \tilde{a}_{t}^{k}-\kappa_{\alpha}^{k} \tilde{\alpha}_{t}^{k}\right)\right)
$$


where.

$$
\begin{aligned}
& \varphi_{y} \equiv \frac{\left(1+\frac{1}{\eta}\right)}{\left(1+\frac{1}{\eta}\right)-(1-\sigma)\left(1-\alpha^{a g}-\alpha^{i n d}\right)} \\
& \kappa_{n} \equiv \frac{\left(1-\alpha^{a g}-\alpha^{i n d}\right)}{\left(1+\frac{1}{\eta}\right)} \\
& \kappa_{\tilde{a}} \equiv \Phi \Lambda \tilde{\varphi}^{-1}=\frac{\sum_{k^{\prime}=a g, i n d} \alpha^{k^{\prime}}\left(\frac{\theta_{k^{\prime}, c} \varphi^{k^{\prime}}}{1+\left(\theta_{k^{\prime}, c}-1\right) \varphi^{k^{\prime}}}\right)}{\sum_{k^{\prime}=a g, i n d}\left(\frac{\theta_{k^{\prime}, c} \varphi^{k^{\prime}}}{1+\left(\theta_{k^{\prime}, c}-1\right) \varphi^{k^{\prime}}}\right)} \\
& \kappa_{\Sigma} \equiv \Phi \Lambda \tilde{\varphi}^{-1}=\frac{\sum_{k^{\prime}=a g, i n d} \alpha^{k^{\prime}}\left(\frac{\theta_{k^{\prime}, c} \varphi^{k^{\prime}}}{1+\left(\theta_{k^{\prime}, c}-1\right) \varphi^{k^{\prime}}}\right)}{\sum_{k^{\prime}=a g, i n d}\left(\frac{\theta_{k^{\prime}, c} \varphi^{k^{\prime}}}{1+\left(\theta_{k^{\prime}, c}-1\right) \varphi^{k^{\prime}}}\right)} \\
& \kappa_{v}^{k} \equiv\left(\frac{\alpha^{k}-\Phi \Lambda \tilde{\varphi}^{-1}}{1+\left(\theta_{k, c}-1\right) \varphi^{k}}\right)=\left(\frac{1}{1+\left(\theta_{k, c}-1\right) \varphi^{k}}\right) \frac{\sum_{k^{\prime}=a g, \text { ind }}\left(\alpha^{k}-\alpha^{k^{\prime}}\right)\left(\frac{\theta_{k^{\prime}, c} \varphi^{k^{\prime}}}{1+\left(\theta_{k^{\prime}, c}-1\right) \varphi^{k^{\prime}}}\right)}{\sum_{k^{\prime}=a g, \text { ind }}\left(\frac{\theta_{k^{\prime}, c} \varphi^{k^{\prime}}}{1+\left(\theta_{k^{\prime}, c}-1\right) \varphi^{k^{\prime}}}\right)} \\
& \kappa_{\alpha}^{k}=\left(\frac{\alpha^{k}}{1-\alpha^{k}} \frac{\left(1-\alpha^{a g}-\alpha^{i n d}\right)}{\left(1+\frac{1}{\eta}\right)}-\left(\varphi_{\alpha}^{k}-\theta_{k, c} \varphi^{k} \kappa_{v}^{k}\right)\right) .
\end{aligned}
$$

Comovement in Commodity Prices First, lets write out the supply curve for commodity $j$, which can be derived from (1) and reproduced here

$$
y_{t}^{k}(j)=\left(1+\varepsilon_{k, j}^{-1}\right) a_{t}^{k}(j)+\varepsilon_{k, j}^{-1}\left(p_{t}^{k}(j)-s_{t}\right)
$$

and where we will use the definition

$$
\left(1+\frac{1}{\varepsilon_{k, j} \theta_{k, c}}\right)^{-1}\left(1+\varepsilon_{k, j}^{-1}\right) a_{t}^{k}(j) \equiv v_{t}^{k}(j) .
$$

That is, write (1) as

$$
p_{t}^{k}(j)=\varepsilon_{k, j} y_{t}^{k}(j)+s_{t}-\frac{\left(1+\varepsilon_{k, j} \theta_{k, c}\right)}{\theta_{k, c}} v_{t}^{k}(j)
$$

where $s_{t}$ appears.

Next, we can write out the demand curve for commodity $j$ from the relative demand equation and final good input share equation, as well as the solution for $y_{t}^{k, c}$ as given in (4). That is, we get

$$
\begin{aligned}
p_{t}^{k}(j)= & -\frac{1}{\theta_{k, c}} y_{t}^{k}(j)+\left(\frac{1}{1+\left(\theta_{k, c}-1\right) \varphi^{k}}\right) y_{t}-\left(\frac{\theta_{k, c}-1}{\theta_{k, c}}\right)\left(\frac{1}{1+\left(\theta_{k, c}-1\right) \varphi^{k}}\right) v_{t}^{k} \\
& +\left(\frac{\left(\theta_{k, c}-1\right) \varphi^{k}}{1+\left(\theta_{k, c}-1\right) \varphi^{k}}\right) s_{t}+\left(\frac{1}{1+\left(\theta_{k, c}-1\right) \varphi^{k}}\right) \tilde{\alpha}_{t}^{k}
\end{aligned}
$$


where there is a dependence not just on $s_{t}$, but now also on $y_{t}$ directly.

Lets simplify the above further by replacing the solution for $s_{t}$. Start with the (13), to get

$$
\begin{aligned}
p_{t}^{k}(j) & =\varepsilon_{k, j} y_{t}^{k}(j)-\frac{\left(1+\varepsilon_{k, j} \theta_{k, c}\right)}{\theta_{k, c}} v_{t}^{k}(j) \\
& +\frac{1}{\sum_{k=a g, \text { ind }}\left(\frac{\theta_{k, c} \varphi^{k}}{1+\left(\theta_{k, c}-1\right) \varphi^{k}}\right)}\left[\sum_{k=a g, i n d}\left(\frac{1}{1+\left(\theta_{k, c}-1\right) \varphi^{k}}\right) v_{t}^{k}-\sum_{k=a g, \text { ind }} \tilde{a}_{t}^{k}-\Sigma_{t}\right]+y_{t} \\
& +\frac{1}{\sum_{k=a g, \text { ind }}\left(\frac{\theta_{k, c} \varphi^{k}}{1+\left(\theta_{k, c}-1\right) \varphi^{k}}\right)} \sum_{k=a g, \text { ind }}\left[\frac{\theta_{k, c} \varphi^{k}}{1+\left(\theta_{k, c}-1\right) \varphi^{k}} \tilde{\alpha}_{t}^{k}\right] .
\end{aligned}
$$

Next, do the same manipulations for (14), to get

$$
\begin{aligned}
p_{t}^{k}(j) & =-\frac{1}{\theta_{k, c}} y_{t}^{k}(j)+y_{t}-\left(\frac{\theta_{k, c}-1}{\theta_{k, c}}\right)\left(\frac{1}{1+\left(\theta_{k, c}-1\right) \varphi^{k}}\right) v_{t}^{k} \\
& +\frac{\left(\frac{\left(\theta_{k, c}-1\right) \varphi^{k}}{1+\left(\theta_{k, c}-1\right) \varphi^{k}}\right)}{\sum_{k=a g, i n d}\left(\frac{\theta_{k, c} \varphi^{k}}{1+\left(\theta_{k, c}-1\right) \varphi^{k}}\right)}\left[\sum_{k=a g, i n d}\left(\frac{1}{1+\left(\theta_{k, c}-1\right) \varphi^{k}}\right) v_{t}^{k}-\sum_{k=a g, i n d} \tilde{a}_{t}^{k}-\Sigma_{t}\right] \\
& +\frac{\left(\frac{\left(\theta_{k, c}-1\right) \varphi^{k}}{1+\left(\theta_{k, c}-1\right) \varphi^{k}}\right)}{\sum_{k=a g, i n d}\left(\frac{\theta_{k, c} \varphi^{k}}{1+\left(\theta_{k, c}-1\right) \varphi^{k}}\right)} \sum_{k=a g, \text { ind }}\left[\left(\frac{\theta_{k, c} \varphi^{k}}{1+\left(\theta_{k, c}-1\right) \varphi^{k}}\right) \tilde{\alpha}_{t}^{k}\right] \\
& +\left(\frac{1}{1+\left(\theta_{k, c}-1\right) \varphi^{k}}\right) \tilde{\alpha}_{t}^{k} .
\end{aligned}
$$

These intermediate derivations for the commodity demand and supply are useful for intuition. We can later derive the final formulations after we determine the solution for $\Sigma_{t}$, the level of energy good produced in this economy.

Commodity Prices Next, we can solve for commodity prices, by combining (15) and (16) above

$$
\begin{aligned}
\left(1+\varepsilon_{k, j} \theta_{k, c}\right) p_{t}^{k}(j) & =\left(1+\varepsilon_{k, j} \theta_{k, c}\right) y_{t}-\varepsilon_{k, j} \theta_{k, c}\left(\frac{\theta_{k, c}-1}{\theta_{k, c}}\right)\left(\frac{1}{1+\left(\theta_{k, c}-1\right) \varphi^{k}}\right) v_{t}^{k} \\
& \left.+\frac{1+\varepsilon_{k, j} \theta_{k, c}\left(\frac{\left(\theta_{k, c}-1\right) \varphi^{k}}{1+\left(\theta_{k, c}-1\right) \varphi^{k}}\right)}{\sum_{k^{\prime}=a g, i n d}\left(\frac{\theta_{k^{\prime}, c} \varphi^{k^{\prime}}}{1+\left(\theta_{k^{\prime}, c}-1\right) \varphi^{k^{\prime}}}\right)} \sum_{k^{\prime}=a g, i n d}\left[\left(\frac{1}{1+\left(\theta_{k^{\prime}, c}-1\right) \varphi^{k^{\prime}}}\right) v_{t}^{k^{\prime}}\right]-\sum_{k^{\prime}=a g, i n d} \tilde{a}_{t}^{k^{\prime}}-\Sigma_{t}\right] \\
& +\frac{1+\varepsilon_{k, j} \theta_{k, c}\left(\frac{\left(\theta_{k, c}-1\right) \varphi^{k}}{1+\left(\theta_{k, c}-1\right) \varphi^{k}}\right)}{\sum_{k^{\prime}=a g, i n d}\left(\frac{\theta_{k^{\prime}, c} \varphi^{k^{\prime}}}{1+\left(\theta_{k^{\prime}, c}-1\right) \varphi^{k^{\prime}}}\right)} \sum_{k=a g, i n d}\left[\left(\frac{\theta_{k^{\prime}, c} \varphi^{k^{\prime}}}{1+\left(\theta_{k^{\prime}, c}-1\right) \varphi^{k^{\prime}}}\right) \tilde{\alpha}_{t}^{k^{\prime}}\right] \\
& +\varepsilon_{k, j} \theta_{k, c}\left(\frac{1}{1+\left(\theta_{k, c}-1\right) \varphi^{k}}\right) \tilde{\alpha}_{t}^{k} \\
& -\frac{\left(1+\varepsilon_{k, j} \theta_{k, c}\right)}{\theta_{k, c}} v_{t}^{k}(j)
\end{aligned}
$$


where we have two averages of commodity producer productivity that appear in (17). We have defined them as

$$
\begin{gathered}
v_{t}^{k}(j)=\left(1+\frac{1}{\varepsilon_{k, j} \theta_{k, c}}\right)^{-1}\left(1+\varepsilon_{k, j}^{-1}\right) a_{t}^{k}(j) \\
v_{t}^{k}=\int_{0}^{1} v_{t}^{k}(j) d j \\
\tilde{a}_{t}^{k}=\int_{0}^{1} a_{t}^{k}(j) d j
\end{gathered}
$$

Lets assume then that there is a common and idiosyncratic component to the commodity producer productivity $a_{t}(j)$ (with the idiosyncratic components orthogonal across commodity producers)

$$
a_{t}^{k}(j)=a_{t}^{k, a}+a_{t}^{k, j}
$$

which also means, multiplying by $\left(1+\frac{1}{\varepsilon_{k, j} \theta_{k, c}}\right)^{-1}\left(1+\varepsilon_{k, j}^{-1}\right)$ on both sides

$$
v_{t}^{k}(j)=v_{t}^{k, a}+v_{t}^{k, j}
$$

where we define

$$
\begin{aligned}
v_{t}^{k, j} & \equiv\left(1+\frac{1}{\varepsilon_{k, j} \theta_{k, c}}\right)^{-1}\left(1+\varepsilon_{k, j}^{-1}\right) a_{t}^{k, j} \\
v_{t}^{k, a} & \equiv\left(1+\frac{1}{\varepsilon_{k, j} \theta_{k, c}}\right)^{-1}\left(1+\varepsilon_{k, j}^{-1}\right) a_{t}^{k, a}
\end{aligned}
$$

Then, this implies that

$$
\begin{aligned}
\tilde{a}_{t}^{k} & \equiv \int_{0}^{1} a_{t}^{k}(j) d j=a_{t}^{k, a} \\
v_{t}^{k} & \equiv \int_{0}^{1} v_{t}^{k}(j) d j=v_{t}^{k, a} \\
v_{t}^{k, a} & \equiv\left(1+\frac{1}{\varepsilon_{k, j} \theta_{k, c}}\right)^{-1}\left(1+\varepsilon_{k, j}^{-1}\right) a_{t}^{k, a} \\
v_{t}^{k, j} & \equiv\left(1+\frac{1}{\varepsilon_{k, j} \theta_{k, c}}\right)^{-1}\left(1+\varepsilon_{k, j}^{-1}\right) a_{t}^{k, j}
\end{aligned}
$$


Now lets substitute these in (17) above to get

$$
\begin{aligned}
p_{t}^{k}(j) & =y_{t}-\left(1+\varepsilon_{k, j} \theta_{k, c}\right)^{-1} \frac{1+\varepsilon_{k, j} \theta_{k, c}\left(\frac{\left(\theta_{k, c}-1\right) \varphi^{k}}{1+\left(\theta_{k, c}-1\right) \varphi^{k}}\right)}{\sum_{k^{\prime}=a g, i n d}\left(\frac{\theta_{k^{\prime}, c} \varphi^{k^{\prime}}}{1+\left(\theta_{k^{\prime}, c}-1\right) \varphi^{k^{\prime}}}\right)} \Sigma_{t}-\frac{1}{\theta_{k, c}} v_{t}^{k, j} \\
& \left.-\left(1+\varepsilon_{k, j} \theta_{k, c}\right)^{-1}\left(\frac{\theta_{k, c}-1}{\theta_{k, c}}\right)\left(\frac{\varepsilon_{k, j} \theta_{k, c}}{1+\left(\theta_{k, c}-1\right) \varphi^{k}}\right)+\frac{\left(1+\varepsilon_{k, j} \theta_{k, c}\right)}{\theta_{k, c}}\right) v_{t}^{k, a} \\
& +\left(1+\varepsilon_{k, j} \theta_{k, c}\right)^{-1}\left(\frac{\varepsilon_{k, j} \theta_{k, c}}{\left.1+\left(\theta_{k, c}-1\right) \varphi^{k}\right) \tilde{\alpha}_{t}^{k}}\right) \\
& +\left(1+\varepsilon_{k, j} \theta_{k, c}\right)^{-1} \frac{1+\varepsilon_{k, j} \theta_{k, c}\left(\frac{\left(\theta_{k, c}-1\right) \varphi^{k}}{1+\left(\theta_{k, c}-1\right) \varphi^{k}}\right)}{\sum_{k^{\prime}=a g, i n d}\left(\frac{\theta_{k^{\prime}, c} \varphi^{k^{\prime}}}{1+\left(\theta_{k^{\prime}, c}-1\right) \varphi^{k^{\prime}}}\right)} \sum_{k^{\prime}=a g, i n d}\left[\left(\frac{1}{1+\left(\theta_{k^{\prime}, c}-1\right) \varphi^{k^{\prime}}}-\frac{1+\varepsilon_{k^{\prime}, j} \theta_{k^{\prime}, c}}{\left(1+\varepsilon_{k^{\prime}, j}\right) \theta_{k^{\prime}, c}}\right) v_{t}^{k^{\prime}, a}\right] \\
& +\left(1+\varepsilon_{k, j} \theta_{k, c}\right)^{-1} \frac{1+\varepsilon_{k, j} \theta_{k, c}\left(\frac{\left(\theta_{k, c}-1\right) \varphi^{k}}{1+\left(\theta_{k, c}-1\right) \varphi^{k}}\right)}{\sum_{k^{\prime}=a g, i n d}\left(\frac{\theta_{k^{\prime}, c} \varphi^{k^{\prime}}}{1+\left(\theta_{k^{\prime}, c}-1\right) \varphi^{k^{\prime}}}\right)} \sum_{k^{\prime}=a g, i n d}\left[\frac{\theta_{k^{\prime}, c} \varphi^{k^{\prime}}}{1+\left(\theta_{k^{\prime}, c}-1\right) \varphi^{k^{\prime}}} \tilde{\alpha}_{t}^{k^{\prime}}\right] .
\end{aligned}
$$

Here, note that $\left(\frac{\alpha_{k, j}}{1-\alpha_{k, j}}\right) \equiv \varepsilon_{k, j}$ where $1-\alpha_{k, j}$ is the "energy-share" of each commodity producer.

Given the endogenous determination of $\Sigma_{t}$ however, we need to do further manipulations to write this solution in terms of $y_{t}$ and aggregate shocks. Moreover, we need to further manipulate to find a solution for the energy price $s_{t}$. For this purpose, lets first simplify the current solution for $s_{t}$ given in (10) to

$$
\begin{aligned}
s_{t}= & \frac{1}{\sum_{k^{\prime}=a g, \text { ind }}\left(\frac{\theta_{k^{\prime}, c} \varphi^{k^{\prime}}}{1+\left(\theta_{k^{\prime}, c}-1\right) \varphi^{k^{\prime}}}\right)} \sum_{k^{\prime}=a g, i n d}\left[\left(\frac{1}{1+\left(\theta_{k^{\prime}, c}-1\right) \varphi^{k^{\prime}}}-\left(1+\frac{1}{\varepsilon_{k^{\prime}, j} \theta_{k^{\prime}, c}}\right)\left(1+\varepsilon_{k^{\prime}, j}^{-1}\right)^{-1}\right) v_{t}^{k^{\prime}, a}\right] \\
& -\frac{1}{\sum_{k^{\prime}=a g, \text { ind }}\left(\frac{\theta_{k^{\prime}, c} \varphi^{k^{\prime}}}{1+\left(\theta_{k^{\prime}, c}-1\right) \varphi^{k^{\prime}}}\right)} \sum_{t}+y_{t} \\
& +\frac{1}{\sum_{k^{\prime}=a g, \text { ind }}\left(\frac{\theta_{k^{\prime}, c} \varphi^{k^{\prime}}}{1+\left(\theta_{k^{\prime}, c}-1\right) \varphi^{k^{\prime}}}\right)} \sum_{k^{\prime}=a g, \text { ind }}\left[\left(\frac{\theta_{k^{\prime}, c} \varphi^{k^{\prime}}}{1+\left(\theta_{k^{\prime}, c}-1\right) \varphi^{k^{\prime}}}\right) \tilde{\alpha}_{t}^{k^{\prime}}\right]
\end{aligned}
$$

Next, we have from the firm/supply side of the energy sector given in (8)

$$
\frac{\Sigma_{t}}{\Sigma}=\frac{1}{\left(1-(1-\gamma)\left(1+\frac{1}{\eta}\right)^{-1}\right)} \Xi_{t}+\frac{(1-\gamma)\left(1+\frac{1}{\eta}\right)^{-1}}{\left(1-(1-\gamma)\left(1+\frac{1}{\eta}\right)^{-1}\right)}\left[s_{t}-\sigma y_{t}\right]
$$

Lets use the two expressions above to solve for $\Sigma_{t}$ as a function of $y_{t}$ and aggregate shocks We 
substitute for and get

$$
\begin{aligned}
& \Sigma^{-1} \Sigma_{t}=\frac{1}{\left(1-(1-\gamma)\left(1+\frac{1}{\eta}\right)^{-1}\right)} \Xi_{t} \\
& +\frac{\frac{(1-\gamma)\left(1+\frac{1}{\eta}\right)^{-1}}{\left(1-(1-\gamma)\left(1+\frac{1}{\eta}\right)^{-1}\right)}}{\sum_{k^{\prime}=a g, i n d}\left(\frac{\theta_{k^{\prime}, c} \varphi^{k^{\prime}}}{1+\left(\theta_{k^{\prime}, c}-1\right) \varphi^{k^{\prime}}}\right)} \sum_{k^{\prime}=a g, \text { ind }}\left[\left(\frac{1}{1+\left(\theta_{k^{\prime}, c}-1\right) \varphi^{k^{\prime}}}-\left(1+\frac{1}{\varepsilon_{k^{\prime}, j} \theta_{k^{\prime}, c}}\right)\left(1+\varepsilon_{k^{\prime}, j}^{-1}\right)^{-1}\right) v_{t}^{k^{\prime}, a}\right] \\
& -\frac{\frac{(1-\gamma)\left(1+\frac{1}{\eta}\right)^{-1}}{\left(1-(1-\gamma)\left(1+\frac{1}{\eta}\right)^{-1}\right)}}{\sum_{k^{\prime}=a g, i n d}\left(\frac{\theta_{k^{\prime}, c} \varphi^{k^{\prime}}}{1+\left(\theta_{k^{\prime}, c}-1\right) \varphi^{k^{\prime}}}\right)} \Sigma_{t}+\frac{(1-\gamma)\left(1+\frac{1}{\eta}\right)^{-1}}{\left(1-(1-\gamma)\left(1+\frac{1}{\eta}\right)^{-1}\right)} y_{t} \\
& +\frac{\frac{(1-\gamma)\left(1+\frac{1}{\eta}\right)^{-1}}{\left(1-(1-\gamma)\left(1+\frac{1}{\eta}\right)^{-1}\right)}}{\sum_{k^{\prime}=a g, i n d}\left(\frac{\theta_{k^{\prime}, c} \varphi^{k^{\prime}}}{1+\left(\theta_{k^{\prime}, c}-1\right) \varphi^{k^{\prime}}}\right)} \sum_{k^{\prime}=a g, \text { ind }}\left[\left(\frac{\theta_{k^{\prime}, c} \varphi^{k^{\prime}}}{1+\left(\theta_{k^{\prime}, c}-1\right) \varphi^{k^{\prime}}}\right) \tilde{\alpha}_{t}^{k^{\prime}}\right] \\
& +\frac{(1-\gamma)\left(1+\frac{1}{\eta}\right)^{-1}}{\left(1-(1-\gamma)\left(1+\frac{1}{\eta}\right)^{-1}\right)}\left(-\sigma y_{t}\right)
\end{aligned}
$$

For ease of notation, we define

$$
\gamma_{\eta} \equiv(1-\gamma)\left(1+\frac{1}{\eta}\right)^{-1}
$$

where note that $\gamma_{\eta}=0$ when $\gamma=1$, the case where energy good supply is exogenous. Then,

$$
\begin{gathered}
\left(\Sigma^{-1}+\frac{\frac{\gamma_{\eta}}{\left(1-\gamma_{\eta}\right)}}{\sum_{k^{\prime}=a g, \text { ind }}\left(\frac{\theta_{k^{\prime}, c} \varphi^{k^{\prime}}}{1+\left(\theta_{k^{\prime}, c}-1\right) \varphi^{k^{\prime}}}\right)}\right) \Sigma_{t}=\frac{1}{\left(1-\gamma_{\eta}\right)} \Xi_{t}+\frac{\gamma_{\eta}}{\left(1-\gamma_{\eta}\right)}\left((1-\sigma) y_{t}\right) \\
+\frac{\frac{\gamma_{\eta}}{\left(1-\gamma_{\eta}\right)}}{\sum_{k^{\prime}=a g, \text { ind }}\left(\frac{\theta_{k^{\prime}, c} \varphi^{k^{\prime}}}{1+\left(\theta_{k^{\prime}, c}-1\right) \varphi^{k^{\prime}}}\right)} \sum_{k^{\prime}=a g, \text { ind }}\left(\left(\frac{1}{1+\left(\theta_{k^{\prime}, c}-1\right) \varphi^{k^{\prime}}}-\left(1+\frac{1}{\varepsilon_{k^{\prime}, j} \theta_{k^{\prime}, c}}\right)\left(1+\varepsilon_{k^{\prime}, j}^{-1}\right)^{-1}\right) v_{t}^{k^{\prime}, a}\right) \\
+\frac{\frac{\gamma_{\eta}}{\left(1-\gamma_{\eta}\right)}}{\sum_{k^{\prime}=a g, \text { ind }}\left(\frac{\theta_{k^{\prime}, c} \varphi^{k^{\prime}}}{1+\left(\theta_{k^{\prime}, c}-1\right) \varphi^{k^{\prime}}}\right)} \sum_{k^{\prime}=a g, \text { ind }}\left(\left(\frac{\theta_{k^{\prime}, c} \varphi^{k^{\prime}}}{1+\left(\theta_{k^{\prime}, c}-1\right) \varphi^{k^{\prime}}}\right) \tilde{\alpha}_{t}^{k^{\prime}}\right)
\end{gathered}
$$

Here, (19) is important so that we can plug this back into the earlier solution for commodity prices. In particular, for ease of notation lets define

$$
\frac{1+\varepsilon_{k, j} \theta_{k, c}\left(\frac{\left(\theta_{k, c}-1\right) \varphi^{k}}{1+\left(\theta_{k, c}-1\right) \varphi^{k}}\right)}{\sum_{k^{\prime}=a g, \text { ind }}\left(\frac{\theta_{k^{\prime}, c} \varphi^{k^{\prime}}}{1+\left(\theta_{k^{\prime}, c}-1\right) \varphi^{k^{\prime}}}\right)} \equiv \sum_{j, c}^{k}
$$


and lets define the following for use in (19)

$$
\Sigma_{\eta} \equiv\left(\Sigma^{-1}+\frac{\frac{\gamma_{\eta}}{\left(1-\gamma_{\eta}\right)}}{\sum_{k^{\prime}=a g, i n d}\left(\frac{\theta_{k^{\prime}, c} \varphi^{k^{\prime}}}{1+\left(\theta_{k^{\prime}, c}-1\right) \varphi^{k^{\prime}}}\right)}\right)
$$

where note that $\Sigma_{\eta}=\Sigma^{-1}$ when $\gamma=1$ as then $\gamma_{\eta}=0$. Then, plugging in (19) gives

$$
\begin{aligned}
p_{t}^{k}(j) & =\left(1-\left(1+\varepsilon_{k, j} \theta_{k, c}\right)^{-1} \Sigma_{j, c}^{k} \Sigma_{\eta}^{-1} \frac{\gamma_{\eta}}{\left(1-\gamma_{\eta}\right)}(1-\sigma)\right) y_{t}-\frac{1}{\theta_{k, c}} v_{t}^{k, j} \\
- & \frac{\left(1+\varepsilon_{k, j} \theta_{k, c}\right)^{-1} \Sigma_{j, c}^{k} \Sigma_{\eta}^{-1} \Xi_{t}}{\left(1-\gamma_{\eta}\right)} \\
+ & \frac{\left(1+\varepsilon_{k, j} \theta_{k, c}\right)^{-1}\left(1+\frac{\varepsilon_{k, j} \theta_{k, c}\left(\theta_{k, c}-1\right) \varphi^{k}}{1+\left(\theta_{k, c}-1\right) \varphi^{k}}-\Sigma_{j, c}^{k} \Sigma_{\eta}^{-1} \frac{\gamma_{\eta}}{\left(1-\gamma_{\eta}\right)}\right)}{\sum_{k^{\prime}=a g, i n d}\left(\frac{\theta_{k^{\prime}, c} \varphi^{k^{\prime}}}{1+\left(\theta_{k^{\prime}, c}-1\right) \varphi^{k^{\prime}}}\right)} \sum_{k^{\prime}=a g, i n d}\left[\left(\frac{1}{1+\left(\theta_{k^{\prime}, c}-1\right) \varphi^{k^{\prime}}}-\frac{1+\varepsilon_{k^{\prime}, j} \theta_{k^{\prime}, c}}{\left(1+\varepsilon_{k^{\prime}, j}\right) \theta_{k^{\prime}, c}}\right) v_{t}^{k^{\prime}, a}\right] \\
+ & \frac{\left(1+\varepsilon_{k, j} \theta_{k, c}\right)^{-1}\left(1+\frac{\varepsilon_{k, j} \theta_{k, c}\left(\theta_{k, c}-1\right) \varphi^{k}}{1+\left(\theta_{k, c}-1\right) \varphi^{k}}-\Sigma_{j, c}^{k} \Sigma_{\eta}^{-1} \frac{\gamma_{\eta}}{\left(1-\gamma_{\eta}\right)}\right)}{\sum_{k^{\prime}=a g, i n d}\left(\frac{\theta_{k^{\prime}, c} \varphi^{k^{\prime}}}{1+\left(\theta_{k^{\prime}, c}-1\right) \varphi^{k^{\prime}}}\right)} \sum_{k^{\prime}=a g, i n d}\left[\left(\frac{\theta_{k^{\prime}, c} \varphi^{k^{\prime}}}{1+\left(\theta_{k^{\prime}, c}-1\right) \varphi^{k^{\prime}}}\right) \tilde{\alpha}_{t}^{k^{\prime}}\right] \\
& -\left(1+\varepsilon_{k, j} \theta_{k, c}\right)^{-1}\left(\left(\frac{\theta_{k, c}-1}{\theta_{k, c}}\right)\left(\frac{\varepsilon_{k, j} \theta_{k, c}}{1+\left(\theta_{k, c}-1\right) \varphi^{k}}\right)+\frac{\left(1+\varepsilon_{k, j} \theta_{k, c}\right)}{\theta_{k, c}}\right) v_{t}^{k, a} \\
+ & \left(1+\varepsilon_{k, j} \theta_{k, c}\right)^{-1}\left(\frac{\varepsilon_{k, j} \theta_{k, c}}{1+\left(\theta_{k, c}-1\right) \varphi^{k}}\right) \tilde{\alpha}_{t}^{k}
\end{aligned}
$$

where (20) now gives a version of the solution for commodity prices.

Aggregate output solution in terms of shocks We can also similarly give the final solution for aggregate output. Currently, we have (12), where we now substitute in for the solution to $\Sigma_{t}$, to get

$$
\begin{aligned}
& y_{t}=\Omega^{-1} \varphi_{y}\left(a_{t}+\kappa_{n} \varepsilon_{t}^{n}+\sum_{k^{\prime}=a g, i n d}\left(\kappa_{v}^{k^{\prime}} v_{t}^{k^{\prime}, a}+\kappa_{\tilde{a}} \tilde{a}_{t}^{k^{\prime}}-\kappa_{\alpha}^{k^{\prime}} \tilde{\alpha}_{t}^{k^{\prime}}\right)\right) \\
&+\quad \Omega^{-1} \Sigma_{\eta}^{-1} \varphi_{y} \kappa_{\Sigma}\left[\frac{1}{\left(1-\gamma_{\eta}\right)} \Xi_{t}\right] \\
&+ \frac{\Sigma_{\eta}^{-1} \varphi_{y} \kappa_{\Sigma} \frac{\gamma_{\eta}}{\left(1-\gamma_{\eta}\right)}}{\sum_{k^{\prime}=a g, i n d}\left(\frac{\theta_{k^{\prime}, c} \varphi^{k^{\prime}}}{1+\left(\theta_{k^{\prime}, c}-1\right) \varphi^{k^{\prime}}}\right)} \sum_{k^{\prime}=a g, \text { ind }}\left[\left(\frac{1}{1+\left(\theta_{k^{\prime}, c}-1\right) \varphi^{k^{\prime}}}\right) v_{t}^{k^{\prime}, a}\right] \\
&-\Omega^{-1} \frac{\Sigma_{\eta}^{-1} \varphi_{y} \kappa_{\Sigma} \frac{\gamma_{\eta}}{\left(1-\gamma_{\eta}\right)}}{\sum_{k^{\prime}=a g, i n d}\left(\frac{\theta_{k^{\prime}, c} \varphi^{k^{\prime}}}{1+\left(\theta_{k^{\prime}, c}-1\right) \varphi^{k^{\prime}}}\right)} \sum_{k^{\prime}=a g, \text { ind }}\left[\left(1+\frac{1}{\varepsilon_{k^{\prime}, j} \theta_{k^{\prime}, c}}\right)\left(1+\varepsilon_{k^{\prime}, j}^{-1}\right)^{-1} v_{t}^{k^{\prime}, a}\right] \\
&+\Omega^{-1} \frac{\Sigma_{\eta}^{-1} \varphi_{y} \kappa_{\Sigma} \frac{\gamma_{\eta}}{\left(1-\gamma_{\eta}\right)}}{\sum_{k^{\prime}=a g, i n d}\left(\frac{\theta_{k^{\prime}, c} \varphi^{k^{\prime}}}{1+\left(\theta_{k^{\prime}, c}-1\right) \varphi^{k^{\prime}}}\right)} \sum_{k^{\prime}=a g, \text { ind }}\left[\left(\frac{\theta_{k^{\prime}, c} \varphi^{k^{\prime}}}{1+\left(\theta_{k^{\prime}, c}-1\right) \varphi^{k^{\prime}}}\right) \tilde{\alpha}_{t}^{k^{\prime}}\right]
\end{aligned}
$$


where

$$
\Omega=1-\Sigma_{\eta}^{-1} \varphi_{y} \kappa_{\Sigma} \frac{\gamma_{\eta}}{\left(1-\gamma_{\eta}\right)}(1-\sigma)
$$

which means that the coefficients just for $a_{t}, \varepsilon_{t}^{n}$ are

$$
\left[\Omega^{-1} \varphi_{y}\right] a_{t} \quad,\left[\Omega^{-1} \varphi_{y} \kappa_{n}\right] \varepsilon_{t}^{n}
$$

respectively. Here, note that we have defined

$$
\begin{aligned}
\varphi_{y} & \equiv \frac{\left(1+\frac{1}{\eta}\right)}{\left(1+\frac{1}{\eta}\right)-(1-\sigma)\left(1-\alpha^{a g}-\alpha^{i n d}\right)} \\
\kappa_{n} & \equiv \frac{\left(1-\alpha^{a g}-\alpha^{i n d}\right)}{\left(1+\frac{1}{\eta}\right)} \\
\kappa_{\Sigma} & \equiv \frac{\sum_{k^{\prime}=a g, \text { ind }} \alpha^{k^{\prime}}\left(\frac{\theta_{k^{\prime}, \varphi^{k^{\prime}}}}{1+\left(\theta_{k^{\prime}, c}-1\right) \varphi^{k^{\prime}}}\right)}{\sum_{k^{\prime}=a g, \text { ind }}\left(\frac{\theta_{k^{\prime}, c} \varphi^{k^{\prime}}}{1+\left(\theta_{k^{\prime}, c}-1\right) \varphi^{k^{\prime}}}\right)} .
\end{aligned}
$$

This solution given in (21), above for aggregate output is the two-sector counterpart to the version that appears in the text in Equation (1). Then as in the text, we can define,

$$
\begin{aligned}
y_{t}=y_{t}^{n c}\left(a_{t}, \varepsilon_{t}^{n}\right)+ & \Omega^{-1} \varphi_{y}\left(\sum_{k^{\prime}=a g, i n d}\left(\kappa_{v}^{k^{\prime}} v_{t}^{k^{\prime}, a}+\kappa_{\tilde{a}} \tilde{a}_{t}^{k^{\prime}}-\kappa_{\alpha}^{k^{\prime}} \tilde{\alpha}_{t}^{k^{\prime}}\right)\right) \\
+ & \Omega^{-1} \Sigma_{\eta}^{-1} \varphi_{y} \kappa_{\Sigma}\left[\frac{1}{\left(1-\gamma_{\eta}\right)} \Xi_{t}\right] \\
+\Omega^{-1} & \frac{\Sigma_{\eta}^{-1} \varphi_{y} \kappa_{\Sigma} \frac{\gamma_{\eta}}{\left(1-\gamma_{\eta}\right)}}{\sum_{k^{\prime}=a g, i n d}\left(\frac{\theta_{k^{\prime}, c} \varphi^{k^{\prime}}}{1+\left(\theta_{k^{\prime}, c}-1\right) \varphi^{k^{\prime}}}\right)} \sum_{k^{\prime}=a g, i n d}\left[\left(\frac{1}{1+\left(\theta_{k^{\prime}, c}-1\right) \varphi^{k^{\prime}}}\right) v_{t}^{k^{\prime}, a}\right] \\
-\Omega^{-1} & \frac{\Sigma_{\eta}^{-1} \varphi_{y} \kappa_{\Sigma} \frac{\gamma_{\eta}}{\left(1-\gamma_{\eta}\right)}}{\sum_{k^{\prime}=a g, i n d}\left(\frac{\theta_{k^{\prime}, c} \varphi^{k^{\prime}}}{1+\left(\theta_{k^{\prime}, c}-1\right) \varphi^{k^{\prime}}}\right)} \sum_{k^{\prime}=a g, i n d}\left[\left(1+\frac{1}{\varepsilon_{k^{\prime}, j} \theta_{k^{\prime}, c}}\right)\left(1+\varepsilon_{k^{\prime}, j}^{-1}\right)^{-1} v_{t}^{k^{\prime}, a}\right] \\
+\Omega^{-1} & \frac{\Sigma_{\eta}^{-1} \varphi_{y} \kappa_{\Sigma} \frac{\gamma_{\eta}}{\left(1-\gamma_{\eta}\right)}}{\sum_{k^{\prime}=a g, i n d}\left(\frac{\theta_{k^{\prime}, c} \varphi^{k^{\prime}}}{1+\left(\theta_{k^{\prime}, c}-1\right) \varphi^{k^{\prime}}}\right)} \sum_{k^{\prime}=a g, i n d}\left[\left(\frac{\theta_{k^{\prime}, c} \varphi^{k^{\prime}}}{1+\left(\theta_{k^{\prime}, c}-1\right) \varphi^{k^{\prime}}}\right) \tilde{\alpha}_{t}^{k^{\prime}}\right]
\end{aligned}
$$

where we have defined

$$
y_{t}^{n c}\left(a_{t}, \varepsilon_{t}^{n}\right)=\Omega^{-1} \varphi_{y}\left(a_{t}+\kappa_{n} \varepsilon_{t}^{n}\right) .
$$

This expression given in (22) above for aggregate output and $y_{t}^{n c}\left(a_{t}, \varepsilon_{t}^{n}\right)$ is the two-sector counterpart to the version that appears in the text of the paper.

Solution for commodity prices Consider the solution for commodity prices above in (20), where below we sign the coefficient only on aggregate output

$$
p_{t}(j)=\left(1-\left(1+\varepsilon_{k, j} \theta_{k, c}\right)^{-1} \Sigma_{j, c}^{k} \Sigma_{\eta}^{-1} \frac{\gamma_{\eta}}{\left(1-\gamma_{\eta}\right)}(1-\sigma)\right) y_{t}
$$


where we have

$$
\begin{gathered}
\Sigma_{j, c}^{k} \equiv \frac{1+\varepsilon_{k, j} \theta_{k, c}\left(\frac{\left(\theta_{k, c}-1\right) \varphi^{k}}{1+\left(\theta_{k, c}-1\right) \varphi^{k}}\right)}{\sum_{k^{\prime}=a g, i n d}\left(\frac{\theta_{k^{\prime}, \varphi^{k^{\prime}}}}{1+\left(\theta_{k^{\prime}, c}-1\right) \varphi^{k^{\prime}}}\right)} \\
\varepsilon_{k, j} \equiv\left(\frac{\alpha_{k, j}}{1-\alpha_{k, j}}\right) \\
\varphi^{k} \equiv \int_{0}^{1}\left(1+\varepsilon_{k, j} \theta_{k, c}\right)^{-1} d j \\
\Sigma_{\eta} \equiv\left(\Sigma^{-1}+\frac{\frac{\gamma_{\eta}}{\left(1-\gamma_{\eta}\right)}}{\sum_{k^{\prime}=a g, i n d}\left(\frac{\theta_{k^{\prime}, c} \varphi^{k^{\prime}}}{1+\left(\theta_{k^{\prime}, c}-1\right) \varphi^{k^{\prime}}}\right)}\right) \\
\Sigma=\int_{0}^{1}\left(1-\alpha_{i n d, j}\right) d j+\int_{0}^{1}\left(1-\alpha_{a g, j}\right) d j \\
\gamma_{\eta} \equiv(1-\gamma)\left(1+\frac{1}{\eta}\right)^{-1}
\end{gathered}
$$

and $0 \leq \gamma<1 ; 0 \leq \alpha_{k, j}<1 ; \eta>0 ; \theta_{k, c}>1$. Given this, we have

$$
\begin{aligned}
& \varepsilon_{k, j} \equiv\left(\frac{\alpha_{k, j}}{1-\alpha_{k, j}}\right)>0 \\
& \varphi^{k} \equiv \int_{0}^{1}\left(1+\varepsilon_{k, j} \theta_{k, c}\right)^{-1} d j>0 \\
& \Sigma_{j, c}^{k} \equiv \frac{1+\varepsilon_{k, j} \theta_{k, c}\left(\frac{\left(\theta_{k, c}-1\right) \varphi^{k}}{1+\left(\theta_{k, c}-1\right) \varphi^{k}}\right)}{\sum_{k^{\prime}=a g, i n d}\left(\frac{\theta_{k^{\prime}, c} \varphi^{k^{\prime}}}{1+\left(\theta_{k^{\prime}, c}-1\right) \varphi^{k^{\prime}}}\right)}>0 \\
& \Sigma=\int_{0}^{1}\left(1-\alpha_{i n d, j}\right) d j+\int_{0}^{1}\left(1-\alpha_{a g, j}\right) d j>0 \\
& \gamma_{\eta} \equiv(1-\gamma)\left(1+\frac{1}{\eta}\right)^{-1}>0 \text { and } \gamma_{\eta}<1 \\
& \Sigma_{\eta} \equiv\left(\Sigma^{-1}+\frac{\frac{\gamma_{\eta}}{\left(1-\gamma_{\eta}\right)}}{\sum_{k^{\prime}=a g, i n d}\left(\frac{\theta_{k^{\prime}, c} \varphi^{k^{\prime}}}{1+\left(\theta_{k^{\prime}, c}-1\right) \varphi^{k^{\prime}}}\right)}\right)>0
\end{aligned}
$$

which means that a sufficient condition for

$$
\left(1-\left(1+\varepsilon_{k, j} \theta_{k, c}\right)^{-1} \Sigma_{j, c}^{k} \Sigma_{\eta}^{-1} \frac{\gamma_{\eta}}{\left(1-\gamma_{\eta}\right)}(1-\sigma)\right)>0
$$


is that

$$
\sigma>1 .
$$

Moreover, note that the two components/shocks that only affect aggregate output $y_{t}$ have the following coefficients in the final solution for $y_{t}$

$$
\begin{aligned}
& {\left[\left(1-\Sigma_{\eta}^{-1} \varphi_{y} \kappa_{\Sigma} \frac{\gamma_{\eta}}{\left(1-\gamma_{\eta}\right)}(1-\sigma)\right)^{-1} \varphi_{y}\right] a_{t}} \\
& {\left[\left(1-\Sigma_{\eta}^{-1} \varphi_{y} \kappa_{\Sigma} \frac{\gamma_{\eta}}{\left(1-\gamma_{\eta}\right)}(1-\sigma)\right)^{-1} \varphi_{y} \kappa_{n}\right] \varepsilon_{t}^{n}}
\end{aligned}
$$

respectively. That is, here, we are trying to sign the coefficients on $y_{t}^{n c}\left(a_{t}, \varepsilon_{t}^{n}\right)$ that we have defined in (23). Note that

$$
\begin{aligned}
\varphi_{y} & \equiv \frac{\left(1+\frac{1}{\eta}\right)}{\left(1+\frac{1}{\eta}\right)-(1-\sigma)\left(1-\alpha^{a g}-\alpha^{i n d}\right)} \\
\kappa_{n} & \equiv \frac{\left(1-\alpha^{a g}-\alpha^{i n d}\right)}{\left(1+\frac{1}{\eta}\right)} \\
\kappa_{\Sigma} & \equiv \frac{\sum_{k^{\prime}=a g, i n d} \alpha^{k^{\prime}}\left(\frac{\theta_{k^{\prime}, \varphi^{k^{\prime}}}}{1+\left(\theta_{k^{\prime}, c}-1\right) \varphi^{k^{\prime}}}\right)}{\sum_{k^{\prime}=a g, \text { ind }}\left(\frac{\theta_{k^{\prime}, c} \varphi^{k^{\prime}}}{1+\left(\theta_{k^{\prime}, c}-1\right) \varphi^{k^{\prime}}}\right)}
\end{aligned}
$$

Then, when $\sigma>1$, we have

$$
\begin{aligned}
& \varphi_{y} \equiv \frac{\left(1+\frac{1}{\eta}\right)}{\left(1+\frac{1}{\eta}\right)-(1-\sigma)\left(1-\alpha^{a g}-\alpha^{i n d}\right)}>0 \\
& \kappa_{n} \equiv \frac{\left(1-\alpha^{a g}-\alpha^{i n d}\right)}{\left(1+\frac{1}{\eta}\right)}>0 \\
& \kappa_{\Sigma} \equiv \frac{\sum_{k^{\prime}=a g, \text { ind }} \alpha^{k^{\prime}}\left(\frac{\theta_{k^{\prime}, \varphi^{k^{\prime}}}}{1+\left(\theta_{k^{\prime}, c}-1\right) \varphi^{k^{\prime}}}\right)}{\sum_{k^{\prime}=a g, \text { ind }}\left(\frac{\theta_{k^{\prime}, c} \varphi^{k^{\prime}}}{1+\left(\theta_{k^{\prime}, c}-1\right) \varphi^{k^{\prime}}}\right)}>0
\end{aligned}
$$

which implies that

$$
\begin{gathered}
{\left[\left(1-\Sigma_{\eta}^{-1} \varphi_{y} \kappa_{\Sigma} \frac{\gamma_{\eta}}{\left(1-\gamma_{\eta}\right)}(1-\sigma)\right)^{-1} \varphi_{y}\right]>0} \\
{\left[\left(1-\Sigma_{\eta}^{-1} \varphi_{y} \kappa_{\Sigma} \frac{\gamma_{\eta}}{\left(1-\gamma_{\eta}\right)}(1-\sigma)\right)^{-1} \varphi_{y} \kappa_{n}\right]>0}
\end{gathered}
$$


Next, consider the solution for commodity prices again, where we now look at the coefficient on the energy shock

$$
p_{t}(j)=-\left(1+\varepsilon_{k, j} \theta_{k, c}\right)^{-1} \Sigma_{j, c}^{k} \Sigma_{\eta}^{-1} \frac{1}{\left(1-\gamma_{\eta}\right)} \Xi_{t}
$$

and where we now want to check how the coefficient depends on $1-\alpha_{j}$. From before, note the various definitions of the parameters above

$$
\begin{gathered}
\sum_{j, c}^{k} \equiv \frac{1+\varepsilon_{k, j} \theta_{k, c}\left(\frac{\left(\theta_{k, c}-1\right) \varphi^{k}}{1+\left(\theta_{k, c}-1\right) \varphi^{k}}\right)}{\sum_{k^{\prime}=a g, i n d}\left(\frac{\theta_{k^{\prime}, c} \varphi^{k^{\prime}}}{1+\left(\theta_{k^{\prime}, c}-1\right) \varphi^{k^{\prime}}}\right)} \\
\varepsilon_{k, j} \equiv\left(\frac{\alpha_{k, j}}{1-\alpha_{k, j}}\right) \\
\varphi^{k} \equiv \int_{0}^{1}\left(1+\varepsilon_{k, j} \theta_{k, c}\right)^{-1} d j \\
\Sigma_{\eta} \equiv\left(\Sigma^{-1}+\frac{\frac{\gamma_{\eta}}{\left(1-\gamma_{\eta}\right)}}{\sum_{k^{\prime}=a g, i n d}\left(\frac{\theta_{k^{\prime}, c} \varphi^{k^{\prime}}}{1+\left(\theta_{k^{\prime}, c}-1\right) \varphi^{k^{\prime}}}\right)}\right) \\
\Sigma=\int_{0}^{1}\left(1-\alpha_{i n d, j}\right) d j+\int_{0}^{1}\left(1-\alpha_{a g, j}\right) d j \\
\gamma_{\eta} \equiv(1-\gamma)\left(1+\frac{1}{\eta}\right)^{-1}
\end{gathered}
$$

Thus, first we can manipulate the component that depends on $1-\alpha_{k, j}$

$$
\begin{aligned}
\left(1+\varepsilon_{k, j} \theta_{k, c}\right)^{-1} \Sigma_{j, c}^{k} & =\left(1+\varepsilon_{k, j} \theta_{k, c}\right)^{-1}\left[\frac{1+\varepsilon_{k, j} \theta_{k, c}\left(\frac{\left(\theta_{k, c}-1\right) \varphi^{k}}{1+\left(\theta_{k, c}-1\right) \varphi^{k}}\right)}{\sum_{k^{\prime}=a g, i n d}\left(\frac{\theta_{k^{\prime}, c} \varphi^{k^{\prime}}}{1+\left(\theta_{k^{\prime}, c}-1\right) \varphi^{k^{\prime}}}\right)}\right] \\
& =\frac{\left(1+\left(\theta_{k, c}-1\right) \varphi^{k}\right)^{-1}}{\sum_{k^{\prime}=a g, i n d}\left(\frac{\theta_{k^{\prime}, c} \varphi^{k^{\prime}}}{1+\left(\theta_{k^{\prime}, c}-1\right) \varphi^{k^{\prime}}}\right)}\left(\frac{1}{1+\varepsilon_{k, j} \theta_{k, c}}+\left(\theta_{k, c}-1\right) \varphi^{k}\right)
\end{aligned}
$$

Then,

$$
\frac{\partial\left(1+\varepsilon_{j} \theta_{c}\right)^{-1} \Sigma_{j, c}}{\partial \varepsilon_{j}}=-\frac{\frac{\theta_{k, c}}{1+\left(\theta_{k, c}-1\right) \varphi^{k}}\left(1+\varepsilon_{k, j} \theta_{k, c}\right)^{-2}}{\sum_{k^{\prime}=a g, i n d}\left(\frac{\theta_{k^{\prime}, c} \varphi^{k^{\prime}}}{1+\left(\theta_{k^{\prime}, c}-1\right) \varphi^{k^{\prime}}}\right)}<0
$$

The term multiplying this above, which is $\Sigma_{\eta}^{-1} \frac{1}{\left(1-\gamma_{\eta}\right)}$ is positive. Then, since $\varepsilon_{k, j} \equiv\left(\frac{\alpha_{k, j}}{1-\alpha_{k, j}}\right)$, this means that when the share of energy in the commodity production, which is given by $\left(1-\alpha_{k, j}\right)$ increases, then the coefficient in the factor structure of commodity prices on the "energy shock" also increases. 
Factor structure of commodity prices Finally, note that we use the definition of $y_{t}^{n c}\left(a_{t}, \varepsilon_{t}^{n}\right)$ given in (23) in (20) to derive the factor structure of prices in the form presented in the text. Then,

$$
\begin{aligned}
& p_{t}^{k}(j)=\left(1-\left(1+\varepsilon_{k, j} \theta_{k, c}\right)^{-1} \Sigma_{j, c}^{k} \Sigma_{\eta}^{-1} \frac{\gamma_{\eta}}{\left(1-\gamma_{\eta}\right)}(1-\sigma)\right) y_{t}^{n c}\left(a_{t}, \varepsilon_{t}^{n}\right) \\
& +\left(1-\left(1+\varepsilon_{k, j} \theta_{k, c}\right)^{-1} \Sigma_{j, c}^{k} \Sigma_{\eta}^{-1} \frac{\gamma_{\eta}}{\left(1-\gamma_{\eta}\right)}(1-\sigma)\right) \Omega^{-1} \varphi_{y}\left(\sum_{k^{\prime}=a g, i n d}\left(\kappa_{v}^{k^{\prime}} v_{t}^{k^{\prime}, a}+\kappa_{\tilde{a}} \tilde{a}_{t}^{k^{\prime}}-\kappa_{\alpha}^{k^{\prime}} \tilde{\alpha}_{t}^{k^{\prime}}\right)\right) \\
& +\frac{\Omega^{-1} \Sigma_{\eta}^{-1}}{\left(1-\gamma_{\eta}\right)}\left(\varphi_{y} \kappa_{\Sigma}-\left(1+\varepsilon_{k, j} \theta_{k, c}\right)^{-1} \Sigma_{j, c}^{k}\right) \Xi_{t} \\
& +\frac{\Omega^{-1} \Sigma_{\eta}^{-1} \frac{\gamma_{\eta}}{\left(1-\gamma_{\eta}\right)}\left(\varphi_{y} \kappa_{\Sigma}-\left(1+\varepsilon_{k, j} \theta_{k, c}\right)^{-1} \sum_{j, c}^{k}\right)}{\sum_{k^{\prime}=a g, \text { ind }}\left(\frac{\theta_{k^{\prime}, \varphi^{k^{\prime}}}}{1+\left(\theta_{k^{\prime}, c}-1\right) \varphi^{k^{\prime}}}\right)} \sum_{k^{\prime}=a g, i n d}\left[\left(\frac{1}{1+\left(\theta_{k^{\prime}, c}-1\right) \varphi^{k^{\prime}}}-\frac{1+\varepsilon_{k^{\prime}, j} \theta_{k^{\prime}, c}}{\left(1+\varepsilon_{k^{\prime}, j}\right) \theta_{k^{\prime}, c}}\right) v_{t}^{k^{\prime}, a}\right] \\
& +\frac{1-\left(1+\varepsilon_{k, j} \theta_{k, c}\right)^{-1} \frac{\varepsilon_{k, j} \theta_{k, c}}{1+\left(\theta_{k, c}-1\right) \varphi^{k}}}{\sum_{k^{\prime}=a g, \text { ind }}\left(\frac{\theta_{k^{\prime}, c} \varphi^{k^{\prime}}}{1+\left(\theta_{k^{\prime}, c}-1\right) \varphi^{k^{\prime}}}\right)} \sum_{k^{\prime}=a g, i n d}\left[\left(\frac{1}{1+\left(\theta_{k^{\prime}, c}-1\right) \varphi^{k^{\prime}}}-\frac{1+\varepsilon_{k^{\prime}, j} \theta_{k^{\prime}, c}}{\left(1+\varepsilon_{k^{\prime}, j}\right) \theta_{k^{\prime}, c}}\right) v_{t}^{k^{\prime}, a}\right] \\
& +\frac{\Omega^{-1} \Sigma_{\eta}^{-1} \frac{\gamma_{\eta}}{\left(1-\gamma_{\eta}\right)}\left(\varphi_{y} \kappa_{\Sigma}-\left(1+\varepsilon_{k, j} \theta_{k, c}\right)^{-1} \sum_{j, c}^{k}\right)}{\sum_{k^{\prime}=a g, \text { ind }}\left(\frac{\theta_{k^{\prime}, c} \varphi^{k^{\prime}}}{1+\left(\theta_{k^{\prime}, c}-1\right) \varphi^{k^{\prime}}}\right)} \sum_{k^{\prime}=a g, \text { ind }}\left[\left(\frac{\theta_{k^{\prime}, c} \varphi^{k^{\prime}}}{1+\left(\theta_{k^{\prime}, c}-1\right) \varphi^{k^{\prime}}}\right) \tilde{\alpha}_{t}^{k^{\prime}}\right] \\
& +\frac{1-\left(1+\varepsilon_{k, j} \theta_{k, c}\right)^{-1} \frac{\varepsilon_{k, j} \theta_{k, c}}{1+\left(\theta_{k, c}-1\right) \varphi^{k}}}{\sum_{k^{\prime}=a g, i n d}\left(\frac{\theta_{k^{\prime}, c} \varphi^{k^{\prime}}}{1+\left(\theta_{k^{\prime}, c}-1\right) \varphi^{k^{\prime}}}\right)} \sum_{k^{\prime}=a g, \text { ind }}\left[\left(\frac{\theta_{k^{\prime}, c} \varphi^{k^{\prime}}}{1+\left(\theta_{k^{\prime}, c}-1\right) \varphi^{k^{\prime}}}\right) \tilde{\alpha}_{t}^{k^{\prime}}\right] \\
& -\frac{1}{\theta_{k, c}} v_{t}^{k, j} \\
& -\left(1+\varepsilon_{k, j} \theta_{k, c}\right)^{-1}\left(\left(\frac{\theta_{k, c}-1}{\theta_{k, c}}\right)\left(\frac{\varepsilon_{k, j} \theta_{k, c}}{1+\left(\theta_{k, c}-1\right) \varphi^{k}}\right)+\frac{\left(1+\varepsilon_{k, j} \theta_{k, c}\right)}{\theta_{k, c}}\right) v_{t}^{k, a} \\
& +\left(1+\varepsilon_{k, j} \theta_{k, c}\right)^{-1}\left(\frac{\varepsilon_{k, j} \theta_{k, c}}{1+\left(\theta_{k, c}-1\right) \varphi^{k}}\right) \tilde{\alpha}_{t}^{k}
\end{aligned}
$$

This (24) above is the two-sector version of the expression that appears in Equation (4) in the text of the paper. 
The coefficient on energy shock is

$$
\begin{aligned}
-\frac{\Omega^{-1} \Sigma_{\eta}^{-1}}{\left(1-\gamma_{\eta}\right)}\left(\left(1+\varepsilon_{k, j} \theta_{k, c}\right)^{-1} \Sigma_{j, c}^{k}-\varphi_{y} \kappa_{\Sigma}\right) \Xi_{t}= & -\frac{\Omega^{-1} \Sigma_{\eta}^{-1}}{\left(1-\gamma_{\eta}\right)}\left(\frac{1-\left(\frac{1}{1+\left(\theta_{k, c}-1\right) \varphi^{k}}\right)+\frac{1}{1+\varepsilon_{k, j} \theta_{k, c}}\left(\frac{1}{1+\left(\theta_{k, c}-1\right) \varphi^{k}}\right)}{\sum_{k^{\prime}=a g, i n d}\left(\frac{\theta_{k^{\prime}, c} \varphi^{k^{\prime}}}{1+\left(\theta_{k^{\prime}, c}-1\right) \varphi^{k^{\prime}}}\right)}-\varphi_{y} \kappa_{\Sigma}\right) \\
= & -\frac{\Omega^{-1} \Sigma_{\eta}^{-1}}{\left(1-\gamma_{\eta}\right)}\left(\frac{\frac{\left(\theta_{k, c}-1\right) \varphi^{k}}{1+\left(\theta_{k, c}-1\right) \varphi^{k}}}{\sum_{k^{\prime}=a g, i n d}\left(\frac{\theta_{k^{\prime}, c} \varphi^{k^{\prime}}}{1+\left(\theta_{k^{\prime}, c}-1\right) \varphi^{k^{\prime}}}\right)}-\varphi_{y} \kappa_{\Sigma}\right) \\
& -\frac{\Omega^{-1} \Sigma_{\eta}^{-1}}{\left(1-\gamma_{\eta}\right)}\left(\frac{\left(\frac{1}{1+\left(\theta_{k, c}-1\right) \varphi^{k}}\right)}{\sum_{k^{\prime}=a g, i n d}\left(\frac{\theta_{k^{\prime}, c} \varphi^{k^{\prime}}}{1+\left(\theta_{k^{\prime}, c}-1\right) \varphi^{k^{\prime}}}\right)} \frac{1}{1+\varepsilon_{k, j} \theta_{k, c}}\right)
\end{aligned}
$$

Then,

$$
\frac{\partial}{\partial \varepsilon_{k, j}}\left[-\frac{\Omega^{-1} \Sigma_{\eta}^{-1}}{\left(1-\gamma_{\eta}\right)}\left(\left(1+\varepsilon_{k, j} \theta_{k, c}\right)^{-1} \Sigma_{j, c}^{k}-\varphi_{y} \kappa_{\Sigma}\right) \Xi_{t}\right]>0
$$

This implies that if the coefficient on the energy shock is negative, the coefficient is (in absolute term) decreasing in $\varepsilon_{k, j}$. 


\section{Appendix B: Price Observations Dropped}
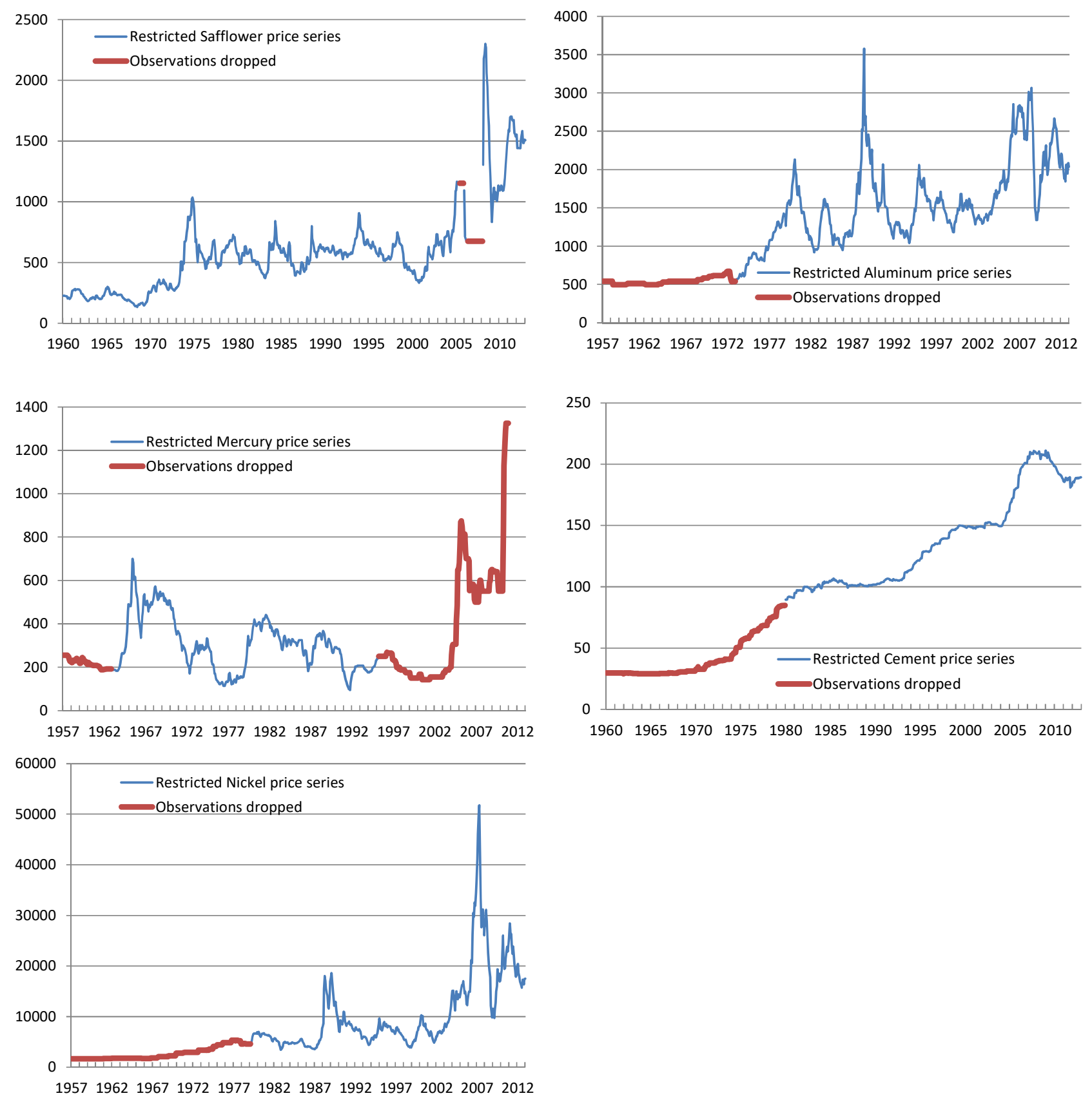

Notes: Each figure presents the price series used in the empirical analysis (light blue line: "Restricted X price series") and the observations dropped (thick red line: "Observations dropped). 


\section{Appendix C: Notes on Commodity Price Data}

\begin{tabular}{|c|c|c|c|c|}
\hline Commodity & Sources & Description & $\begin{array}{l}\text { Available } \\
\text { Sample }\end{array}$ & Additional Notes \\
\hline Apples & CRB & $\begin{array}{l}\text { Wholesale price of (delicious) apples in U.S. } \\
\text { until 1978:12, apple price received by } \\
\text { growers starting 1979:1 }\end{array}$ & $\begin{array}{l}1957: 1- \\
2011: 12\end{array}$ & $\begin{array}{l}\text { Data from } 1979: 1 \text { are apple prices received by growers. } \\
\text { Data prior to that are wholesale prices of (delicious) } \\
\text { applies in U.S., rescaled by the average price ratio of the } \\
\text { two series from } 1979: 1-1980: 12 \text {. Data prior to } 1979 \\
\text { have numerous missing values. }\end{array}$ \\
\hline Bananas & WB & $\begin{array}{l}\text { Bananas (Central and South America), major } \\
\text { brands, U.S. import price, free on truck } \\
\text { (f.o.t.) U.S. Gulf ports }\end{array}$ & $\begin{array}{l}1960: 1- \\
2013: 1\end{array}$ & \\
\hline Barley & $\mathrm{CRB} / \mathrm{WB}$ & $\begin{array}{l}\text { WB: Barley (Canada), feed, Western No. 1, } \\
\text { Winnipeg Commodity Exchange, spot, } \\
\text { wholesale farmers' price; CRB: No. } 3 \\
\text { straight Barley, Minneapolis Exchange }\end{array}$ & $\begin{array}{l}1957: 1- \\
2013: 1\end{array}$ & $\begin{array}{l}\text { Data from 1957:1-1959:12 are CRB series. Data from } \\
\text { 1960:1-2013:1 are WB series rescaled by the ratio of the } \\
\text { two series in 1960:1. }\end{array}$ \\
\hline Beef & IMF & $\begin{array}{l}\text { Australia and New Zealand, frozen boneless, } \\
85 \% \text { visible lean cow meat, U.S. import price } \\
\text { FOB port of entry }\end{array}$ & $\begin{array}{l}1957: 1- \\
2013: 1\end{array}$ & \\
\hline Cocoa & IMF & $\begin{array}{l}\text { International Cocoa Organization cash price; } \\
\text { average of the three nearest active futures } \\
\text { trading months in the New York Cocoa } \\
\text { Exchange at noon and the London Terminal } \\
\text { market at closing time, CIF U.S. and } \\
\text { European ports }\end{array}$ & $\begin{array}{l}1957: 1- \\
2012: 12\end{array}$ & \\
\hline Coffee & IMF & $\begin{array}{l}\text { International Coffee Organization; cash } \\
\text { prices for } 4 \text { kinds of beans: Brazilian } \\
\text { unwashed Arabica, Columbian mild } \\
\text { Arabica, other mild Arabica and Robustas }\end{array}$ & $\begin{array}{l}1957: 1- \\
2012: 12\end{array}$ & $\begin{array}{l}\text { Value for } 1957: 1 \text { is average across all four types of } \\
\text { coffee beans. Subsequent values are the equally } \\
\text { weighted average of percent change in price of each kind } \\
\text { of bean times the previous period's price. }\end{array}$ \\
\hline Corn & IMF & $\begin{array}{l}\text { U.S. No. } 2 \text { yellow, prompt shipment, FOB } \\
\text { Gulf of Mexico ports (USDA, Grain and } \\
\text { Feed Market News, Washington, D.C.) }\end{array}$ & $\begin{array}{l}1957: 1- \\
2012: 12\end{array}$ & \\
\hline Fishmeal & IMF & $\begin{array}{l}\text { Peru Fish meal/pellets, } 65 \% \text { protein, CIF } \\
\text { United Kingdom (DataStream) }\end{array}$ & $\begin{array}{l}1957: 1- \\
2012: 12\end{array}$ & \\
\hline
\end{tabular}




\begin{tabular}{|c|c|c|c|c|}
\hline Hay & CRB & $\begin{array}{l}\text { Mid-month price received by farmers for all } \\
\text { hay (baled) in the United States, dollars per } \\
\text { ton }\end{array}$ & $\begin{array}{l}1957: 1- \\
2012: 2\end{array}$ & \\
\hline Oats & CRB CD & & $\begin{array}{l}1957: 1- \\
2010: 11\end{array}$ & \\
\hline Orange juice & CRB CD & $\begin{array}{l}\text { Orange Juice Frozen Concentrate: nearest- } \\
\text { term futures contract traded on ICE }\end{array}$ & $\begin{array}{l}1967: 1- \\
2012: 10\end{array}$ & \\
\hline Onions & CRB & Average price received by farmers & $\begin{array}{l}1957: 1- \\
2011: 12\end{array}$ & \\
\hline Pepper & $\mathrm{CRB}$ & $\begin{array}{l}\text { (1) Average black pepper (Brazilian) } \\
\text { arriving in New York; (2) Average black } \\
\text { pepper (Lampong) arriving in New York }\end{array}$ & $\begin{array}{l}1957: 1- \\
2007: 6\end{array}$ & $\begin{array}{l}\text { From } 1984: 1-2007: 6 \text {, we use the Brazilian pepper price. } \\
\text { Prior to } 1984 \text {, we use Lampong price rescaled by the } \\
\text { ratio of the two prices in } 1984: 1 \text {. }\end{array}$ \\
\hline Potatoes & CRB & Average price received by farmers & $\begin{array}{l}1957: 1- \\
2011: 12\end{array}$ & \\
\hline Rice & IMF & $\begin{array}{l}\text { Thai, white milled, } 5 \% \text { broken, nominal } \\
\text { price quotes, FOB Bangkok (USDA, Rice } \\
\text { Market News, Little Rock, Arkansas). }\end{array}$ & $\begin{array}{l}1957: 1- \\
2012: 12\end{array}$ & \\
\hline Shrimp & IMF & $\begin{array}{l}\text { Mexican, west coast, white, No. 1, shell-on, } \\
\text { headless, } 26 \text { to } 30 \text { count per pound, } \\
\text { wholesale price at New York }\end{array}$ & $\begin{array}{l}1957: 1- \\
2013: 1\end{array}$ & \\
\hline Sorghums & $\mathrm{CRB} / \mathrm{WB}$ & $\begin{array}{l}\text { CRB: average price of no. 2, yellow, at } \\
\text { Kansas City, } \$ / 100 \text { pounds; WB: no. } 2 \text { milo } \\
\text { yellow, FOB Gulf ports }\end{array}$ & $\begin{array}{l}1957: 1- \\
2013: 1\end{array}$ & $\begin{array}{l}\text { From } 1960: 1-2013: 1 \text {, we use the WB series. Prior to } \\
1960: 1 \text {, we use the CRB series rescaled by the ratio of } \\
\text { the two series in } 1960: 1 \text {. }\end{array}$ \\
\hline Soybeans & CRB CD & No. 1 yellow, Chicago Board of Trade & $\begin{array}{l}1959: 7- \\
2012: 9\end{array}$ & \\
\hline Sugar & IMF & $\begin{array}{l}\text { CSCE contract No. 11, nearest future } \\
\text { position (Coffee, Sugar and Cocoa } \\
\text { Exchange, New York Board of Trade) }\end{array}$ & $\begin{array}{l}1957: 1- \\
2012: 12\end{array}$ & \\
\hline Tea & IMF & $\begin{array}{l}\text { Mombasa auction price for best PF1, Kenyan } \\
\text { Tea, replaces London auction price } \\
\text { beginning July } 1998\end{array}$ & $\begin{array}{l}1957: 1- \\
2013: 1\end{array}$ & \\
\hline Tobacco & WB & $\begin{array}{l}\text { Tobacco (any origin), unmanufactured, } \\
\text { general import, CIF United States }\end{array}$ & $\begin{array}{l}\text { 1968:1- } \\
2013: 1\end{array}$ & \\
\hline
\end{tabular}




\begin{tabular}{|c|c|c|c|c|}
\hline Wheat & IMF & $\begin{array}{l}\text { U.S. No. } 1 \text { hard red winter, ordinary protein, } \\
\text { prompt shipment, FOB \$/Mt, } \\
\text { Gulf of Mexico ports (USDA, Grain and } \\
\text { Feed Market News) }\end{array}$ & $\begin{array}{l}1957: 1- \\
2012: 12\end{array}$ & \\
\hline Coconut oil & CRB & $\begin{array}{l}\text { Average price of coconut oil (crude) at } \\
\text { Pacific Coast of U.S. and average price of } \\
\text { coconut oil (crude) tank cars in New York }\end{array}$ & $\begin{array}{l}1965: 1- \\
2010: 12\end{array}$ & $\begin{array}{l}\text { Data from 1965:1-1980:12 are Pacific Coast, data from } \\
\text { 1981:1-2010:12 are NY. Series have identical prices in } \\
\text { overlapping months: } 1980: 1-1980: 12 \text {. }\end{array}$ \\
\hline Groundnut oil & WB & Groundnut oil (any origin), CIF Rotterdam & $\begin{array}{l}\text { 1960:1- } \\
2013: 1\end{array}$ & \\
\hline Palm oil & IMF & $\begin{array}{l}\text { Crude Palm Oil Futures (first contract } \\
\text { forward) } 4-5 \% \text { FFA, Bursa Malaysian } \\
\text { Derivatives Berhad }\end{array}$ & $\begin{array}{l}1957: 1- \\
2013: 1\end{array}$ & \\
\hline Rapeseed oil & IMF & Crude, FOB Rotterdam (Datastream) & $\begin{array}{l}\text { 1980:1- } \\
2013: 1\end{array}$ & \\
\hline Sun/Safflower oil & IMF & $\begin{array}{l}\text { Sunflower Oil, crude, U.S. export price from } \\
\text { Gulf of Mexico (Datastream) }\end{array}$ & $\begin{array}{l}1960: 1- \\
2013: 1\end{array}$ & $\begin{array}{l}\text { Data from } 2005: 7-2005: 12 \text { and data from } 2006: 6- \\
2008: 2 \text { are treated as missing because of no price } \\
\text { variation. }\end{array}$ \\
\hline Aluminum & IMF & $\begin{array}{l}\text { London Metal Exchange, standard grade, } \\
\text { spot price, minimum purity } 99.5 \% \text {, CIF U.K. } \\
\text { ports (Wall Street Journal, New York, and } \\
\text { Metals Week, New York); prior to } 1979 \text {, } \\
\text { U.K. producer price, minimum purity } 99 \%\end{array}$ & $\begin{array}{l}1957: 1- \\
2013: 1\end{array}$ & $\begin{array}{l}\text { Data from 1957:1-1972:12 are treated as missing } \\
\text { because of infrequent price variation. }\end{array}$ \\
\hline Burlap & CRB CD & Original source of data is USDA. & $\begin{array}{l}1957: 1- \\
2012: 9\end{array}$ & \\
\hline Cement & BLS & $\begin{array}{l}\text { BLS PPI Index Industry (series } \\
\text { PCU32731-32731) Cement Manufacturing }\end{array}$ & $\begin{array}{l}1965: 1- \\
2012: 12\end{array}$ & $\begin{array}{l}\text { Data prior to } 1980: 1 \text { are treated as missing because of } \\
\text { infrequent price variation. }\end{array}$ \\
\hline Copper & IMF & $\begin{array}{l}\text { London Metal Exchange, grade A cathodes, } \\
\text { spot price, CIF European ports (Wall Street } \\
\text { Journal, New York, and Metals Week, New } \\
\text { York); prior to July 1986, higher grade, wire } \\
\text { bars or cathodes }\end{array}$ & $\begin{array}{l}1957: 1- \\
2012: 12\end{array}$ & \\
\hline Cotton & IMF & $\begin{array}{l}\text { Middling 1-3/32-inch staple, Liverpool } \\
\text { Index "A", average of the cheapest } 5 \text { of } 14\end{array}$ & $\begin{array}{l}1957: 1- \\
2012: 12\end{array}$ & \\
\hline
\end{tabular}




\begin{tabular}{|c|c|c|c|c|}
\hline & & $\begin{array}{l}\text { styles, CIF Liverpool (Cotton Outlook, } \\
\text { Liverpool); from } \\
\text { January } 1968 \text { to May } 1981 \text { strict middling 1- } \\
\text { 1/16-inch staple; prior to } 1968, \text { Mexican 1- } \\
\text { 1/16-inch staple }\end{array}$ & & \\
\hline Lead & IMF & $\begin{array}{l}\text { London Metal Exchange, } 99.97 \% \text { pure, spot } \\
\text { price, CIF European ports }\end{array}$ & $\begin{array}{l}\text { 1957:1- } \\
2012: 12\end{array}$ & \\
\hline Lumber & $\mathrm{CRB} / \mathrm{IMF}$ & $\begin{array}{l}\text { CRB: Douglas fir softwood lumber } 2 \times 4 \\
\text { dried, S4S; IMF: Average export price of } \\
\text { Douglas fir, Western hemlock and other } \\
\text { sawn softwood exported from Canada }\end{array}$ & $\begin{array}{l}1957: 1- \\
2012: 12\end{array}$ & $\begin{array}{l}\text { From } 1975: 1-2012: 12 \text {, we use the IMF series. Prior to } \\
1975: 1 \text {, we use the CRB series rescaled by the ratio of } \\
\text { the two price series in } 1975: 1 \text {. }\end{array}$ \\
\hline Mercury & CRB & $\begin{array}{l}\text { Average cash price in New York for flask of } \\
76 \text { pounds }\end{array}$ & $\begin{array}{l}1957: 1- \\
2010: 12\end{array}$ & $\begin{array}{l}\text { Only data from 1962:12-1995:3 are used; other periods } \\
\text { display infrequent price adjustment. }\end{array}$ \\
\hline Nickel & IMF & $\begin{array}{l}\text { London Metal Exchange, melting grade, spot } \\
\text { price, CIF Northern European ports (Wall } \\
\text { Street Journal, New York, and Metals Week, } \\
\text { New York); prior to 1980, INCO, melting } \\
\text { grade, CIF Far East and American ports } \\
\text { (Metal Bulletin, London) }\end{array}$ & $\begin{array}{l}1957: 1- \\
2013: 1\end{array}$ & $\begin{array}{l}\text { Data prior to } 1979: 3 \text { are treated as missing because of } \\
\text { infrequent price variation. }\end{array}$ \\
\hline Rubber & CRB & $\begin{array}{l}\text { Average spot crude rubber prices (smoked } \\
\text { sheets, no 1, ribbed, plantation rubber) in } \\
\text { New York, cents per pound }\end{array}$ & $\begin{array}{l}1957: 1- \\
2010: 12\end{array}$ & \\
\hline Tin & IMF & $\begin{array}{l}\text { London Metal Exchange, standard grade, } \\
\text { spot price, CIF European ports (Wall Street } \\
\text { Journal, New York); from December } 1985 \\
\text { to June 1989, Malaysian, straits, minimum } \\
\text { 99.85\% purity, Kuala Lumpur Tin Market } \\
\text { settlement price; prior to November 1985, } \\
\text { London Metal Exchange }\end{array}$ & $\begin{array}{l}1957: 1- \\
2012: 12\end{array}$ & \\
\hline Wool & IMF & $\begin{array}{l}23 \text { micron (AWEX, Australian Wool } \\
\text { Exchange) Sidney, Australia }\end{array}$ & $\begin{array}{l}1957: 1- \\
2012: 12\end{array}$ & \\
\hline Zinc & IMF & $\begin{array}{l}\text { London Metal Exchange, high grade } 98 \% \\
\text { pure, spot price, CIF U.K. ports (Wall Street }\end{array}$ & $\begin{array}{l}1957: 1- \\
2012: 12\end{array}$ & \\
\hline
\end{tabular}


Journal, New York, and Metals Week, New

York); prior to January 1987, standard grade 


\section{Appendix D: The Production and Use of Commodities}

\begin{tabular}{|c|c|c|}
\hline & Largest Producers & Primary Uses \\
\hline \multicolumn{3}{|l|}{ Agr./Food Commodities } \\
\hline Apples (1990-91) & U.S. (0.21), Germany (0.10), Italy (0.10) & Food (0.86), beverage, feed \\
\hline Bananas* (1990) & India (0.15), Brazil (0.12), Ecuad. (0.07) & Food (0.84), feed, other \\
\hline Barley (1990-91) & USSR (0.28), Germany (0.08) & Feed $(0.73)$, distillation, food \\
\hline Beef & & Food \\
\hline Cocoa (1990-91) & Ivory Coast (0.32), Brazil (0.25) & Food $(0.96)$ \\
\hline Coffee (1990-91) & Brazil (0.31), Columbia (0.14) & Food/beverages $(0.98)$ \\
\hline Corn (1990-91) & U.S. (0.42), Brazil (0.05) & Feed (0.62), food (0.16), adhesives \\
\hline Fishmeal* (1984) & Japan (0.21), Chile (0.17), Peru (0.08) & Feed $(0.90)$ \\
\hline Hay & & Feed \\
\hline Oats (1990-91) & USSR (0.39), U.S. (0.13) & Food (0.74), feed (0.09), ref. solvent \\
\hline Orange juice (1990-1) & Oranges: Brazil (0.35), Spain (0.07) & Beverage (pulp for feed, oil) \\
\hline Onions* (1990) & China (0.16), India (0.10) & Food $(0.91)$ \\
\hline Pepper (1990) & Main exporters: Indonesia, India & Food (0.96), oil (medical, perfumes) \\
\hline Potatoes* (1990) & USSR (0.24), Poland (0.13) & Food (0.52), distillation, feed (0.19) \\
\hline Rice (1990-91) & China (0.36), India $(0.21)$ & Food (0.84), distillation, other \\
\hline Shrimp & & Food \\
\hline Sorghum* (1990) & U.S. (0.26), India (0.21), Mex. (0.11) & Food (0.39), feed (0.52) \\
\hline Soybeans (1990-91) & U.S. (0.50), Brazil (0.15) & $\begin{array}{c}\text { Food/feed (0.11), industrial (paints, } \\
\text { plastics) }\end{array}$ \\
\hline Sugar (1990-91) & India (0.12), Brazil (0.07), Cuba (0.07) & Food/beverages ( 0.96$)$, fuel \\
\hline Tea (1990) & India (0.29), China (0.21), S. Lank (.09) & Beverage (0.98) \\
\hline Tobacco (1990) & China (0.37), U.S. (0.10) & Smoking \\
\hline Wheat (1990-91) & USSR (0.17), China (0.17), U.S. (0.13) & Food $(0.65)$, feed $(0.22)$ \\
\hline
\end{tabular}

Oils 


\begin{tabular}{|c|c|c|}
\hline Coconut oil (1990-91) & Philippines (0.41), Indonesia (0.27) & Food (0.57), cosmetics, synth. rubbe \\
\hline Groundnut oil* (1990) & India (0.45), China (0.22), Nigeria (.09) & Food $(0.98)$ \\
\hline Palm oil (1990-91) & Malaysia (0.55), Indonesia $(0.25)$ & Food (0.57), soaps, machine lubrican \\
\hline Rapeseed oil (1990) & China (0.28), India (0.20), Canada (.13) & Food (0.82), inks, pharma, cosmetic \\
\hline Sun/Safflower oil (90-1) & USSR (0.29), Argentina (0.17) & Food (0.90), fuel \\
\hline \multicolumn{3}{|l|}{ ndustrial Commodities } \\
\hline Aluminum (1990) & U.S. (0.22), USSR (0.12), Canada (0.09) & Transportation, containers \\
\hline Burlap* (1990) & India (0.52), Bangladesh (0.30) & Fabric \\
\hline Cement (1990) & China (0.18), USSR (0.12), Japan (0.07) & Construction \\
\hline Copper (1990) & Chile (0.18), U.S. (0.18) & Electrical $(0.75)$, construction \\
\hline Cotton (1990-91) & China (0.24), U.S. (0.18), Uzb. (0.14) & Clothing, furnishings, medical \\
\hline Lead (1990) & U.S. (0.23), Kazakhstan (0.12) & Construction, lining, batteries \\
\hline Lumber & Russia (0.39), Canada (0.39) & Construction, industrial uses \\
\hline Mercury (1990) & China (0.22), USSR (0.18) & Batteries, paints, dental \\
\hline Nickel (1990) & USSR (0.24), Canada (0.22) & Coins, batteries, electronics \\
\hline Natural rubber (1990) & Malaysia $(0.25)$, Thailand $(0.24)$ & Household and industrial uses \\
\hline Tin (1990) & China (0.19), Brazil (0.18) & Industrial uses \\
\hline Wool (1990-91) & Australia (0.35), New Zealand (0.12) & Clothing/furnishing, insulation \\
\hline Zinc (1990) & USSR (0.13), Japan (0.10), Can. (0.08) & Coating, alloy, batteries, medical \\
\hline
\end{tabular}

Notes: The table presents information on the largest-producing countries for each type of commodity in 1990 or as available. These data come from the CRB or, if marked with a *, from the FAO. The third column presents the most common uses of each commodity in 1990, as reported by the CRB (for industrials) or by the FAO (for all others). 


\section{Appendix E: Contribution of Common Factors to Individual Commodity Prices}

Cumulative $R^{2}$ from Common Factors

\begin{tabular}{|c|c|c|c|c|c|}
\hline \multirow[b]{2}{*}{ Number of Factors: } & & & & & \\
\hline & 1 & 2 & 3 & 4 & 5 \\
\hline \multicolumn{6}{|l|}{ Agricultural/Food } \\
\hline Apples & 0.20 & 0.22 & 0.22 & 0.23 & 0.38 \\
\hline Bananas & 0.34 & 0.37 & 0.43 & 0.43 & 0.63 \\
\hline Barley & 0.62 & 0.73 & 0.78 & 0.86 & 0.86 \\
\hline Beef & 0.74 & 0.77 & 0.77 & 0.85 & 0.85 \\
\hline Cocoa & 0.76 & 0.80 & 0.88 & 0.89 & 0.90 \\
\hline Coffee & 0.69 & 0.75 & 0.86 & 0.87 & 0.87 \\
\hline Corn & 0.91 & 0.91 & 0.93 & 0.94 & 0.94 \\
\hline Fishmeal & 0.85 & 0.85 & 0.85 & 0.86 & 0.86 \\
\hline Hay & 0.73 & 0.75 & 0.76 & 0.84 & 0.87 \\
\hline Oats & 0.82 & 0.82 & 0.82 & 0.84 & 0.84 \\
\hline Orange juice & 0.51 & 0.59 & 0.64 & 0.73 & 0.78 \\
\hline Onions & 0.24 & 0.43 & 0.46 & 0.47 & 0.53 \\
\hline Pepper & 0.25 & 0.50 & 0.52 & 0.59 & 0.59 \\
\hline Potatoes & 0.54 & 0.55 & 0.64 & 0.64 & 0.69 \\
\hline Rice & 0.87 & 0.87 & 0.89 & 0.89 & 0.89 \\
\hline Shrimp & 0.14 & 0.76 & 0.79 & 0.79 & 0.80 \\
\hline Sorghums & 0.90 & 0.90 & 0.93 & 0.93 & 0.93 \\
\hline Soybeans & 0.91 & 0.91 & 0.93 & 0.93 & 0.93 \\
\hline Sugar & 0.61 & 0.62 & 0.71 & 0.73 & 0.75 \\
\hline Tea & 0.71 & 0.80 & 0.82 & 0.83 & 0.84 \\
\hline Tobacco & 0.65 & 0.82 & 0.82 & 0.83 & 0.84 \\
\hline Wheat & 0.87 & 0.87 & 0.89 & 0.90 & 0.90 \\
\hline
\end{tabular}




$\begin{array}{lccccc}\text { Coconut oil } & 0.71 & 0.71 & 0.71 & 0.71 & 0.79 \\ \text { Groundnut oil } & 0.75 & 0.75 & 0.78 & 0.83 & 0.86 \\ \text { Palm oil } & 0.81 & 0.81 & 0.81 & 0.85 & 0.90 \\ \text { Rapeseed oil } & 0.46 & 0.63 & 0.71 & 0.85 & 0.85 \\ \text { Sun/Safflower oil } & 0.73 & 0.76 & 0.78 & 0.84 & 0.85\end{array}$

\section{Industrials}

$\begin{array}{llllll}\text { Aluminum } & 0.62 & 0.62 & 0.68 & 0.78 & 0.79 \\ \text { Burlap } & 0.72 & 0.72 & 0.73 & 0.81 & 0.85 \\ \text { Cement } & 0.14 & 0.14 & 0.79 & 0.79 & 0.80 \\ \text { Copper } & 0.44 & 0.83 & 0.85 & 0.92 & 0.93 \\ \text { Cotton } & 0.80 & 0.88 & 0.89 & 0.89 & 0.89 \\ \text { Lead } & 0.60 & 0.86 & 0.87 & 0.87 & 0.87 \\ \text { Lumber } & 0.25 & 0.33 & 0.53 & 0.64 & 0.76 \\ \text { Mercury } & 0.25 & 0.49 & 0.51 & 0.73 & 0.77 \\ \text { Nickel } & 0.13 & 0.70 & 0.70 & 0.84 & 0.87 \\ \text { Rubber } & 0.71 & 0.84 & 0.86 & 0.86 & 0.86 \\ \text { Tin } & 0.84 & 0.85 & 0.92 & 0.93 & 0.93 \\ \text { Wool } & 0.78 & 0.79 & 0.79 & 0.79 & 0.79 \\ \text { Zinc } & 0.39 & 0.48 & 0.54 & 0.54 & 0.65\end{array}$

\footnotetext{
Notes: The table presents the $R^{2}$ associated with the cumulative number of factors across columns for
} each commodity. Imputed values are not included in $R^{2}$ calculations. See section 3.2 for details. 
Appendix F: Robustness Checks
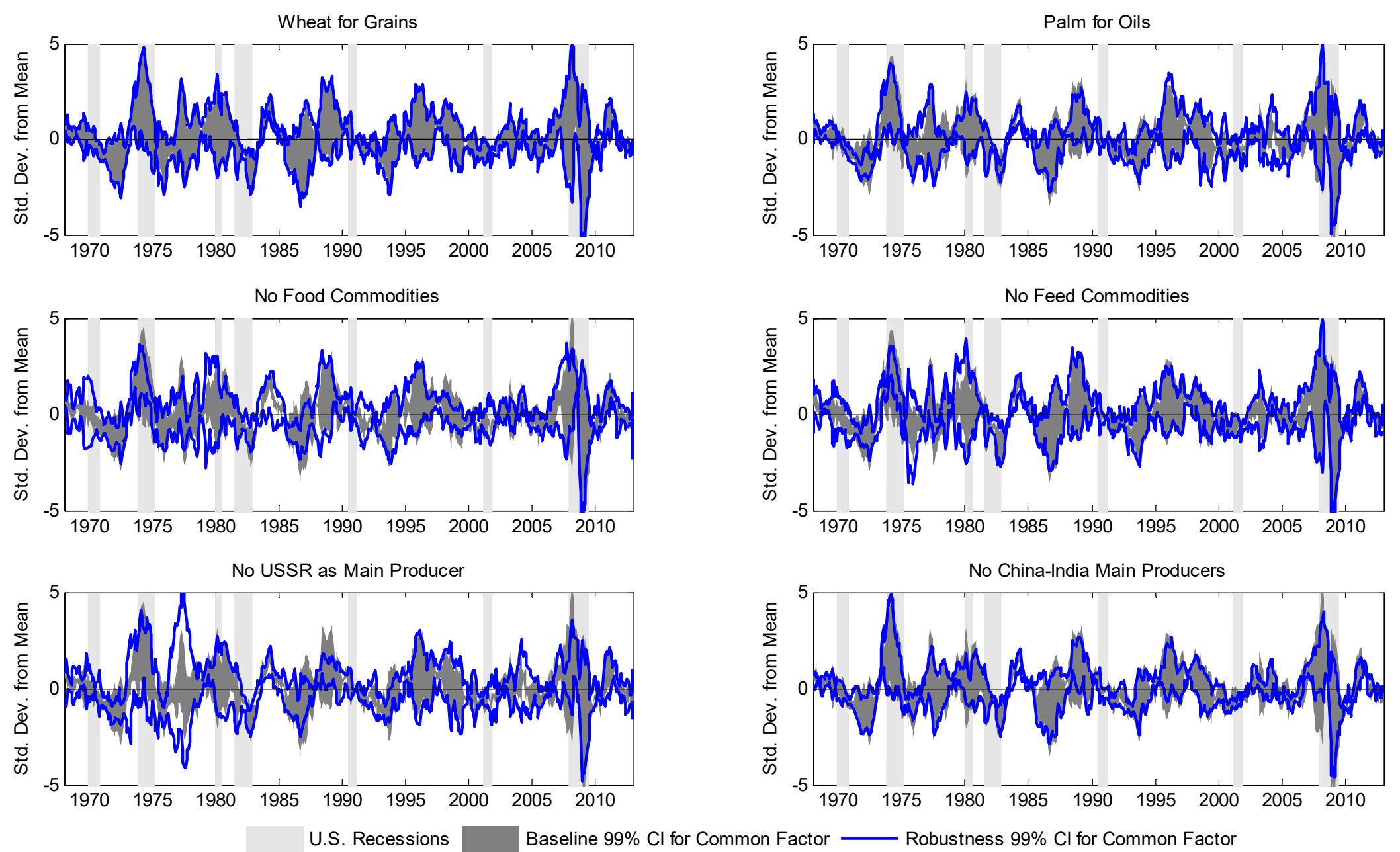

Notes: The figures present the baseline 99\% confidence interval (CI) for the (HP-filtered) IC factor (grey shaded area) and the $99 \%$ confidence intervals for the HP-filtered IC factor for subsets of commodities (areas between blue lines). In the top two panels, we drop from the cross-section of commodities barley, hay, oats and sorghums (left figure) and coconut oil, peanut oil, rapeseed oil and safflower oil (right figure). In the two middle panels, we drop all commodities for which food is the primary use (left figure) and all commodities for which feed is the primary use (right figure). In the bottom two panels, we drop all commodities for which the former USSR was the primary producer in 1990 (8 commodities, left figure) and all commodities for which China or India were primary producers (13 commodities, right figure). See section 3.3 for details. 

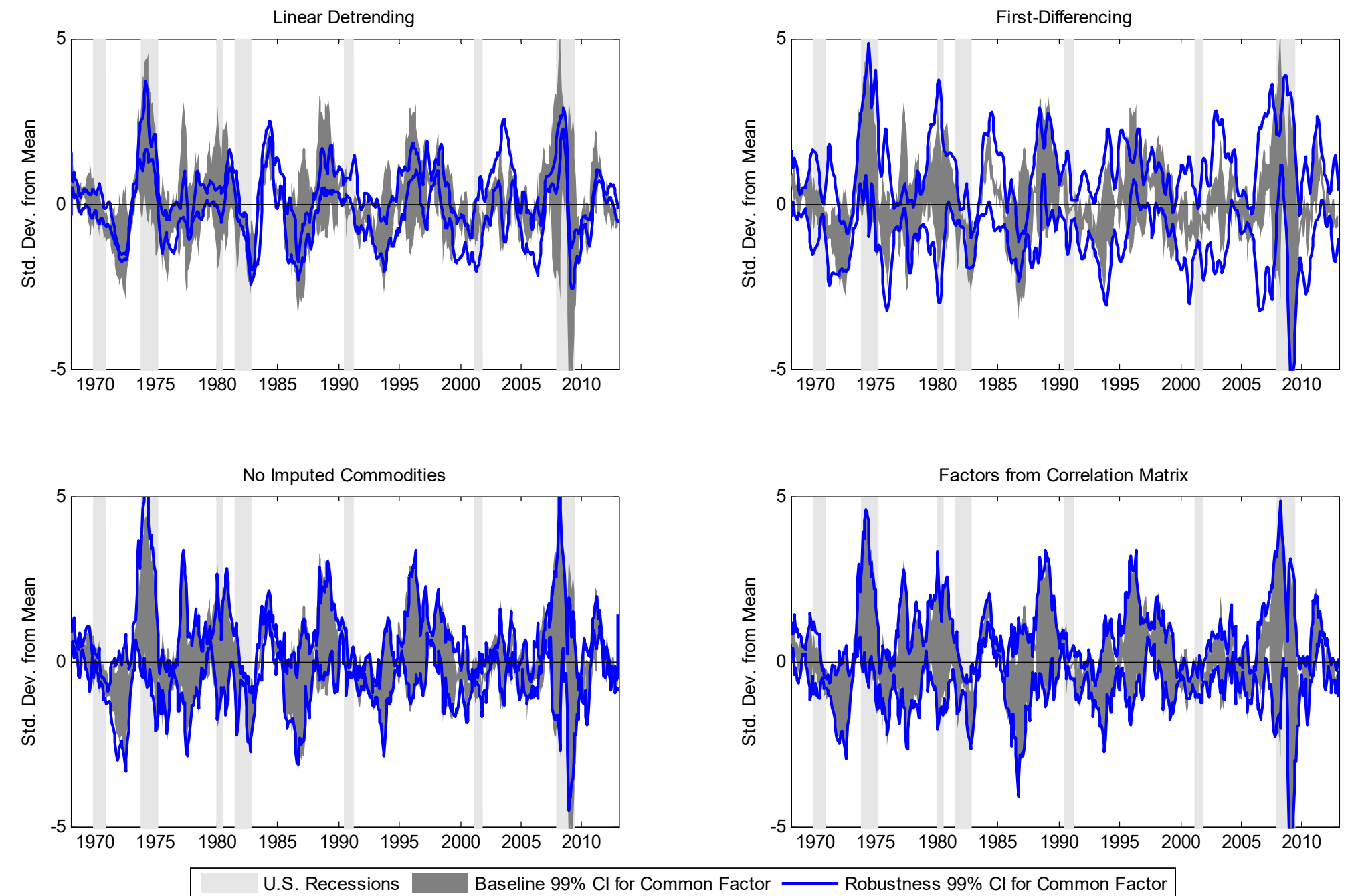

Notes: The figures present the baseline $99 \%$ confidence interval (CI) for the (HP-filtered) IC factor (grey shaded area) and the $99 \%$ confidence intervals for the HP-filtered IC factor under alternative conditions (areas between blue lines). In the top left figure, we linearly detrend each real commodity price series prior to factor analysis. In the top right figure, we implement factor analysis in first-differences. In the bottom left figure, we include only commodities for which no imputation was necessary prior to 2010. In the bottom right figure, we extract factors from the correlation matrix of the cross-section of real commodity prices rather than the covariance matrix. See section 3.3 for details. 


\section{Appendix G: Time Series of $(\log )$ Real Commodity Prices and Imputed Values}
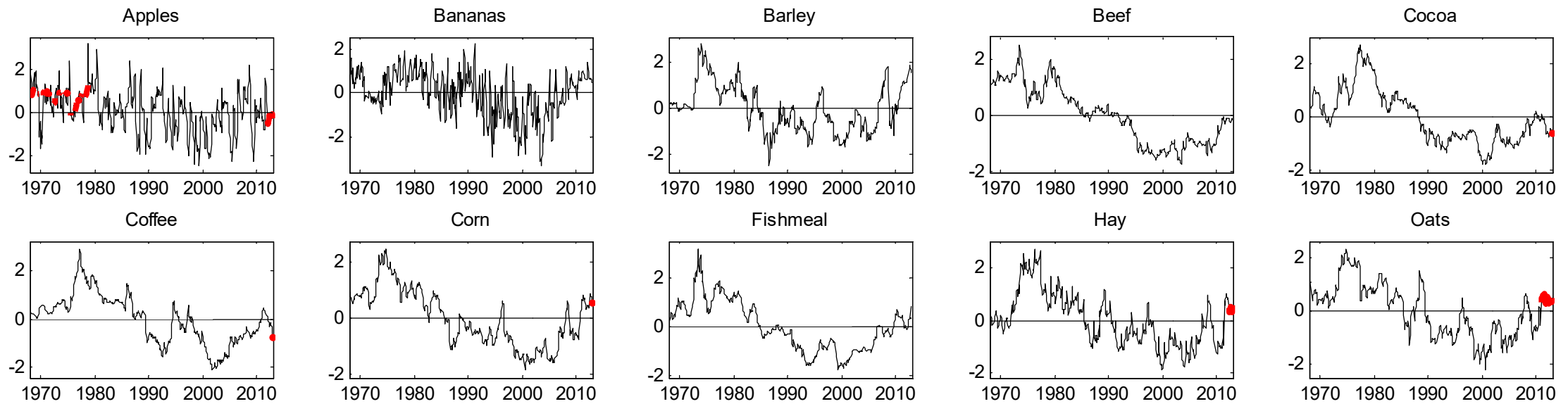

$$
\text { Hay }
$$

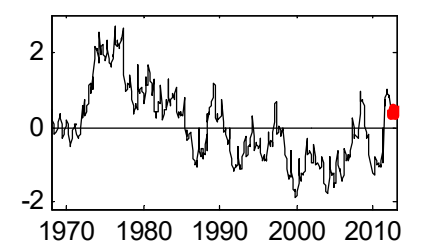

Oats
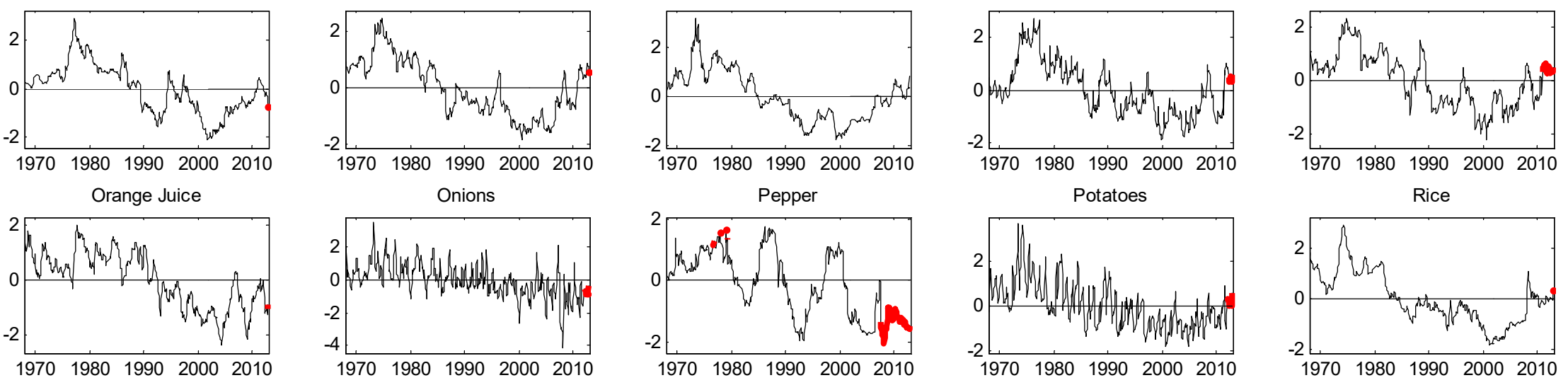

$$
\text { Onions }
$$

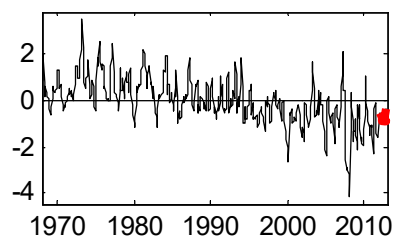

Pepper

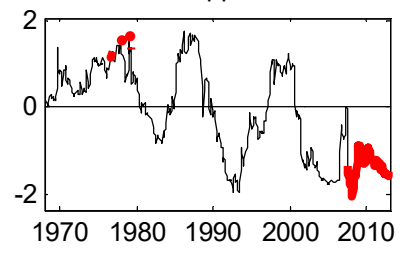

Soybeans

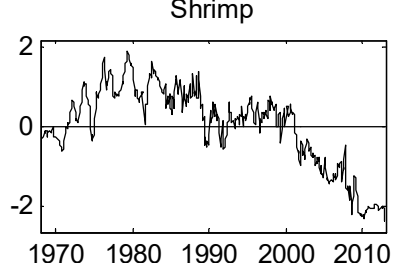

Sorghums
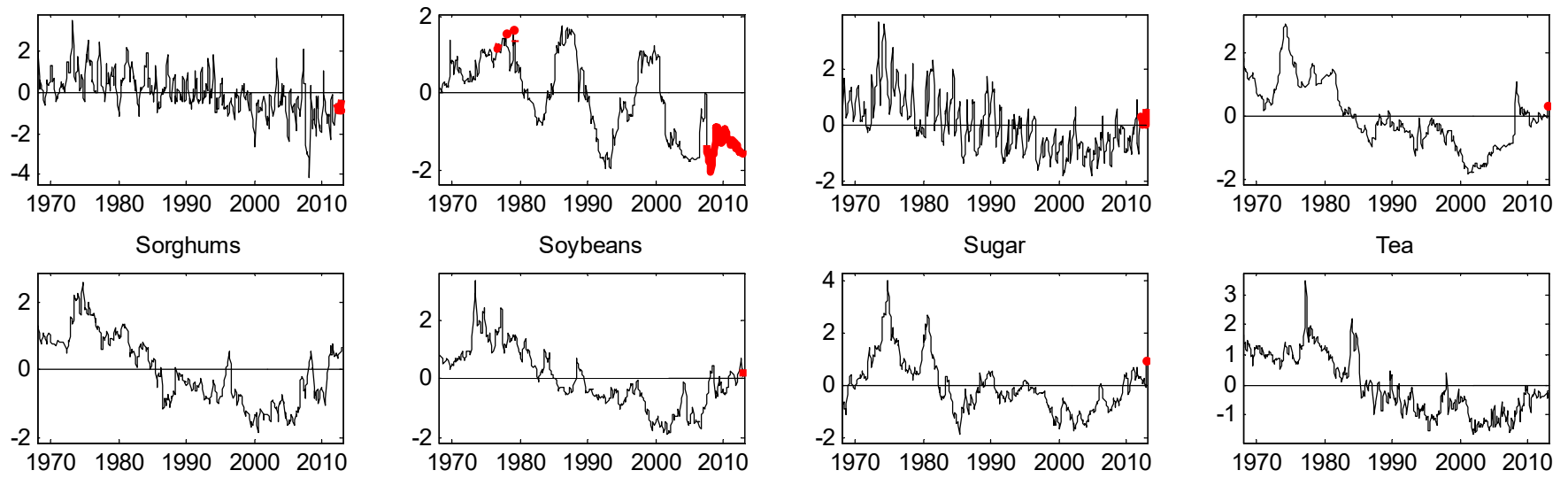

Sugar
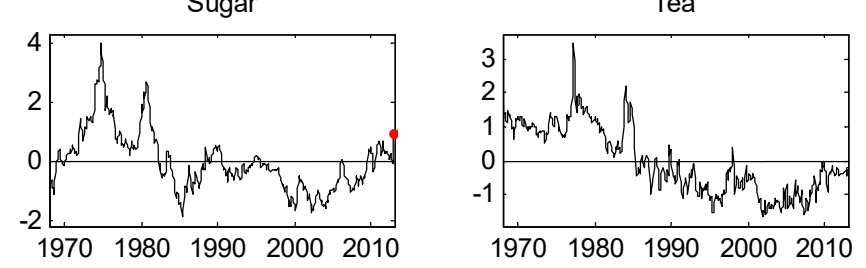

Notes: The figure plots real commodity prices (black lines) and imputed values (bold red values) from the expectation-maximization (EM) algorithm of Stock and Watson (2002). 

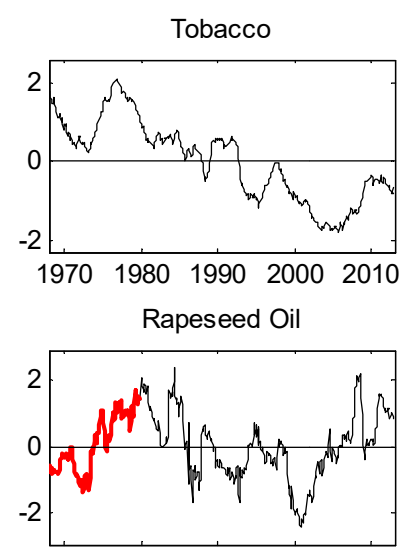

19701980199020002010 Copper

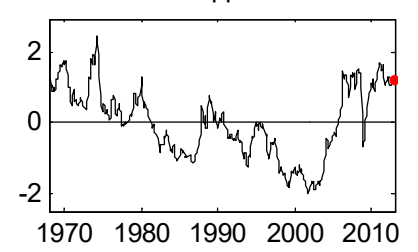

Nickel

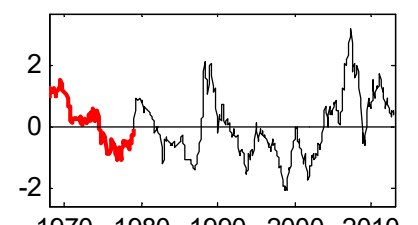

19701980199020002010
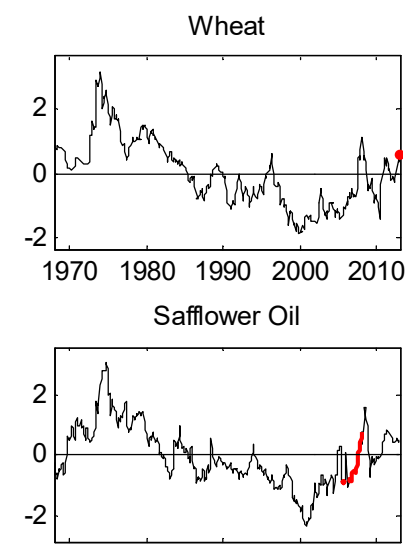

19701980199020002010

Cotton

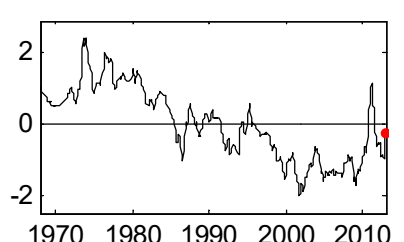

Rubber

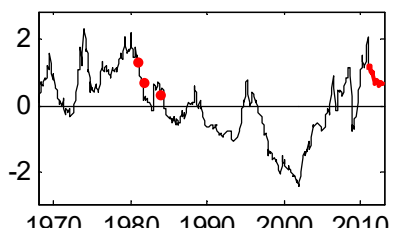

19701980199020002010

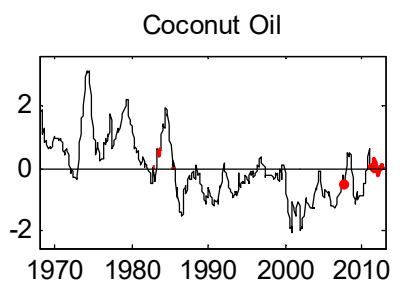

Aluminum

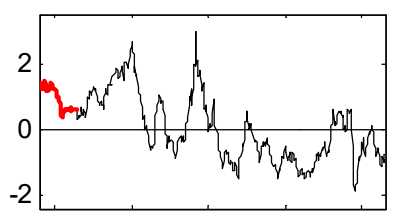

19701980199020002010

Lead

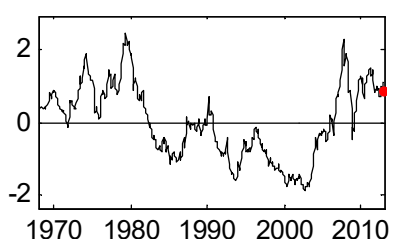

Tin

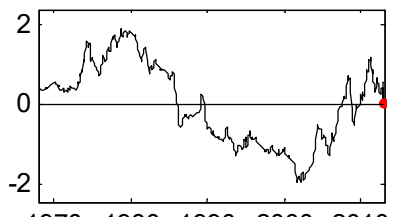

19701980199020002010

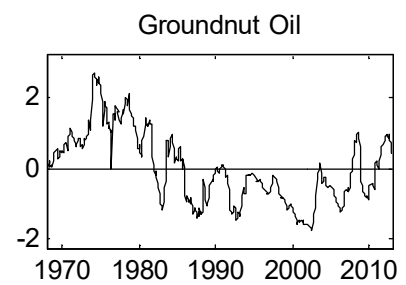

Burlap

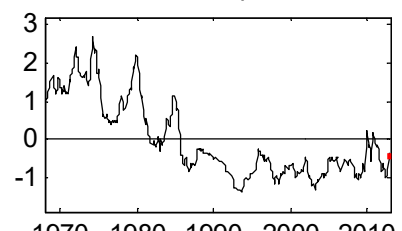

19701980199020002010

Lumber

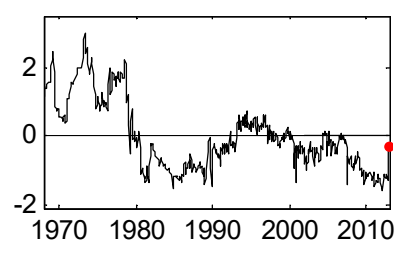

Wool

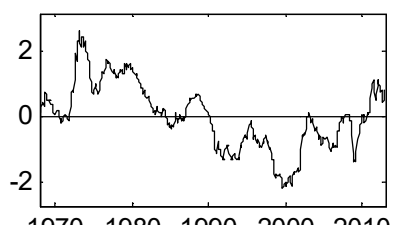

19701980199020002010

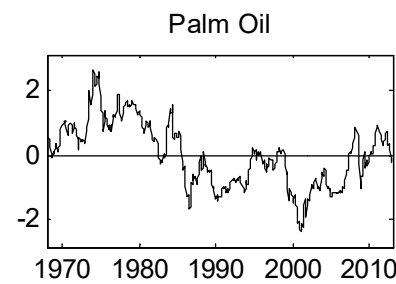

Cement

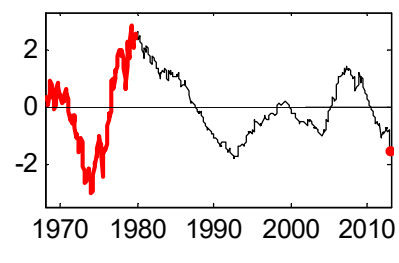

Mercury

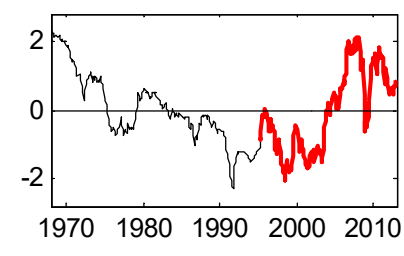

Zinc

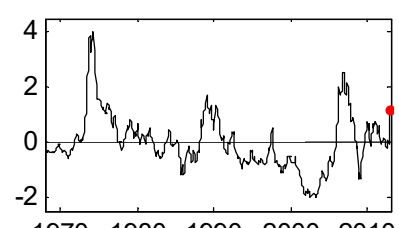

$1970 \quad 19801990 \quad 20002010$

Notes: The figure plots real commodity prices (black lines) and imputed values (bold red values) from the expectation-maximization (EM) algorithm of Stock and Watson (2002). 


\section{Appendix H: Robustness to Dropping Commodities for which the Null Hypothesis of No First-Order Speculation Is Rejected}

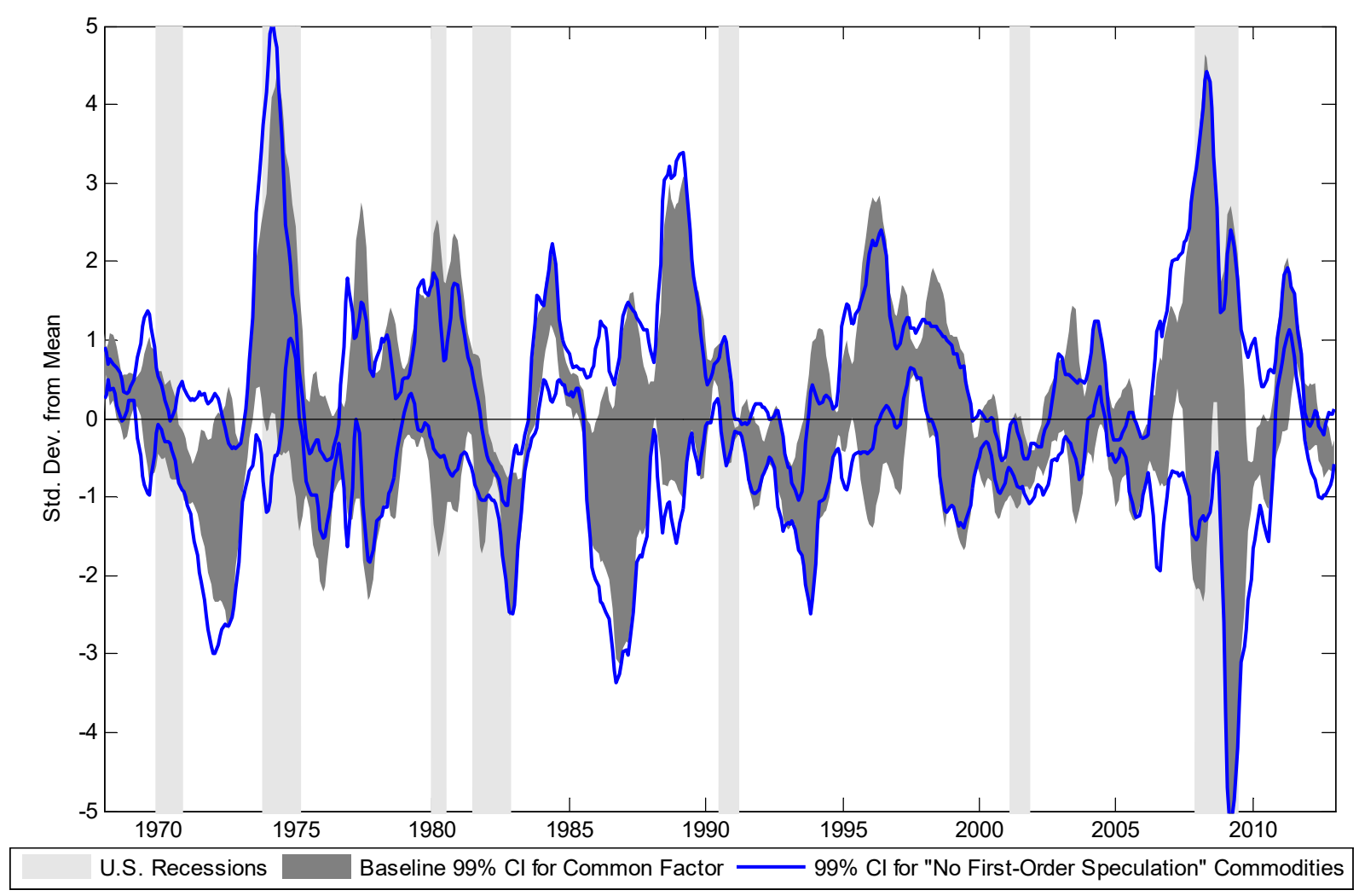

Notes: The figure presents the baseline $99 \%$ confidence interval of the (HP-filtered) IC factor from the factor analysis on the full cross-section of commodities in section 3.3 using the estimated rotation parameters from GMM estimates (grey shaded area). The blue lines correspond to the $99 \%$ confidence interval for the equivalent factor using only those commodities for which we cannot reject the null of no first-order speculative price effects in Table 4. Confidence intervals are 3-month moving averages. See section 4 for details. 


\section{Appendix I: Storage}

The model in section 2 yields a factor structure of commodity prices whose properties conform closely to the data and permit us to make causal inferences about the relationship between global real activity and commodity-related shocks. The key to the identification in the factor structure is that all indirect shocks to commodity markets (i.e., all shocks that affect commodity prices through the general-equilibrium response of output) are aggregated into a single factor, the IC factor. This conclusion relies on the premise that all indirect shocks induce identical comovement in commodity prices.

This aggregation property of the factor structure can be broken in the presence of storage. To see why, suppose that we extend the model to include a perfectly competitive storage sector for each primary commodity $j$ that purchases or sells that commodity on the spot market, leading it to hold inventories in the steady state. As illustrated in Deaton and Laroque (1992), the key determinant of whether the storage sector increases or decreases its inventories is the expected path of prices of the commodity. If a current increase in prices is not expected to persist, then the storage sector sells a positive amount of its inventories on the spot market today when prices are high and rebuilds inventories in future periods when prices are lower. This behavior increases the current supply of the good and reduces it in the future. In contrast, if the shock is expected to generate a persistent increase in prices, the storage sector does not have an incentive to change its stock of inventories and therefore is not a net purchaser of the good. Thus, the persistence of the driving process affects the size of net purchases by the storage sector through its effect on the path of expected prices. For example, if aggregate productivity shocks in the model were highly persistent while labor supply shocks were less persistent, the presence of storage would lead these shocks to have different supply responses, depending on the size of the storage sector's net purchases. The comovement in commodity prices would then not necessarily be the same across the two shocks, potentially breaking the aggregation result.

In practice, this issue is unlikely to be quantitatively important for three reasons. First, if the aggregation of indirect shocks into a single IC factor were broken, we would expect a factor decomposition of commodity prices to indicate that many factors were required to explain the comovement of commodity prices, since a number of different aggregate structural shocks are likely affecting commodity prices through the indirect channel of global activity, such as financial shocks, markup shocks and fiscal shocks, in addition to the productivity and labor supply shocks that we explicitly model. But, as documented in Table 1, the comovement of commodity prices is well-characterized by two factors, with any additional factors adding little explanatory power. This finding suggests that either different indirect shocks have common effects on expected price paths of commodity prices (such that the response of the storage sector 
is similar across all indirect shocks and, therefore, that the aggregation of indirect shocks still holds) or the effects of net purchases for the storage motive are second-order in affecting commodity prices.

The second reason why storage is unlikely to be important is precisely because the effects of net purchases for storage motives appear to be second-order for most commodities. To examine this claim, suppose again that we integrated a storage sector for each primary commodity into the model, in which firms purchase or sell the commodity on the spot market as well as store it. The storage sector would therefore affect spot markets through its forward-looking net purchases, defined as $N P_{t}(j)$ at time $t$ for commodity $j$. The market-clearing condition in the presence of an additional storage sector would then be given by $Q_{t}(j)=Y_{t}(j)+N P_{t}(j)$ such that high (low) net purchases by the storage sector to accumulate (draw down) inventories would increase (decrease) the demand for commodity $j$ at time $t$, holding all else constant. Allowing for trend growth in production such that $Y / Q$ and $N P / Q$ are stationary along the balanced growth path, the log-linearized version of this equation is

$$
(Y / Q-1) n p_{t}(j)=(Y / Q) y_{t}(j)
$$

where the terms in parentheses are balanced growth path ratios. For the storage sector to have first-order effects on equilibrium outcomes (including prices), it must be the case that net purchases are different from zero on average, or equivalently that the ratio of consumption to production $(Y / Q)$ of the commodity is different from one.

Table I.1 presents estimates of the mean annual ratio of consumption to production (minus 1) for commodities for which such data could be collected: $r_{t}=Y_{t} / Q_{t}-1 .{ }^{1}$ Out of 32 commodities, we reject the null hypothesis that $r_{t}=0$ on average for only nine: apples, bananas, onions, potatoes, rice, sugar, tea, palm oil and safflower oil. Four of these are highly perishable commodities (apples, bananas, onions and potatoes), thus one would expect some fraction of the goods to spoil while being transported from production to retail facilities. But even in the case of these highly perishable goods, the implied gaps between consumption and production are small-less than 1\% per year. Furthermore, in the case of potatoes, the rejection of the null has the wrong sign (i.e., consumption is larger than production on average). Among the less perishable agricultural commodities (e.g., grains), there is little evidence that consumption is significantly less than production, on average, with most of the point estimates being less

\footnotetext{
${ }^{1}$ We use measures of consumption and production of commodities from the CRB. When these are not available, we rely on measures from the UN FAO for agricultural and oil commodities, from the U.S. Department of Agriculture's Food and Agricultural Services (USDA FAS), and from trade associations. Aluminum data were provided to us by the European Aluminum Association (EAA), data for copper are from the International Copper Study Group (ICSG), data for tin were provided by the International Tin Research Institute (ITRI), nickel data are from International Nickel Study Group (INSG), while data for zinc and lead were tabulated from the International Lead and Zinc Study Group's Monthly Bulletin. For many commodities, we were able to construct global production and consumption data going back to 1968 . There are only eight commodities for which we could not compile consumption and production data: beef, hay, orange juice, shrimp, cement, lumber, mercury and wool.
} 
than $1 \%$. This conclusion also applies to industrial commodities, which are highly storable and for which one would expect inventory motives to be potentially important. In fact, there is little evidence of non-zero net purchases by the storage sector. Thus, with the exception of a few commodities, it is difficult to reject the null that speculative motives through storage have only second-order effects on prices. ${ }^{2}$ Furthermore, the failure to reject the null does not typically reflect large standard errors. Rather, the point estimates of the net ratio are typically smaller than $1 \%$, which suggests that net flows to the storage sector are small on average. Finally, if we replicate our baseline factor analysis using only the commodities for which we cannot reject the null of zero net purchases on average, there is little effect on the estimated IC factor (Appendix H).

A third way to assess the possibility that the effects of storage could break the aggregation of indirect commodities into a common IC factor is to note that, in the presence of storage motives, interest rates would play an important role in affecting commodity prices (Deaton and Laroque 1992; and Frankel 2008). As a result, the logic of the model in section 2 would imply that monetary policy shocks would directly affect commodity prices through changes in desired inventories. Therefore, in a factor decomposition, these monetary policy shocks would not be incorporated into the indirect factor. Hence, a testable implication of a quantitatively important storage motive is that monetary policy shocks should not affect the IC factor.

To test this prediction, we identify U.S. monetary policy shocks using a time-varying-coefficients (TVC) Taylor rule

$$
i_{t}=c_{t}+\varphi_{t}^{\pi} F_{t} \pi_{t+1, t+2}+\varphi_{t}^{g y} F_{t} g y_{t}+\varphi_{t}^{x} F_{t} x_{t}+\rho_{t} i_{t-1}+\varepsilon_{t}^{m p}
$$

in which the central bank responds to real-time forecasts $\left(F_{t}\right)$ of average inflation over the next two quarters $\left(\pi_{t+1, t+2}\right)$, the current quarter's output growth $\left(g y_{t}\right)$, the current quarter's output gap $\left(x_{t}\right)$, and the previous period's interest rate, as in Kozicki and Tinsley (2009) and Coibion and Gorodnichenko (2011). We assume that each of the TVCs follows a random walk, including the intercept that captures changes in the central bank's target levels of macroeconomic variables and the natural rate of interest. Following Orphanides (2003) and Romer and Romer (2004), we use the Greenbook forecasts prepared by the staff of the Federal Reserve before each Federal Open Market Committee (FOMC) meeting to characterize the FOMC's realtime beliefs about current and future macroeconomic conditions. The TVCs allow us to distinguish between systematic changes in the monetary policy rule from transitory deviations captured by the residuals. We estimate this rule using data on the frequency of FOMC meetings from March 1969 until December 2008. Because Greenbook data are not available after 2007, we use Blue Chip Economic Indicator forecasts. The sample ends in December 2008 when the zero lower bound on interest rates was reached. We then define

\footnotetext{
${ }^{2}$ This evidence is also consistent with the well-documented inconsistencies between the standard storage model and the observed data (see, among others, $\mathrm{Ng} 1996$ ).
} 
the residuals estimated from equation (8) as monetary policy shocks and construct a monthly time series from the shock series.

To quantify the effects of monetary policy shocks on the indirect common factor, we use a vector autoregressive representation of macroeconomic dynamics with four variables: our measure of monetary policy shocks, the $\log$ of U.S. industrial production, the log of the U.S. Consumer Price Index (CPI) and the IC factor. We order the monetary policy shock first, given that it should already incorporate the most recent economic information obtained from the Greenbook forecasts and to allow other variables to respond to the impact of this shock. We use data from March 1969 until December 2008 to estimate the VAR with 18 months of lags, midway between the 12-month lag specifications typical of monetary VARs and the 24month lag specification used by Romer and Romer (2004). We then plot in Figure I.1 the impulse responses of industrial production, the CPI and the IC factor to a monetary policy innovation.

An expansionary monetary policy shock in the VAR leads to higher industrial production, with peak effects happening one to two years after the shock. The CPI rises moderately but persistently around six months after the shock, consistent with the delayed effect on prices of monetary policy shocks long observed in the empirical monetary policy literature (e.g., Christiano et al. 1999). The indirect factor rises much more rapidly, within the first three months, but does not peak until nearly two years after the shock before gradually declining back toward zero. The responses are significantly different from zero at the 5\% level for the first 20 months and are briefly at the $1 \%$ level. ${ }^{3}$ Thus, we can statistically reject the null hypothesis that monetary policy shocks have no effect on the IC factor. In addition, the quantitative contribution of U.S. monetary policy shocks to the indirect factor is relatively large, accounting for much of the sustained increase in the IC factor from late 1975 until 1980 and around two-thirds of the subsequent decline from 1980 to 1982.

\footnotetext{
${ }^{3}$ The reported standard errors do not account for the fact that the IC factor is a generated regressor, and they therefore may understate the true uncertainty around the point estimates. However, there are at least two reasons to suspect that this is not quantitatively important. First, one could also test the null that monetary policy shocks have no effect on the IC factor by regressing it on current and lagged monetary shocks, i.e., $F_{t}^{I C}=c+\sum_{i=0}^{I} \beta_{i} \varepsilon_{t-i}^{m p}+v_{t}$, setting $I=36$ months to account for the gradual effects of monetary policy shocks on macroeconomic variables. From this procedure, we can reject the null hypothesis that monetary policy shocks have no effect on the IC factor (i.e., $\hat{\beta}_{i}=$ $0 \forall i$ ) with a $p$-value of 0.019 . The generated regressor issue is not binding in this case, since the IC factor is only on the left-hand side and the null hypothesis is that the coefficients on monetary policy shocks are zero, thus asymptotic (Newey-West) standard errors are valid (Pagan 1984). The advantage of the VAR specification is that it also purges the monetary policy shocks of potentially remaining predictability from macroeconomic variables and is in this respect a more conservative approach. Second, given that we cannot reject the null of the rotation matrix being equal to the identity matrix, one can use the unrotated first common factor in the VAR in lieu of the rotated one. Since the unrotated factor can be treated as observable following Bai and $\mathrm{Ng}$ (2002) and Stock and Watson (2002) for large enough crosssections and time samples, the corresponding standard errors are valid. The results from this alternative specification are almost identical, and we can reject the null of no response at the same confidence level.
} 
In short, while the presence of commodity storage could potentially break the aggregation of indirect shocks into a common IC factor, there is little quantitative evidence in favor of this claim. ${ }^{4}$ First, the fact that the comovement in commodity prices is well characterized by a small number of factors is difficult to reconcile with the aggregation result failing to hold. Second, for most commodities, we cannot reject the null that storage has only second-order effects on commodity prices. And third, monetary policy shocks have both statistically and economically significant effects on the IC factor, which suggests that the factor decomposition is not treating them as a direct commodity-related shock, as would be the case if speculative considerations were economically important. While storage motives are nonetheless likely to play a role in commodity prices in periods when inventory constraints are close to binding, the results suggest that, on average, the aggregation result from section 2 provides a succinct and adequate characterization of the data.

\footnotetext{
${ }^{4}$ Another reason why one might be skeptical of the quantitative importance of the storage mechanism is that recent work examining the role of speculative shocks in oil markets has found little evidence that these have contributed in economically significant ways to historical oil price fluctuations, either in statistical VAR models such as in Kilian and Murphy (2014) and Kilian and Lee (2014) or in DSGE models such as in Unalmis et al. (2012). While little evidence exists on this question for other commodities, one would expect that oil markets would be most likely to display sensitivity to speculation, given the relative ease with which oil can be stored (both underground and in aboveground storage facilities) and the potentially large convenience yields to refineries associated with holding oil as inventories. The fact that storage shocks are not quantitatively important does not imply that storage has no effects on the response of prices to other shocks, but it is consistent with this result.
} 
Table I.1: Testing the Null Hypothesis of Zero Net Purchases by Storage Sector

\begin{tabular}{|c|c|c|c|c|c|}
\hline \multirow[b]{2}{*}{ Number of Factors: } & \multicolumn{5}{|c|}{ Estimates of Mean Ratio of Consumption to Production -1} \\
\hline & $\hat{c}$ & $\operatorname{se}(\hat{c})$ & $\mathrm{N}$ & Sample & Source \\
\hline \multicolumn{6}{|c|}{ Agr./Food Commodities } \\
\hline Apples & $-0.007 * * *$ & $(0.003)$ & 42 & 1968-2009 & UN FAO \\
\hline Bananas & $-0.008 * *$ & $(0.004)$ & 42 & 1968-2009 & UN FAO \\
\hline Barley & 0.001 & $(0.005)$ & 33 & $1979-2011$ & $\mathrm{CRB}$ \\
\hline \multicolumn{6}{|l|}{ Beef } \\
\hline Cocoa & -0.009 & $(0.010)$ & 43 & $1968-2010$ & $\mathrm{CRB}$ \\
\hline Coffee & 0.016 & $(0.011)$ & 41 & 1968-2009 & UN FAO \\
\hline Corn & 0.004 & $(0.005)$ & 32 & $1980-2011$ & CRB \\
\hline Fishmeal & -0.014 & $(0.016)$ & 45 & $1968-2012$ & USDA-FAS \\
\hline \multicolumn{6}{|l|}{ Hay } \\
\hline Oats & 0.002 & $(0.004)$ & 45 & $1968-2012$ & USDA-FAS \\
\hline \multicolumn{6}{|l|}{ Orange juice } \\
\hline Onions & $-0.007 * * *$ & $(0.001)$ & 42 & $1968-2009$ & UN FAO \\
\hline Pepper & -0.000 & $(0.018)$ & 42 & $1968-2009$ & UN FAO \\
\hline Potatoes & $0.005^{* *}$ & $(0.002)$ & 42 & 1968-2009 & UN FAO \\
\hline Rice & $-0.010 * *$ & $(0.005)$ & 45 & $1968-2012$ & USDA-FAS \\
\hline \multicolumn{6}{|l|}{ Shrimp } \\
\hline Sorghums & 0.010 & $(0.009)$ & 28 & $1983-2011$ & CRB \\
\hline Soybeans & -0.002 & $(0.006)$ & 42 & 1968-2009 & UN FAO \\
\hline Sugar & $-0.020 * * *$ & $(0.005)$ & 45 & $1968-2012$ & USDA-FAS \\
\hline Tea & $-0.022 * * *$ & $(0.005)$ & 42 & 1968-2009 & UN FAO \\
\hline Tobacco & 0.004 & $(0.015)$ & 37 & $1968-2004$ & USDA-FAS \\
\hline Wheat & 0.000 & $(0.006)$ & 34 & $1978-2011$ & CRB \\
\hline
\end{tabular}

Oils 


$\begin{array}{llllll}\text { Coconut oil } & 0.003 & (0.009) & 42 & 1968-2009 & \text { UN FAO } \\ \text { Groundnut oil } & -0.003 & (0.004) & 41 & 1971-2011 & \text { USDA-FAS } \\ \text { Palm oil } & -0.045^{* *} & (0.017) & 42 & 1968-2009 & \text { UN FAO } \\ \text { Rapeseed oil } & -0.007 & (0.005) & 45 & 1968-2012 & \text { USDA-FAS } \\ \text { Sun/Safflower oil } & -0.024^{* *} & (0.010) & 41 & 1972-2012 & \text { USDA-FAS }\end{array}$

Industrial Commodities

$\begin{array}{lllllr}\text { Aluminum } & -0.007 & (0.005) & 45 & 1968-2012 & \text { TA } \\ \text { Burlap } & 0.020 & (0.012) & 42 & 1968-2009 & \text { UN FAO } \\ \text { Cement } & & & & & \\ \text { Copper } & 0.001 & (0.005) & 45 & 1968-2011 & \text { TA } \\ \text { Cotton } & 0.001 & (0.010) & 43 & 1968-2010 & \text { CRB } \\ \text { Lead } & -0.001 & (0.004) & 39 & 1972-2012 & \text { TA } \\ \text { Lumber } & & & & & \\ \text { Mercury } & & & & & \\ \text { Nickel } & -0.009 & (0.008) & 45 & 1968-2012 & \text { BREE } \\ \text { Rubber } & 0.001 & (0.004) & 43 & 1968-2010 & \text { CRB } \\ \text { Tin } & 0.011 & (0.012) & 45 & 1968-2012 & \text { TA } \\ \text { Wool } & & & & & \\ \text { Zinc } & -0.007 & (0.006) & 39 & 1972-2012 & \text { TA }\end{array}$

Notes: The table presents the average ratio of consumption to production (minus one) for each commodity and associated NeweyWest standard errors. Data on global consumption and production are from the Commodity Research Bureau (CRB), trade associations (TA), the United Nations Food and Agriculture Organization (UN FAO), the Food and Agricultural Services of the U.S. Department of Agriculture (USDA-FAS), or the Bureau of Resources and Energy Economics of the Australian Government (BREE). Series left blank are those for which consumption and production data are unavailable. 


\section{FiguRE I.1: EFFECTS OF MONETARY POLICY SHOCKS ON THE INDIRECT COMMON FACTOR}
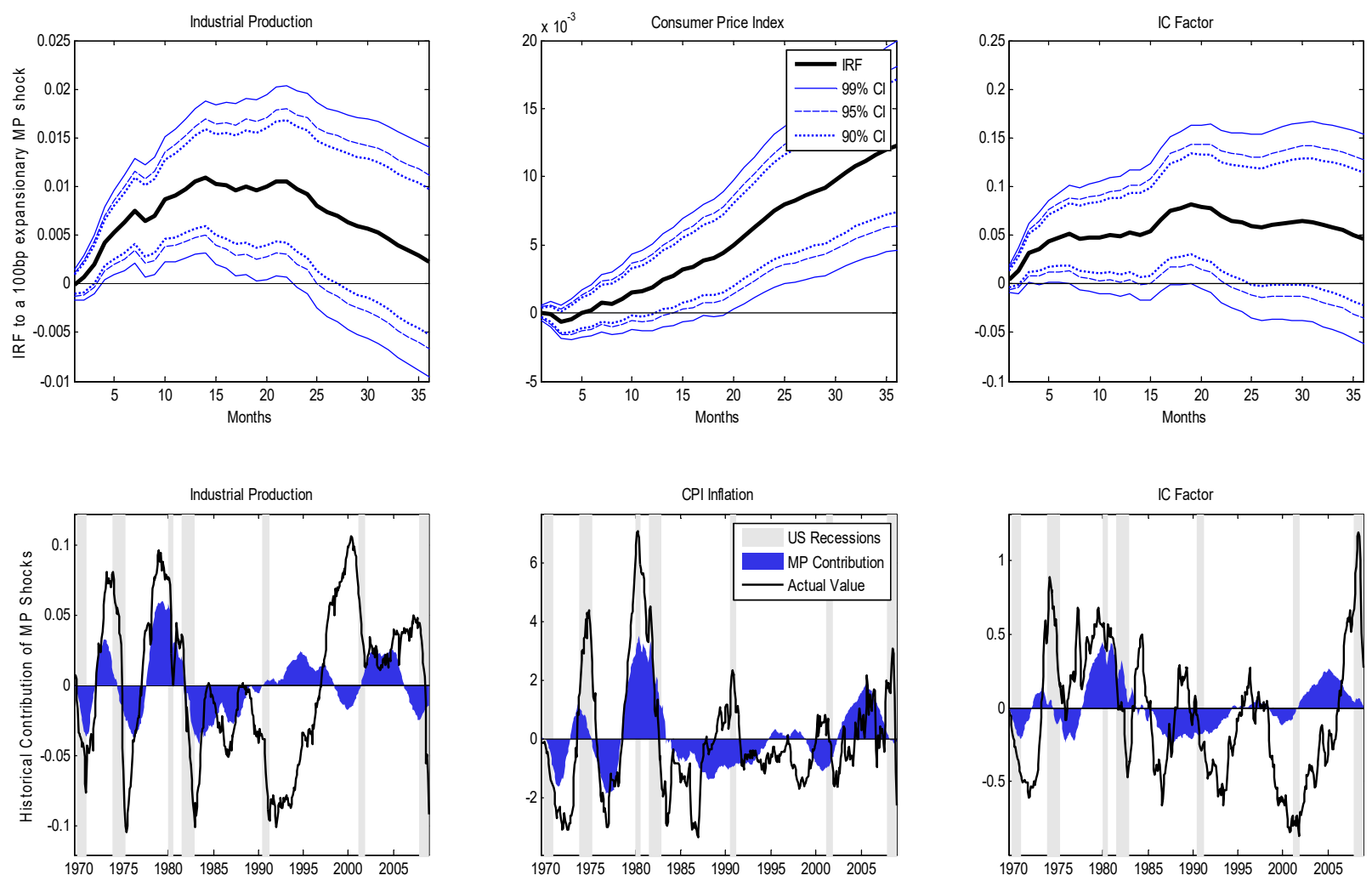

Notes: The figures in the top row present estimated impulse responses of U.S. industrial production, the U.S. consumer price index, and the IC factor to a 100-basis-point expansionary monetary policy shock using the vector autoregression (VAR) described in section 4. Confidence intervals are constructed from the distribution of impulse responses generated by drawing 2,000 times from the estimated distribution of VAR parameters. The bottom row presents actual values of each variable normalized by the predicted values from the VAR given initial conditions and no subsequent shocks (solid black line), U.S. recessions (light grey shaded areas) and the estimated contribution of monetary policy shocks to historical variation in each variable (blue areas). For the CPI, the bottom figure presents year-over-year inflation rates. 
Appendix J: Additional Tables on Out-of-Sample Forecasting

APPENDIX TABLE J.1: RECURSIVE FORECAST ERROR DIAGNOSTICS FOR REAL COMMODITY PRICES

$$
\begin{array}{ccccc}
h=1 & h=3 & h=6 & h=12 & \begin{array}{c}
\text { Forecast Evaluation } \\
\text { Period }
\end{array}
\end{array}
$$

Agr./Food Commodities

\begin{tabular}{|c|c|c|c|c|c|}
\hline Apples & 0.886 & 0.738 & 0.598 & 0.703 & 1982:11-2011:12 \\
\hline Bananas & 0.898 & 0.726 & 0.659 & 0.929 & 1968:1-2013:1 \\
\hline Barley & 0.973 & 0.975 & 1.002 & 0.986 & 1968:1-2013:1 \\
\hline Beef & 1.138 & 1.261 & 1.359 & 1.367 & 1968:1-2013:1 \\
\hline Cocoa & 0.933 & 1.020 & 1.039 & 1.032 & 1968:1-2012:12 \\
\hline Coffee & 0.959 & 0.986 & 1.072 & 1.088 & 1968:1-2012:12 \\
\hline Corn & 0.904 & 0.943 & 0.924 & 0.910 & $1968: 1-2012: 12$ \\
\hline Fishmeal & 1.025 & 1.167 & 1.108 & 1.078 & 1968:1-2013:1 \\
\hline Hay & 1.026 & 0.953 & 0.909 & 0.878 & 1968:1-2013:3 \\
\hline Oats & 0.932 & 0.965 & 0.937 & 0.955 & 1968:1-2010:11 \\
\hline Orange juice & 0.967 & 1.023 & 1.045 & 0.967 & $1971: 2-2012: 10$ \\
\hline Onions & 0.886 & 0.762 & 0.618 & 0.623 & 1968:1-2011:12 \\
\hline Pepper & 0.906 & 1.073 & 1.197 & 1.375 & $1983: 6-2007: 6$ \\
\hline Potatoes & 0.816 & 0.799 & 0.701 & 0.947 & 1968:1-2011:12 \\
\hline Rice & 0.873 & 0.961 & 1.025 & 1.115 & $1968: 1-2012: 12$ \\
\hline Shrimp & 1.029 & 1.100 & 1.136 & 1.256 & 1968:1-2013:1 \\
\hline Sorghum & 0.930 & 0.997 & 0.988 & 0.982 & 1968:1-2013:1 \\
\hline Soybeans & 0.936 & 1.016 & 1.053 & 1.078 & 1968:1-2012:9 \\
\hline Sugar & 0.937 & 0.999 & 1.025 & 1.038 & $1968: 1-2012: 12$ \\
\hline Tea & 1.042 & 1.193 & 1.237 & 1.313 & 1968:1-2013:1 \\
\hline Tobacco & 0.894 & 0.912 & 0.904 & 0.873 & 1968:1-2013:1 \\
\hline Wheat & 0.970 & 1.049 & 0.997 & 0.947 & 1968:1-2012:12 \\
\hline
\end{tabular}




\begin{tabular}{|c|c|c|c|c|c|}
\hline Coconut & 0.988 & 0.984 & 0.964 & 0.914 & 1989:7-2010:12 \\
\hline Groundnut & 0.993 & 0.937 & 0.893 & 0.773 & 1968:1-2013:1 \\
\hline Palm & 0.915 & 1.071 & 1.072 & 1.036 & 1968:1-2013:1 \\
\hline Rapeseed & 1.030 & 0.992 & 1.028 & 0.963 & 1984:1-2013:1 \\
\hline Sunflower & 0.946 & 1.028 & 1.057 & 1.106 & $1968: 1-2005: 6$ \\
\hline \multicolumn{6}{|c|}{ Industrial Commodities } \\
\hline Aluminum & 0.999 & 1.004 & 1.058 & 1.155 & 1977:1-2013:1 \\
\hline Burlap & 0.880 & 1.050 & 1.068 & 1.054 & 1968:1-2012:9 \\
\hline Cement & 1.028 & 1.075 & 1.148 & 1.200 & 1984:1-2012:12 \\
\hline Copper & 0.887 & 1.006 & 1.072 & 1.104 & 1968:1-2012:12 \\
\hline Cotton & 0.762 & 0.927 & 1.000 & 0.950 & 1968:1-2012:12 \\
\hline Lead & 0.964 & 1.034 & 1.084 & 1.092 & 1968:1-2012:12 \\
\hline Lumber & 1.005 & 1.127 & 1.149 & 1.172 & 1968:1-2012:12 \\
\hline Mercury & 0.884 & 1.077 & 1.198 & 1.419 & 1968:1-1995:3 \\
\hline Nickel & 0.955 & 1.157 & 1.444 & 2.422 & 1983:3-2013:1 \\
\hline Rubber & 0.952 & 0.989 & 1.054 & 1.117 & 1968:1-2010:12 \\
\hline Tin & 0.915 & 0.922 & 0.991 & 1.068 & 1968:1-2012:12 \\
\hline Wool & 0.967 & 0.987 & 1.034 & 1.096 & 1968:1-2013:1 \\
\hline Zinc & 0.936 & 1.030 & 1.101 & 1.339 & $1968: 1-2012: 12$ \\
\hline
\end{tabular}

Notes: The forecast evaluation period depends on the commodity. It begins either in 1968:1 or at the earliest date that allows the initial estimation window to contain at least 48 observations. The maximum length of the recursive sample is restricted by the end of the data sample for each commodity and the forecast horizon. All forecasts are obtained from a bivariate VAR that includes the level of the real commodity price and the first principal component extracted from the cross-section of real commodity prices. The lag length of the VAR is chosen recursively using the BIC. The MSPE of the VAR forecast is expressed as a ratio relative to that of the no-change forecast. Entries smaller than 1 indicate that the VAR forecast is superior to the no-change forecast and are shown in boldface. 
APPENDIX TABLE J.2: RECURSIVE FORECAST ERROR DIAGNOSTICS FOR REAL COMMODITY PRICES

\begin{tabular}{|c|c|c|c|c|}
\hline & $h=1$ & $h=3$ & $h=6$ & $h=12$ \\
\hline \multicolumn{5}{|c|}{ Agr./Food Commodities } \\
\hline Bananas & 0.878 & 0.695 & 0.620 & 0.835 \\
\hline Barley & 0.965 & 0.941 & 0.968 & 0.924 \\
\hline Beef & 1.042 & 1.189 & 1.430 & 1.702 \\
\hline Cocoa & 0.971 & 1.006 & 1.020 & 1.000 \\
\hline Coffee & 0.962 & 0.947 & 0.987 & 0.957 \\
\hline Corn & 0.885 & 0.875 & 0.847 & 0.799 \\
\hline Fishmeal & 0.964 & 1.096 & 1.188 & 1.308 \\
\hline Hay & 0.956 & 0.838 & 0.703 & 0.598 \\
\hline Rice & 0.842 & 0.873 & 0.831 & 0.742 \\
\hline Shrimp & 1.032 & 1.082 & 1.086 & 1.202 \\
\hline Sorghum & 0.913 & 0.923 & 0.889 & 0.857 \\
\hline Sugar & 0.946 & 1.013 & 1.006 & 0.944 \\
\hline Tea & 0.955 & 0.983 & 0.973 & 1.004 \\
\hline Tobacco & 0.859 & 0.871 & 0.827 & 0.737 \\
\hline Wheat & 0.923 & 0.928 & 0.850 & 0.782 \\
\hline \multicolumn{5}{|l|}{ Oils } \\
\hline Groundnut & 0.858 & 0.863 & 0.806 & 0.678 \\
\hline Palm & 0.926 & 1.109 & 1.110 & 1.055 \\
\hline Rapeseed & 1.030 & 0.992 & 1.028 & 0.963 \\
\hline \multicolumn{5}{|c|}{ Industrial Commodities } \\
\hline Aluminum & 0.992 & 0.967 & 0.980 & 0.999 \\
\hline Cement & 1.028 & 1.075 & 1.148 & 1.200 \\
\hline Copper & 0.864 & 0.981 & 1.026 & 1.084 \\
\hline
\end{tabular}




$\begin{array}{lllll}\text { Cotton } & \mathbf{0 . 7 8 3} & \mathbf{0 . 9 1 6} & 1.014 & \mathbf{0 . 9 7 1} \\ \text { Lead } & \mathbf{0 . 9 8 9} & 1.041 & 1.074 & 1.118 \\ \text { Lumber } & 1.038 & 1.048 & 1.077 & 1.230 \\ \text { Nickel } & \mathbf{0 . 9 4 9} & 1.140 & 1.431 & 2.417 \\ \text { Tin } & \mathbf{0 . 8 9 1} & \mathbf{0 . 8 8 2} & \mathbf{0 . 9 3 9} & \mathbf{0 . 9 5 5} \\ \text { Wool } & \mathbf{0 . 9 1 8} & \mathbf{0 . 9 5 2} & 1.008 & 1.076 \\ \text { Zinc } & \mathbf{0 . 9 1 9} & \mathbf{0 . 9 5 3} & \mathbf{0 . 9 2 5} & \mathbf{0 . 8 6 9}\end{array}$

Notes: The forecast evaluation period is 1984:1-2012:12. The initial estimation window begins at the earliest date that allows it to contain at least 48 observations. The maximum length of the recursive sample is restricted by the end of the data sample for each commodity and the forecast horizon. All forecasts are obtained from a bivariate VAR that includes the level of the real commodity price and the first principal component extracted from the cross-section of real commodity prices. The lag length of the VAR is chosen recursively using the BIC. The MSPE of the VAR forecast is expressed as a ratio relative to that of the no-change forecast. Entries smaller than 1 indicate that the VAR forecast is superior to the no-change forecast and are shown in boldface. 


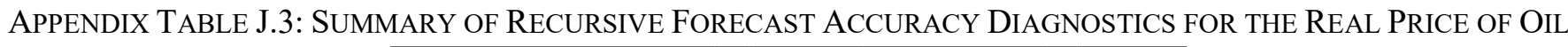

Forecast Evaluation Period: 1984:1-2012:8

\begin{tabular}{lcccc} 
& \multicolumn{2}{c}{ BIC } & \multicolumn{2}{c}{12 lags } \\
& $\underline{\text { FAVAR }}$ & $\underline{\text { VAR }}$ & $\underline{\text { FAVAR }}$ & $\underline{\text { VAR }}$ \\
1 month & $\mathbf{0 . 7 9 0}$ & $\mathbf{0 . 8 2 5}$ & $\mathbf{0 . 8 5 8}$ & $\mathbf{0 . 8 4 3}$ \\
& & & & \\
3 months & $\mathbf{0 . 9 4 7}$ & 1.047 & 1.037 & 1.028 \\
& & & & \\
6 months & 1.111 & 1.268 & 1.224 & 1.206 \\
& & & & \\
12 months & 1.308 & 1.501 & 1.419 & 1.427 \\
& & & & \\
\cline { 3 - 5 } & & & & \\
\end{tabular}

Forecast Evaluation Period: 1992:1-2012:8

\begin{tabular}{ccc}
\multicolumn{1}{c}{ BIC } & \multicolumn{2}{c}{12 lags } \\
$\underline{\text { FAVAR }} \quad \underline{\text { VAR }} \quad \underline{\text { FAVAR }} \underline{\text { VAR }}$
\end{tabular}




\section{$\begin{array}{lllll}1 \text { month } & \mathbf{0 . 8 3 2} & \mathbf{0 . 8 4 6} & \mathbf{0 . 9 0 4} & \mathbf{0 . 8 5 8}\end{array}$}
3 months
0.980
1.016
1.105
0.960

6 months

1.182

1.175

1.329

1.115

12 months $\quad 1.459 \quad 1.336 \quad 1.524 \quad 1.172$

Notes: The data for the oil market are from Baumeister and Kilian (2012) and span the period 1973:1-2012:8. "FAVAR" refers to the bivariate factor-augmented VAR forecasting model that includes the commodity price factor and the real price of oil. "VAR" refers to the four-variable VAR of the oil market, as described in the text. "BIC" indicates that the lag length is chosen recursively using the BIC. "12 lags" indicates that the lag length is fixed at 12. The MSPE ratios of the real oil price forecasts are computed relative to the benchmark no-change forecast. Entries smaller than 1 indicate that the model-based forecast is superior to the no-change forecast and are shown in boldface. 


\section{Appendix K: The Direct Common Factor Loadings and the Energy Intensity of Production}

As a check on the model, we test one of its implications for the loadings on the direct common (DC) factor. This factor represents the composition of shocks that directly affect the commodity sector in the model via exogenous shocks to the energy sector. A direct implication of the model is that the loadings on the DC factor are positively correlated with the share of energy inputs used in the production of the commodity. We computed the energy input share for several commodity producing industries using the 2007 benchmark input-output table for the United States and linked these industries to the commodities in our sample. In the cases where several commodities are in the same industry, we use the arithmetic average of the DC factor loadings for each commodity that belongs in that industry. This approach is similar to the one that Lee and $\mathrm{Ni}$ (JME 2002) used to rank industries by oil intensity.

The first two tables show the industries used in the analysis and the mapping between the commodities in our sample and the NAICS categories. In the first table, the direct input requirement is the amount of a commodity that is directly or initially required to produce a dollar of the industry's output. For example, it takes 11.9 cents of direct energy inputs to produce one dollar in the grain farming industry. The total requirement is the direct requirement plus the indirect requirement.

The two figures depict the positive relationship between the energy input requirements and the DC factor loadings, which is consistent with the prediction of the model. This check provides a validation of one of the model's predictions about the loadings and lends credibility to the framework we use to study the common variation in commodity prices.

Commodity Production: Direct and Total Requirements

\begin{tabular}{clcc}
\hline \hline & & & Total \\
Agricultural/Food & & & \\
$1111 \mathrm{~B} 0$ & Grain farming & 0.119 & 0.418 \\
111900 & Other crop farming & 0.079 & 0.218 \\
$1121 \mathrm{~A} 0$ & Beef cattle ranching and farming & 0.065 & 0.260 \\
$1111 \mathrm{~A} 0$ & Oilseed farming & 0.049 & 0.161 \\
111300 & Fruit and tree nut farming & 0.035 & 0.107 \\
111200 & Vegetable and melon farming & 0.033 & 0.114 \\
113000 & Forestry and logging & 0.026 & 0.098 \\
311920 & Coffee and tea manufacturing & 0.018 & 0.142 \\
& & & \\
Industrials & & & \\
327310 & Cement manufacturing & 0.178 & 0.326 \\
$33131 \mathrm{~A}$ & Alumina refining and primary aluminum production & 0.170 & 0.291 \\
$2122 \mathrm{~A} 0$ & Iron, gold, silver, and other metal ore mining & 0.154 & 0.325 \\
212230 & Copper, nickel, lead, and zinc mining & 0.081 & 0.207 \\
331419 & Primary smelting and refining of nonferrous metal & 0.034 & 0.185 \\
\hline
\end{tabular}

Notes: The data are from 2007 benchmark input-output tables computed by the Bureau of Economic Analysis (https://apps.bea.gov/iTable/index_industry_io.cfm). For the purposes of calculating the energy input requirements, these industries are classified as energy related: Oil and gas extraction (211000); coal mining (212100); electric power generation, transmission, and distribution (221100); natural gas distribution (221200); petroleum refineries (324110); other petroleum and coal products manufacturing (324190); petrochemical manufacturing (325110); and pipeline transportation (486000). The data are ranked by the direct input requirement. 


\section{Commodities and NAICS Categories}

Agricultural/Food

Apples

Bananas

Barley

Beef

Coffee

Corn

Hay

Oats

Orange juice

Onions

Pepper

Potatoes

Rice

Sorghums

Soybeans

Sugar

Tea

Tobacco

Wheat

Coconut oil

Groundnut oil

Palm oil

Rapeseed oil

Sun/Safflower oil
Industry

Fruit and tree nut farming

Fruit and tree nut farming

Grain farming

Beef cattle ranching and farming

Coffee and tea manufacturing

Grain farming

Other crop farming

Grain farming

Fruit and tree nut farming

Vegetable and melon farming

Fruit and tree nut farming

Vegetable and melon farming

Grain farming

Grain farming

Grain farming

Other crop farming

Coffee and tea manufacturing

Other crop farming

Grain farming

Oilseed farming

Oilseed farming

Oilseed farming

Oilseed farming

Oilseed farming

\section{Industrials}

Aluminum

Cement

Copper

Cotton

Lead

Lumber

Mercury

Nickel

Tin

Zinc

\section{Unclassified}

Cocoa; Fishmeal; Shrimp; Burlap; Rubber; Wool 


\section{Direct Energy Input Requirements}

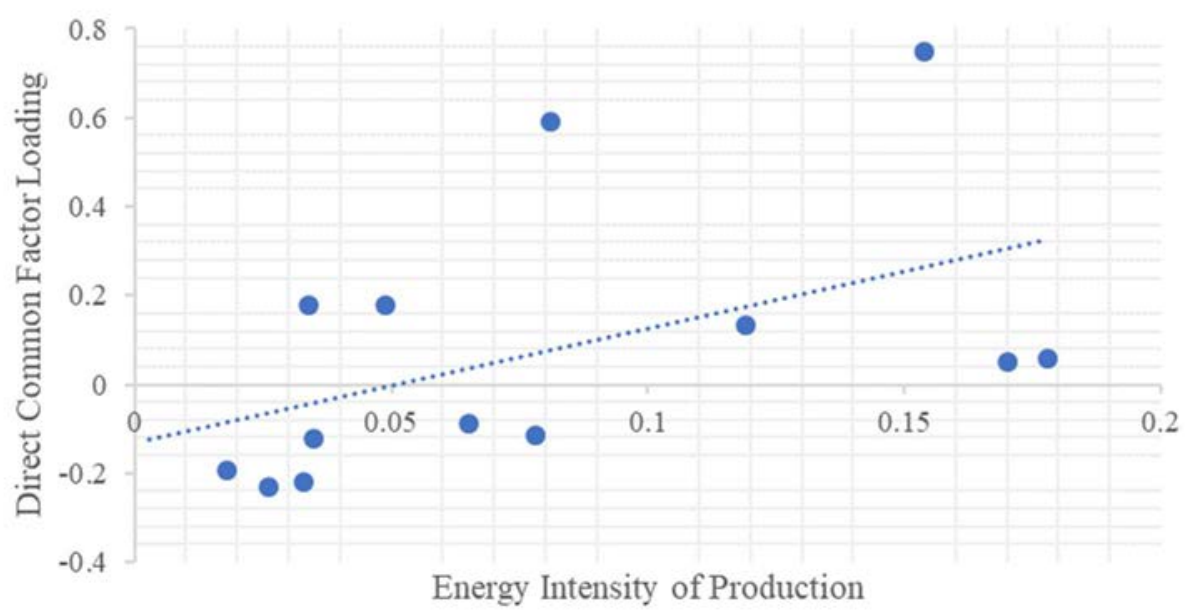

\section{Total Energy Input Requirements}

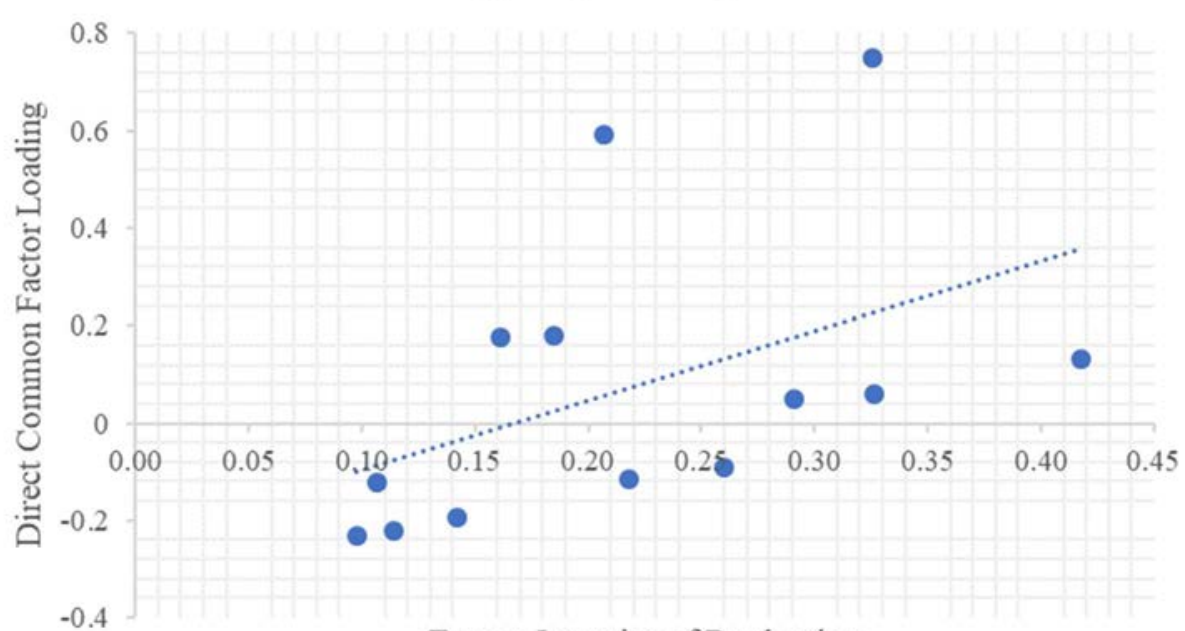

Energy Intensity of Production 